\title{
Investigating Covid- 19 and Prophylactive Measures to Contain Spread of the Disease
}

\author{
B.M Mustapha R.Z Usman \\ College of Agriculture and Animal Science ,Division of Agricultural College.Ahmadu Bello University \\ Zaria.Nigeria
}

\begin{abstract}
Covid-19 disease is a highly infectious and contagious disease and the outbreak has caused high mortality and morbidity with rates of about $5 \%$ and $0.9 \%$ it is a global pandemic requiring immediate attention,some of the symptoms include Anemia ,dehydration,Emaciation,weakness ,pneumonitis and Death. The etiology is covid-19 ,the problem at the moment is the lack of cure for the disease.In this study five continents where of interest and they include North and South America,Europe,Africa and Asia.Data was obtained from the internet from worldometer.info/coronavirus/country and cases from February to 15 december 2020 were considered and analysed statistically using analysis of variants to determine monthly incidence and prevalence,case fatality,morbidity ,mortality and population at risk.The reason for this survey is to establish ways to decrease the high morbidity and mortality rates, reduce the devastating economic impact of this disease and increase daily socialization among Humans and curb hunger and boredom that covid-19 has caused.More so the it is a global pandemic needing urgent attention.In conclusion the morbidity and mortality where highest in the months of July and October and the population at risk are 95\%-98\%.Prophylactic measure to help alleviate the incidence of this disease include daily administration of blood tonic and ascorbic acid in their daily recommended dosages preinfection to enhance growth of tissues and cellular epithelization and boost energy generation and build .

Keywords: Anemia ,Mortality, Morbidity, Prophylaxis, Griscelli syndrome, Genome,Replicase-trypticase,MHC I and II, Lupus erythmatosus $\mathrm{M}$ and $\mathrm{E}$ proteins

DOI: $10.7176 / \mathrm{JBAH} / 11-4-05$

Publication date: February $28^{\text {th }} 2021$

1.0 INTRODUCTON

Statement of research problem

i. High Morbidity and Mortality Rates

ii. Devastating effect on economic development and recovery

iii. Restricted movement and Social distancing among Human beings with a resultant boredom and subsequent hunger.

iv. Zoonotic

Coronavirus is highly infectious and contagious disease and mode of transmission are through direct and indirect routes such as inhalation of contaminated aerosol and ingestion of contaminated food other modes are through formites.Covid -19 high mordity and mortality rates through out the world .This rates are so alarming that existence of the Human race is in jeopardy.

It is so acclaimed that "a Tree cannot make an Island" we need interaction between and among ourselves for survival.It is therefore pertinent that businesses cannot be at a still between and among countries in order for economies not to go into recession, but with decrease interaction among Humans due to the Covid-19 pandemic most countries in the world have gone into recession with some finding it very difficult to navigate their way out. Boredom and it"s intricacies makes life not worth living, what is the use of making money without been able to utilize it for goods and services, more so, covid 19 can be transmitted from man to animals and like-wise, hence zoonotic .Most African countries are hungry and are lagging behind in availability of animal protein and with the subsequent occurrence of this disease living in Africa becomes more difficult in the area of food scarcity and daily animal protein requirement.

1.1.1 Significance of the study

In order for the Human race not to be annihilated from the surface of Earth by Coronavirus because what started as an epidermic in one country has gradually turned into a pandemic with a lot relying on various ways and means of survival. It is therefore evident that Palliative and prophylactive ways need to be abruptly designed to curb the menace of Coronavirus.

1.1.2 Objectives of the study

The objective of the study are:

1 To decrease the high morbidity and mortality rates

2 To decrease the devastating economic effects of this disease

3 To increase the daily socialization among Humans and curb hunger and boredom
\end{abstract}




\subsection{LITERATURE REVIEW}

\subsubsection{History of Coronavirus}

The name "coronavirus" is derived from Latin corona, meaning "crown" or "wreath", ${ }^{[9][10]}$ The name was coined by June Almeida and David Tyrrell who first observed and studied human coronaviruses. ${ }^{[11]}$ The word was first used in print in 1968 by an informal group of virologists in the journal Nature to designate the new family of viruses ${ }^{[8]}$ The name refers to the characteristic appearance of virions (the infective form of the virus) by electron microscopy, which have a fringe of large, bulbous surface projections creating an image reminiscent of the solar corona or halo. ${ }^{[8][11]}$ This morphology is created by the viral spike peplomers, which are proteins on the surface of the virus. ${ }^{[12]}$

The scientific name Coronavirus was accepted as a genus name by the International Committee for the Nomenclature of Viruses (later renamed International Committee on Taxonomy of Viruses) in 1971. ${ }^{[13]}$ As the number of new species increased, the genus was split into four genera, namely Alphacoronavirus, Betacoronavirus, Deltacoronavirus, and Gammacoronavirus in $2009 .{ }^{[14]}$ The common name coronavirus is used to refer to any member of the subfamily Orthocoronavirinae.$^{[5]}$ As of 2020,45 species are officially recognise ${ }^{[15}$

The earliest reports of a coronavirus infection in animals occurred in the late 1920s, when an acute respiratory infection of domesticated chickens emerged in North America ${ }^{[16]}$ Arthur Schalk and M.C. Hawn in 1931 made the first detailed report which described a new respiratory infection of chickens in North Dakota. The infection of new-born chicks was characterized by gasping and listlessness with high mortality rates of 40-90\%. ${ }^{[17]}$ Leland David Bushnell and Carl Alfred Brandly isolated the virus that caused the infection in 1933. ${ }^{[18]}$ The virus was then known as infectious bronchitis virus (IBV). Charles D. Hudson and Fred Robert Beaudette cultivated the virus for the first time in 1937. ${ }^{[19]}$ The specimen came to be known as the Beaudette strain. In the late 1940s, two more animal coronaviruses, JHM that causes brain disease (murine encephalitis) and mouse hepatitis virus (MHV) that causes hepatitis in mice were discovered. ${ }^{[20]}$ It was not realized at the time that these three different viruses were related. ${ }^{[21][13]}$

Human coronaviruses were discovered in the $1960 \mathrm{~s}^{[22][23]}$ using two different methods in the United Kingdom and the United States. ${ }^{[24]}$ E.C. Kendall, Malcolm Bynoe, and David Tyrrell working at the Common Cold Unit of the British Medical Research Council collected a unique common cold virus designated B814 in 1961. ${ }^{[25][26][27]}$ The virus could not be cultivated using standard techniques which had successfully cultivated rhinoviruses, adenoviruses and other known common cold viruses. In 1965, Tyrrell and Bynoe successfully cultivated the novel virus by serially passing it through organ culture of human embryonic trachea. ${ }^{[28]}$ The new cultivating method was introduced to the lab by Bertil Hoorn ${ }^{[29]}$ The isolated virus when intranasally inoculated into volunteers caused a cold and was inactivated by ether which indicated it had a lipid envelope. ${ }^{[25][30]}$ Dorothy Hamre ${ }^{[31]}$ and John Procknow at the University of Chicago isolated a novel cold from medical students in 1962. They isolated and grew the virus in kidney tissue culture, assigning it as 229E. The novel virus caused a cold in volunteers and was inactivated by ether similarly as B814. ${ }^{[32]}$

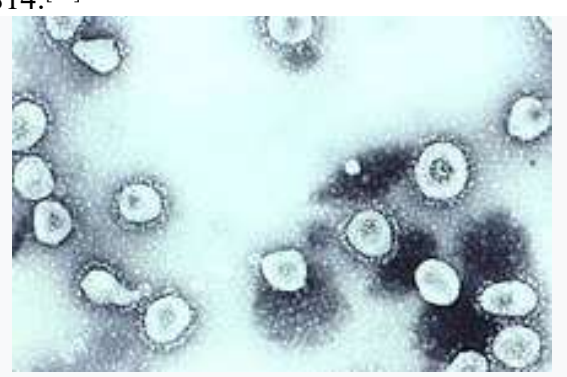

Transmission electron micrograph of organ cultured coronavirus OC43

Scottish virologist June Almeida at St. Thomas Hospital in London, collaborating with Tyrrell, compared the structures of IBV, B814 and 229E in 1967..$^{[3][34]}$ Using electron microscopy the three viruses were shown to be morphologically related by their general shape and distinctive club-like spikes. ${ }^{[35]} \mathrm{A}$ research group at the National Institute of Health the same year was able to isolate another member of this new group of viruses using organ culture and named one of the samples OC43 (OC for organ culture) ${ }^{[36]}$ Like B814, 229E, and IBV, the novel cold virus OC43 had distinctive club-like spikes when observed with the electron microscope. ${ }^{[37][38]}$

The IBV-like novel cold viruses were soon shown to be also morphologically related to the mouse hepatitis virus. ${ }^{[20]}$ This new group of viruses were named coronaviruses after their distinctive morphological appearance. ${ }^{[8]}$ Human coronavirus $229 \mathrm{E}$ and human coronavirus OC43 continued to be studied in subsequent decades. ${ }^{[39][40]}$ The coronavirus strain B814 was lost. It is not known which present human coronavirus it was. ${ }^{[4]}$ Other human coronaviruses have since been identified, including SARS-CoV in 2003, HCoV NL63 in 2003, HCoV HKU1 in 2004, MERS-CoV in 2013, and SARS-CoV-2 in 2020. ${ }^{[42]}$ There have also been a large number of animal coronaviruses identified since the 1960s. ${ }^{[43]}$ 


\subsubsection{Microbiology}

\section{Structure}

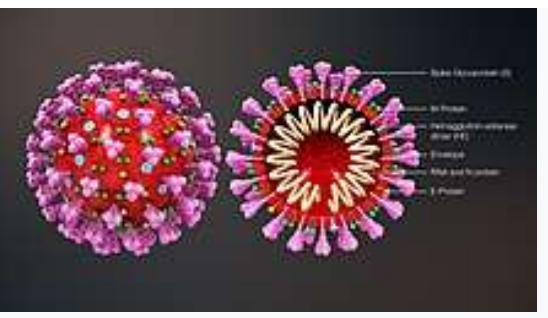

Cross-sectional model of a coronavirus

Coronaviruses are large, roughly spherical particles with unique surface projections. ${ }^{[4]}$ Their size is highly variable and generally is an average diameter of $120 \mathrm{~nm}$. Extreme sizes are known from 50 to $200 \mathrm{~nm}$ in diameter. ${ }^{[45]}$ The total molecular weight is on average $40,000 \mathrm{kDa}$. They are enclosed in an envelope embedded with a number of protein molecules. ${ }^{[46]}$ The lipid bilayer envelope, membrane proteins, and nucleocapsid protect the virus when it is outside the host cell. $\stackrel{[47]}{ }$

The viral envelope is made up of a lipid bilayer, in which the membrane (M), envelope (E) and spike (S) structural proteins are anchored. ${ }^{[48]}$ The ratio of E:S:M in the lipid bilayer is approximately 1:20:300. ${ }^{[49]}$ The E and $\mathrm{M}$ protein are the structural proteins that combined with the lipid bilayer shape the viral envelope and maintain its size. ${ }^{[50]} \mathrm{S}$ proteins are needed for interaction with the host cells. But human coronavirus NL63 is peculiar in that its $\mathrm{M}$ protein has the binding site for the host cell, and not its S protein. ${ }^{[51]}$ The diameter of the envelope is $85 \mathrm{~nm}$. The envelope of the virus in electron micrographs appears as a distinct pair of electron-dense shells (shells that are relatively opaque to the electron beam used to scan the virus particle). $[52][50]$

The $\mathrm{M}$ protein is the main structural protein of the envelope that provides the overall shape and is a type III membrane protein. It consists of 218 to 263 amino acid residues and forms a layer of $7.8 \mathrm{~nm}$ thickness. ${ }^{[46]}$ It has

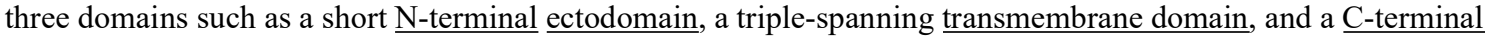
endodomain. The C-terminal domain forms a matrix-like lattice that adds to the extra-thickness of the envelope. Different species can have either $N$ - or $O$-linked glycans in their protein amino-terminal domain. The $\mathrm{M}$ protein is crucial in the life cycle of the virus such as during assembly, budding, envelope formation, and pathogenesis. ${ }^{[53]}$

The E proteins are minor structural proteins and highly variable in different species. There are only about 20 E proteins in a coronavirus. They are 8.4 to $12 \mathrm{kDa}$ in size and are composed of 76 to 109 amino acids. ${ }^{[4]}$ They are integral proteins (i.e. embedded in the lipid layer) and have two domains namely transmembrane domain and extramembrane C-terminal domain. They are almost fully $\alpha$-helical, with a single $\alpha$-helical transmembrane domain, and form pentameric (five-molecular) ion channels in the lipid bilayer. They are responsible for virion assembly, intracellular trafficking and morphogenesis (budding). ${ }^{[46]}$

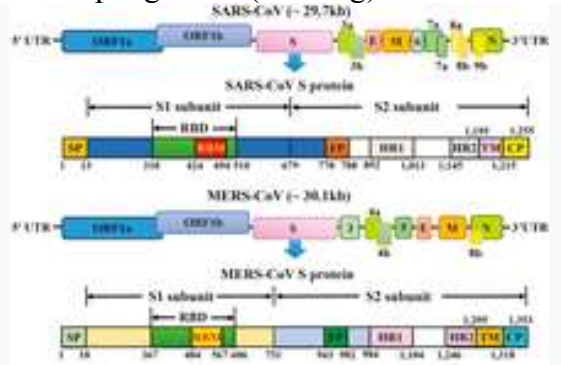

Diagram of the genome and functional domains of the S protein for SARS-CoV and MERS-CoV

The spikes are the most distinguishing feature of coronaviruses, and are responsible for the corona- or halolike surface. On average a coronavirus particle has 74 surface spikes. ${ }^{[54]}$ Each spike is about $20 \mathrm{~nm}$ long and is composed of a trimer of the S protein. The S protein is in turn composed of an S1 and S2 subunit. The homotrimeric $\mathrm{S}$ protein is a class I fusion protein which mediates the receptor binding and membrane fusion between the virus and host cell. The S1 subunit forms the head of the spike and has the receptor binding domain (RBD). The S2 subunit forms the stem which anchors the spike in the viral envelope and on protease activation enables fusion. The two subunits remain noncovalently linked as they are exposed on the viral surface, until they attach on the host cell membrane. ${ }^{[46]}$ In a functionally active state, three $\mathrm{S} 1$ are attached to two S2 subunits. The subunit complex is split to individual subunits when the virus binds and fuses with the host cell under the action of proteases such as cathepsin family and transmembrane protease serine 2 (TMPRSS2) of the host cell. ${ }^{[5]}$

$\mathrm{S} 1$ proteins are the most critical components in terms of infection. They are also the most variable components as they are responsible for host cell specificity. They possess two major domains named N-terminal domain (S1NTD) and C-terminal domain (S1-CTD), both of which serve as the receptor-binding domains. The NTDs 
recognise and bind sugars on the surface of the host cell. An exception is the MHV NTD that binds to a protein receptor carcinoembryonic antigen-related cell adhesion molecule 1 (CEACAM1). S1-CTDs are responsible for recognizing different protein receptors such as angiotensin-converting enzyme 2 (ACE2), aminopeptidase $\mathrm{N}$ (APN), and dipeptidyl peptidase 4 (DPP4).

A subset of coronaviruses (specifically the members of betacoronavirus subgroup A) also have a shorter spike-like surface protein called hemagglutinin esterase (HE). ${ }^{[43]}$ The HE proteins occur as homodimers composed of about 400 amino acid residues and are 40 to $50 \mathrm{kDa}$ in size. They appear as tiny surface projections of 5 to 7 $\mathrm{nm}$ long embedded in between the spikes. They help in attachment to and detachment from the host cell. [56]

Inside the envelope, there is the nucleocapsid, which is formed from multiple copies of the nucleocapsid (N) protein, which are bound to the positive-sense single-stranded RNA genome in a continuous beads-on-a-string type conformation. ${ }^{[50][57]} \mathrm{N}$ protein is a phosphoprotein of 43 to $50 \mathrm{kDa}$ in size, and is divided into three conserved domains. The majority of the protein is made up of domains 1 and 2, which are typically rich in arginines and lysines. Domain 3 has a short carboxy terminal end and has a net negative charge due to excess of acidic over basic amino acid residues. ${ }^{[45]}$

2.1.3 Genome

Severe acute respiratory syndrome-related coronavirus $\$$ Genome

SARS-CoV genome and proteins

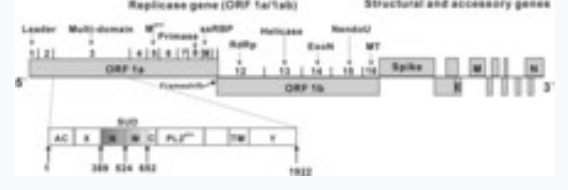

Coronaviruses contain a positive-sense, single-stranded RNA genome. The genome size for coronaviruses ranges from 26.4 to 31.7 kilobases. ${ }^{[7]}$ The genome size is one of the largest among RNA viruses. The genome has

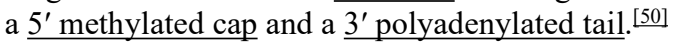

The genome organization for a coronavirus is 5'-leader-UTR-replicase (ORF1ab)-spike (S)-envelope (E)membrane (M)-nucleocapsid (N)-3'UTR-poly (A) tail. The open reading frames 1a and 1b, which occupy the first two-thirds of the genome, encode the replicase polyprotein ( $\mathrm{pp} 1 \mathrm{ab}$ ). The replicase polyprotein self cleaves to form 16 nonstructural proteins $(\mathrm{nsp} 1-\mathrm{nsp} 16) .[50]$

The later reading frames encode the four major structural proteins: spike, envelope, membrane, and nucleocapsid. ${ }^{[58]}$ Interspersed between these reading frames are the reading frames for the accessory proteins. The number of accessory proteins and their function is unique depending on the specific coronavirus. ${ }^{[50]}$

\section{Replication cycle \\ Cell entry}

The life cycle of a coronavirus

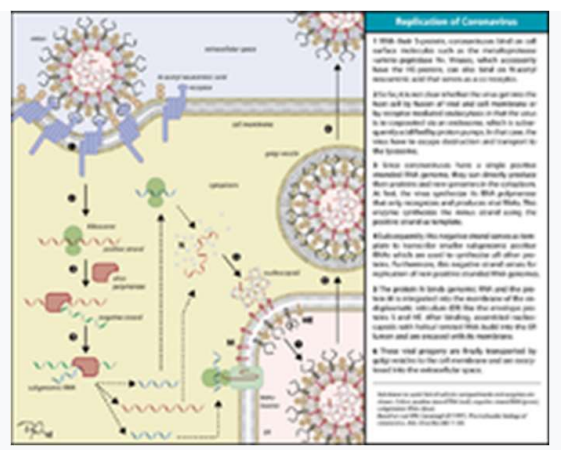

Infection begins when the viral spike protein attaches to its complementary host cell receptor. After attachment, a protease of the host cell cleaves and activates the receptor-attached spike protein. Depending on the host cell protease available, cleavage and activation allows the virus to enter the host cell by endocytosis or direct fusion of the viral envelope with the host membrane.

2.1.4 Genome translation

On entry into the host cell, the virus particle is uncoated, and its genome enters the cell cytoplasm. The coronavirus RNA genome has a 5' methylated cap and a $3^{\prime}$ polyadenylated tail, which allows it to act like a messenger RNA and be directly translated by the host cell's ribosomes. The host ribosomes translate the initial overlapping open reading frames ORF1a and ORF1b of the virus genome into two large overlapping polyproteins, pp1a and pplab. [50]

The larger polyprotein pp $1 \mathrm{ab}$ is a result of a -1 ribosomal frameshift caused by a slippery sequence (UUUAAAC) and a downstream RNA pseudoknot at the end of open reading frame ORF1a. ${ }^{[60]}$ The ribosomal frameshift allows for the continuous translation of ORF1a followed by ORF1b. ${ }^{[50]}$ 
The polyproteins have their own proteases, PLpro (nsp3) and 3CLpro (nsp5), which cleave the polyproteins at different specific sites. The cleavage of polyprotein pplab yields 16 nonstructural proteins (nsp1 to nsp16). Product

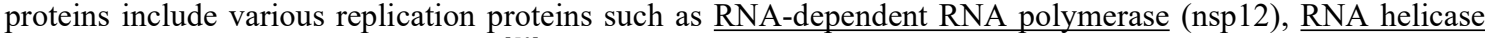
(nsp13), and exoribonuclease (nsp14). $\stackrel{[50]}{ }$

\section{Replicase-transcriptase}

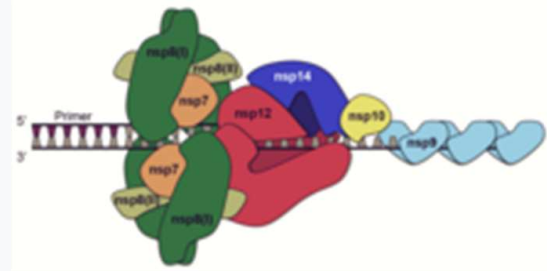

Replicase-transcriptase complex

A number of the nonstructural proteins coalesce to form a multi-protein replicase-transcriptase complex. The main replicase-transcriptase protein is the RNA-dependent RNA polymerase (RdRp). It is directly involved in the replication and transcription of RNA from an RNA strand. The other nonstructural proteins in the complex assist in the replication and transcription process. The exoribonuclease nonstructural protein, for instance, provides extra fidelity to replication by providing a proofreading function which the RNA-dependent RNA polymerase lacks. ${ }^{61]}$ Replication - One of the main functions of the complex is to replicate the viral genome. RdRp directly mediates the synthesis of negative-sense genomic RNA from the positive-sense genomic RNA. This is followed by the replication of positive-sense genomic RNA from the negative-sense genomic RNA. ${ }^{[50]}$

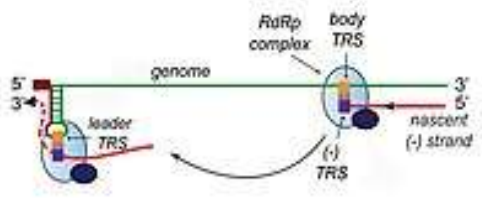

Transcription of nested mRNAs

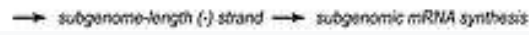

Nested set of subgenomic mRNAs

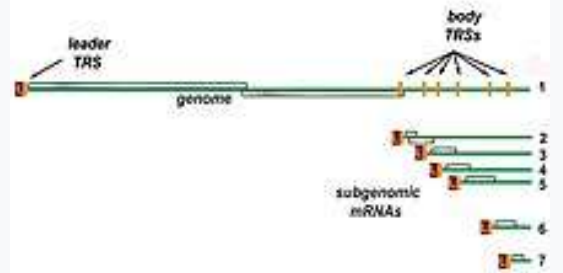

Transcription - The other important function of the complex is to transcribe the viral genome. RdRp directly mediates the synthesis of negative-sense subgenomic RNA molecules from the positive-sense genomic RNA. This process is followed by the transcription of these negative-sense subgenomic RNA molecules to their corresponding positive-sense mRNAs. ${ }^{[50]}$ The subgenomic mRNAs form a "nested set" which have a common 5'-head and partially duplicate 3 '-end. ${ }^{[62]}$

Recombination - The replicase-transcriptase complex is also capable of genetic recombination when at least two

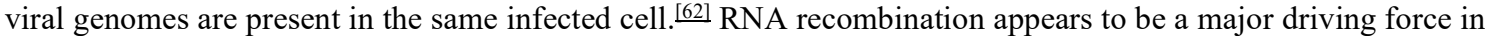
determining genetic variability within a coronavirus species, the capability of a coronavirus species to jump from one host to another and, infrequently, in determining the emergence of novel coronaviruses. ${ }^{[63]}$ The exact mechanism of recombination in coronaviruses is unclear, but likely involves template switching during genome replication. $[63]$

2.1.5 Assembly and release

The replicated positive-sense genomic RNA becomes the genome of the progeny viruses. The mRNAs are gene transcripts of the last third of the virus genome after the initial overlapping reading frame. These mRNAs are translated by the host's ribosomes into the structural proteins and a number of accessory proteins. ${ }^{[50]}$ RNA translation occurs inside the endoplasmic reticulum. The viral structural proteins S, E, and M move along the secretory pathway into the Golgi intermediate compartment. There, the M proteins direct most protein-protein interactions required for assembly of viruses following its binding to the nucleocapsid. Progeny viruses are then released from the host cell by exocytosis through secretory vesicles. Once released the viruses can infect other host cells. $\frac{[64]}{}$

2.1.6 Transmission 
Infected carriers are able to shed viruses into the environment. The interaction of the coronavirus spike protein with its complementary cell receptor is central in determining the tissue tropism, infectivity, and species range of the released virus. ${ }^{[65][66]}$ Coronaviruses mainly target epithelial cells. ${ }^{[43]}$ They are transmitted from one host to another host, depending on the coronavirus species, by either an aerosol, fomite, or fecal-oral route. ${ }^{[67]}$

Human coronaviruses infect the epithelial cells of the respiratory tract, while animal coronaviruses generally infect the epithelial cells of the digestive tract. ${ }^{[43]}$ SARS coronavirus, for example, infects via an aerosol route, $\underline{[68]}$ the human epithelial cells of the lungs by binding to the angiotensin-converting enzyme 2 (ACE2) receptor. ${ }^{69]}$ Transmissible gastroenteritis coronavirus (TGEV) infects, via a fecal-oral route, ${ }^{[67]}$ the pig epithelial cells of the digestive tract by binding to the alanine aminopeptidase (APN) receptor. ${ }^{[50]}$

Classification

Coronaviridae.

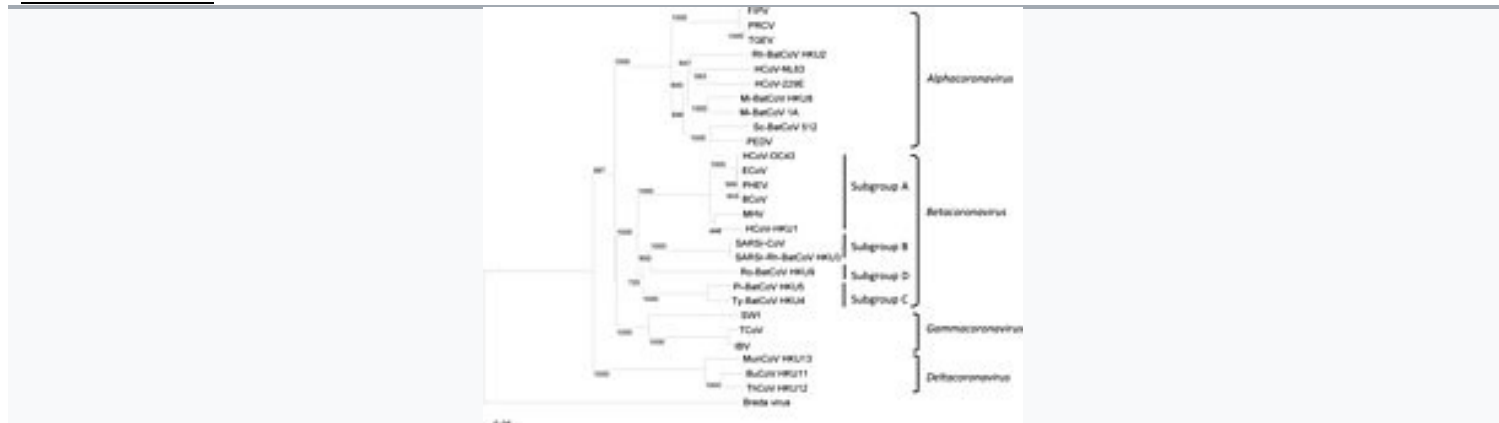

Phylogenetic tree of coronaviruses

Coronaviruses form the subfamily Orthocoronavirinae, ${ }^{[3][4][5]}$ which is one of two sub-families in the family Coronaviridae, order Nidovirales, and realm Riboviria. ${ }^{[43][70]}$ They are divided into the four genera: Alphacoronavirus, Betacoronavirus, Gammacoronavirus and Deltacoronavirus. Alphacoronaviruses and betacoronaviruses infect mammals, while gammacoronaviruses and deltacoronaviruses primarily infect birds. $[71][72]$

- Genus: Alphacoronavirus; $[$ [67] type species: Alphacoronavirus 1 (TGEV)

- Species: Alphacoronavirus 1, Human coronavirus 229E, Human coronavirus NL63, Miniopterus bat coronavirus 1, Miniopterus bat coronavirus HKU8, Porcine epidemic diarrhea virus, Rhinolophus bat coronavirus HKU2, Scotophilus bat coronavirus 512

- Genus Betacoronavirus $;$;68] type species: Murine coronavirus (MHV)

- Species: Betacoronavirus 1 (Bovine Coronavirus, Human coronavirus OC43), Hedgehog coronavirus 1, Human coronavirus HKU1, Middle East respiratory syndrome-related coronavirus, Murine coronavirus, Pipistrellus bat coronavirus HKU5, Rousettus bat coronavirus HKU9, Severe acute respiratory syndrome-related coronavirus (SARS-CoV, $\underline{S A R S-C o V-2}$ ), Tylonycteris bat coronavirus HKU4

- Genus Gammacoronavirus $;{ }^{[19]}$ type species: Avian coronavirus (IBV)

- Species: Avian coronavirus, Beluga whale coronavirus $S W 1$

- Genus Deltacoronavirus; type species: Bulbul coronavirus HKU11

- Species: Bulbul coronavirus HKU11, Porcine coronavirus HKU15

Origin

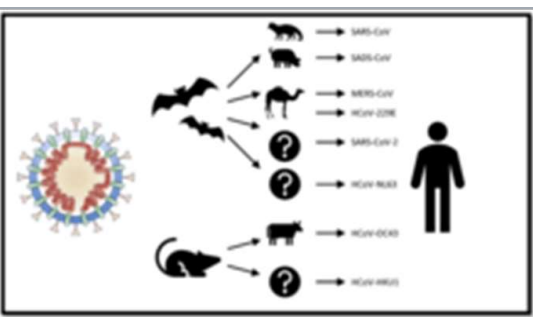

Origins of human coronaviruses with possible intermediate hosts

The most recent common ancestor (MRCA) of all coronaviruses is estimated to have existed as recently as $8000 \mathrm{BCE}$, although some models place the common ancestor as far back as 55 million years or more, implying long term coevolution with bat and avian species. ${ }^{[73]}$ The most recent common ancestor of the alphacoronavirus line has been placed at about $2400 \mathrm{BCE}$, of the betacoronavirus line at $3300 \mathrm{BCE}$, of the gammacoronavirus line 
at $2800 \mathrm{BCE}$, and of the deltacoronavirus line at about $3000 \mathrm{BCE}$. Bats and birds, as warm-blooded flying vertebrates, are an ideal natural reservoir for the coronavirus gene pool (with bats the reservoir for alphacoronaviruses and betacoronavirus - and birds the reservoir for gammacoronaviruses and deltacoronaviruses). The large number and global range of bat and avian species that host viruses has enabled extensive evolution and dissemination of coronaviruses. ${ }^{[74]}$

Many human coronaviruses have their origin in bats. ${ }^{[75]}$ The human coronavirus NL63 shared a common

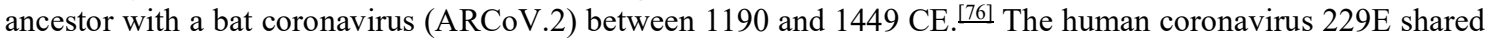

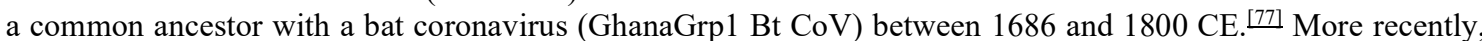
alpaca coronavirus and human coronavirus $229 \mathrm{E}$ diverged sometime before $1960 .{ }^{[78]} \mathrm{MERS}-\mathrm{CoV}$ emerged in humans from bats through the intermediate host of camels. ${ }^{[79]}$ MERS-CoV, although related to several bat

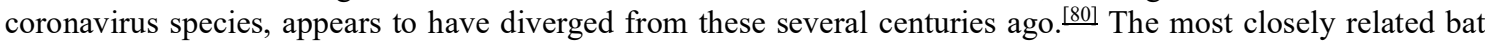
coronavirus and SARS-CoV diverged in $1986 . .^{[81]}$ A possible path of evolution of SARS coronavirus and keen bat coronaviruses is that SARS-related coronaviruses coevolved in bats for a long time. The ancestors of SARS-CoV first infected leaf-nose bats of the genus Hipposideridae; subsequently, they spread to horseshoe bats in the species

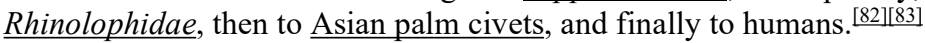

Unlike other betacoronaviruses, bovine coronavirus of the species Betacoronavirus 1 and subgenus Embecovirus is thought to have originated in rodents and not in bats. ${ }^{[75][84]}$ In the $1790 \mathrm{~s}$, equine coronavirus diverged from the bovine coronavirus after a cross-species jump. ${ }^{[85]}$ Later in the 1890 s, human coronavirus OC43

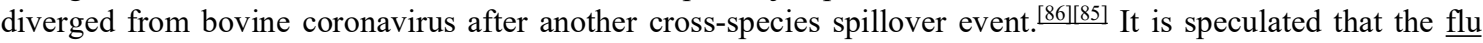
pandemic of 1890 may have been caused by this spillover event, and not by the influenza virus, because of the

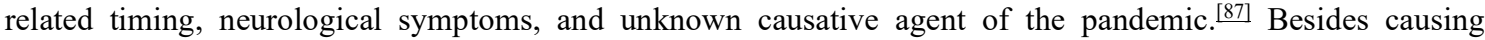
respiratory infections, human coronavirus OC43 is also suspected of playing a role in neurological diseases. $\frac{[88]}{\text { In }}$ the $1950 \mathrm{~s}$, the human coronavirus OC43 began to diverge into its present genotypes. ${ }^{[89]}$ Phylogentically, mouse hepatitis virus (Murine coronavirus), which infects the mouse's liver and central nervous system, ${ }^{[90]}$ is related to human coronavirus OC43 and bovine coronavirus. Human coronavirus HKU1, like the aforementioned viruses, also has its origins in rodents. $[75]$

Infection in humans

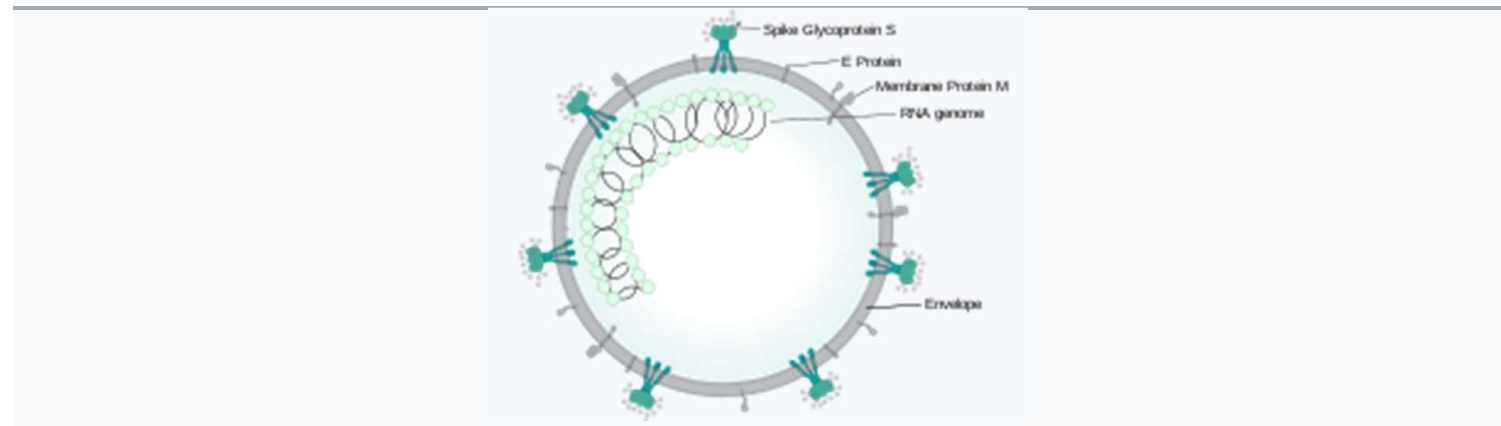

Illustration of SARSr-CoV virion

Coronaviruses vary significantly in risk factor. Some can kill more than $30 \%$ of those infected, such as MERS$\underline{\mathrm{CoV}}$, and some are relatively harmless, such as the common cold. ${ }^{[5]}$ Coronaviruses can cause colds with major symptoms, such as fever, and a sore throat from swollen adenoids. ${ }^{[91]}$ Coronaviruses can cause pneumonia (either direct viral pneumonia or secondary bacterial pneumonia) and bronchitis (either direct viral bronchitis or secondary bacterial bronchitis). ${ }^{[92]}$ The human coronavirus discovered in 2003, SARS-CoV, which causes severe acute respiratory syndrome (SARS), has a unique pathogenesis because it causes both upper and lower respiratory tract infections. ${ }^{[92]}$

Six species of human coronaviruses are known, with one species subdivided into two different strains, making seven strains of human coronaviruses altogether.

Four human coronaviruses produce symptoms that are generally mild:

1. Human coronavirus OC43 $(\mathrm{HCoV}-\mathrm{OC} 43), \beta-\mathrm{CoV}$

2. Human coronavirus HKU1 (HCoV-HKU1), $\beta-\mathrm{CoV}$

3. Human coronavirus $229 \mathrm{E}(\mathrm{HCoV}-229 \mathrm{E}), \underline{\alpha-\mathrm{CoV}}$

4. Human coronavirus NL63 (HCoV-NL63), $\alpha-\mathrm{CoV}$

Three human coronaviruses produce symptoms that are potentially severe:

1. Middle East respiratory syndrome-related coronavirus (MERS-CoV), $\beta-\mathrm{CoV}$

2. Severe acute respiratory syndrome coronavirus (SARS-CoV), $\beta-\mathrm{CoV}$

3. Severe acute respiratory syndrome coronavirus 2 (SARS-CoV-2), $\beta$ $\mathrm{CoV}$ 


\section{Common cold}

The human coronaviruses $\mathrm{HCoV}-\mathrm{OC} 43, \underline{\mathrm{HCoV}-\mathrm{HKU} 1}, \underline{\mathrm{HCoV}-229 \mathrm{E}}$, and HCoV-NL63 continually circulate in the human population and produce the generally mild symptoms of the common cold in adults and children worldwide. ${ }^{[93]}$ These coronaviruses cause about $15 \%$ of common colds, ${ }^{[94]}$ while 40 to $50 \%$ of colds are caused by rhinoviruses. ${ }^{[95]}$

Severe acute respiratory syndrome

\section{Characteristics of zoonotic coronavirus strains MERS-CoV, SARS-CoV, SARS-CoV-2, and related diseases}

\begin{tabular}{|c|c|c|c|}
\hline & MERS-CoV & $\underline{\text { SARS-CoV }}$ & SARS-CoV-2 \\
\hline Disease & MERS & $\underline{\text { SARS }}$ & COVID-19 \\
\hline Outbreaks & $\underline{2012}, \underline{2018}, \quad \underline{2015}$, & $\underline{2002-2004}$ & $\frac{2019-2020}{\text { pandemic }}$ \\
\hline \multicolumn{4}{|c|}{ Epidemiology } \\
\hline $\begin{array}{ll}\text { Date of first } \\
\text { identified case }\end{array}$ & $\begin{array}{l}\text { June } \\
2012\end{array}$ & $\begin{array}{l}\text { November } \\
2002\end{array}$ & $\begin{array}{l}\text { December } \\
2019^{[99]}\end{array}$ \\
\hline $\begin{array}{l}\text { Location of first } \\
\text { identified case }\end{array}$ & $\frac{\text { Jeddah, }}{\text { Saudi Arabia }}$ & $\frac{\text { Shunde, }}{\text { China }}$ & $\frac{\text { Wuhan, }}{\text { China }}$ \\
\hline Age average & 56 & $44_{[100\rceil[a]}$ & $56^{[101]}$ \\
\hline Sex ratio (M:F) & $3.3: 1$ & $0.8: 1^{[102]}$ & $1.6: 1 \stackrel{[101]}{\longleftarrow}$ \\
\hline Confirmed cases & 2494 & $8096^{[103]}$ & $67,618,431^{[104][\mathrm{b}]}$ \\
\hline Deaths & 858 & $774^{[103]}$ & $1,544,985^{[104][\mathrm{b}]}$ \\
\hline Case fatality rate & $37 \%$ & $9.2 \%$ & $2.3 \%$ \\
\hline \multicolumn{4}{|c|}{ Symptoms } \\
\hline Fever & $98 \%$ & $99-100 \%$ & $87.9 \%[105]$ \\
\hline Dry cough & $47 \%$ & $29-75 \%$ & $67.7 \%[105]$ \\
\hline Dyspnea & $72 \%$ & $40-42 \%$ & $18.6 \%$ \\
\hline Diarrhea & $26 \%$ & $20-25 \%$ & $3.7 \%[105]$ \\
\hline Sore throat & $21 \%$ & $13-25 \%$ & $13.9 \%[105]$ \\
\hline Ventilatory use & $24.5 \%$ & $14-20 \%$ & $4.1 \%$ \\
\hline
\end{tabular}

In 2003, following the outbreak of severe acute respiratory syndrome (SARS) which had begun the prior year in Asia, and secondary cases elsewhere in the world, the World Health Organization (WHO) issued a press release stating that a novel coronavirus identified by a number of laboratories was the causative agent for SARS. The virus was officially named the SARS coronavirus (SARS-CoV). More than 8,000 people from 29 different countries and territories were infected, and at least 774 died. ${ }^{[108][69]}$

\section{Middle East respiratory syndrome (MERS)}

Middle East respiratory syndrome

In September 2012, a new type of coronavirus was identified, initially called Novel Coronavirus 2012, and now officially named Middle East respiratory syndrome coronavirus (MERS-CoV). ${ }^{[109][110]}$ The World Health

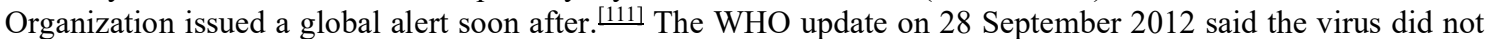
seem to pass easily from person to person. ${ }^{[112]}$ However, on 12 May 2013, a case of human-to-human transmission

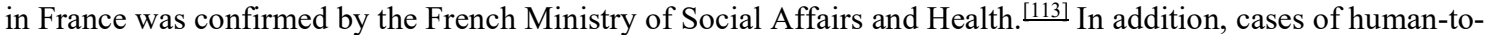
human transmission were reported by the Ministry of Health in Tunisia. Two confirmed cases involved people who seemed to have caught the disease from their late father, who became ill after a visit to Qatar and Saudi Arabia. Despite this, it appears the virus had trouble spreading from human to human, as most individuals who are infected do not transmit the virus. ${ }^{[114]}$ By 30 October 2013, there were 124 cases and 52 deaths in Saudi Arabia. ${ }^{[15]}$

After the Dutch Erasmus Medical Centre sequenced the virus, the virus was given a new name, Human Coronavirus-Erasmus Medical Centre (HCoV-EMC). The final name for the virus is Middle East respiratory syndrome coronavirus (MERS-CoV). The only U.S. cases (both survived) were recorded in May 2014. 116$]$

In May 2015, an outbreak of MERS-CoV occurred in the Republic of Korea, when a man who had traveled 
to the Middle East, visited four hospitals in the Seoul area to treat his illness. This caused one of the largest outbreaks of MERS-CoV outside the Middle East. ${ }^{[117]}$ As of December 2019, 2,468 cases of MERS-CoV infection had been confirmed by laboratory tests, 851 of which were fatal, a mortality rate of approximately $34.5 \%$. ${ }^{[118]}$

2.1.8 Coronavirus disease 2019 (COVID-19)

Coronavirus disease 2019

In December 2019, a pneumonia outbreak was reported in Wuhan, China. ${ }^{[119]}$ On 31 December 2019, the outbreak was traced to a novel strain of coronavirus, ${ }^{[120]}$ which was given the interim name $2019-\mathrm{nCoV}$ by the World Health Organization (WHO),, [121][122][123] later renamed SARS-CoV-2 by the International Committee on Taxonomy of Viruses.

As of 8 December 2020, there have been at least 1,544,985 ${ }^{[104]}$ confirmed deaths and more than $67,618,431^{[104]}$ confirmed cases in the COVID-19 pandemic. The Wuhan strain has been identified as a new strain of Betacoronavirus from group 2B with approximately $70 \%$ genetic similarity to the SARS-CoV. ${ }^{[124]}$ The virus has a $96 \%$ similarity to a bat coronavirus, so it is widely suspected to originate from bats as well. 125$][126]$ The pandemic has resulted in travel restrictions and nationwide lockdowns in many countries.

Infection in animals

Coronaviruses have been recognized as causing pathological conditions in veterinary medicine since the 1930 s. 20$]$ They infect a range of animals including swine, cattle, horses, camels, cats, dogs, rodents, birds and bats. ${ }^{[127]}$ The majority of animal related coronaviruses infect the intestinal tract and are transmitted by a fecal-oral route. $\frac{[128]}{}$ Significant research efforts have been focused on elucidating the viral pathogenesis of these animal coronaviruses, especially by virologists interested in veterinary and zoonotic diseases. ${ }^{[129]}$

\section{Farm animals}

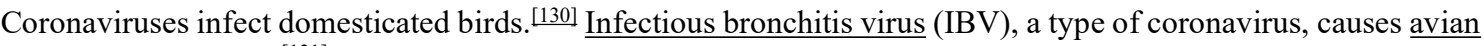
infectious bronchitis. ${ }^{[131]}$ The virus is of concern to the poultry industry because of the high mortality from infection, its rapid spread, and its effect on production. ${ }^{127]}$ The virus affects both meat production and egg production and causes substantial economic loss. $\stackrel{[132]}{2}$ In chickens, infectious bronchitis virus targets not only the respiratory tract but also the urogenital tract. The virus can spread to different organs throughout the chicken. 131$]$ The virus is transmitted by aerosol and food contaminated by feces. Different vaccines against IBV exist and have helped to limit the spread of the virus and its variants. ${ }^{[127]}$ Infectious bronchitis virus is one of a number of strains of the species Avian coronavirus. ${ }^{[133]}$ Another strain of avian coronavirus is turkey coronavirus (TCV) which causes enteritis in turkeys.. .127]

Coronaviruses also affect other branches of animal husbandry such as pig farming and the cattle raising. ${ }^{[127]}$ Swine acute diarrhea syndrome coronavirus (SADS-CoV), which is related to bat coronavirus HKU2, causes diarrhea in pigs. ${ }^{[134]}$ Porcine epidemic diarrhea virus (PEDV) is a coronavirus that has recently emerged and similarly causes diarrhea in pigs. ${ }^{[135]}$ Transmissible gastroenteritis virus (TGEV), which is a member of the species Alphacoronavirus $1, \stackrel{[136]}{1}$ is another coronavirus that causes diarrhea in young pigs. ${ }^{[137][138]}$ In the cattle industry bovine coronavirus (BCV), which is a member of the species Betacoronavirus 1 and related to HCoV-OC43, ${ }^{[139]}$ is responsible for severe profuse enteritis in young calves. ${ }^{[127]}$

Domestic pets

Coronaviruses infect domestic pets such as cats, dogs, and ferrets. $\stackrel{[130]}{ }$ There are two forms of feline coronavirus which are both members of the species Alphacoronavirus $1 . \stackrel{[136]}{ }$ Feline enteric coronavirus is a pathogen of minor clinical significance, but spontaneous mutation of this virus can result in feline infectious peritonitis (FIP), a disease with high mortality. ${ }^{[127]}$ There are two different coronaviruses that infect dogs. Canine coronavirus $(\mathrm{CCoV})$, which is a member of the species Alphacoronavirus $1, \stackrel{[136]}{ }$ causes mild gastrointestinal disease. $\frac{[127]}{\text { Canine }}$ respiratory coronavirus $(\mathrm{CRCoV})$, which is a member of the species Betacoronavirus 1 and related to $\mathrm{HCoV}$ OC43,, 139$]$ cause respiratory disease. ${ }^{[127]}$ Similarly, there are two types of coronavirus that infect ferrets. ${ }^{[140]} \underline{\text { Ferret }}$ enteric coronavirus causes a gastrointestinal syndrome known as epizootic catarrhal enteritis (ECE), and a more lethal systemic version of the virus (like FIP in cats) known as ferret systemic coronavirus (FSC). [141][142]

\section{Laboratory animals}

Coronaviruses infect laboratory animals. ${ }^{[127]}$ Mouse hepatitis virus (MHV), which is a member of the species Murine coronavirus,,${ }^{[143]}$ causes an epidemic murine illness with high mortality, especially among colonies of laboratory mice. ${ }^{[144]}$ Prior to the discovery of SARS-CoV, MHV was the best-studied coronavirus both $\underline{\text { in vivo and }}$ in vitro as well as at the molecular level. Some strains of MHV cause a progressive demyelinating encephalitis in mice which has been used as a murine model for multiple sclerosis. ${ }^{[129]}$ Sialodacryoadenitis virus (SDAV), which is a strain of the species Murine coronavirus, $\stackrel{[143]}{ }$ is highly infectious coronavirus of laboratory rats, which can be transmitted between individuals by direct contact and indirectly by aerosol. Rabbit enteric coronavirus causes acute gastrointestinal disease and diarrhea in young European rabbits. ${ }^{[127]}$ Mortality rates are high. ${ }^{[145]}$

Prevention and treatment

No vaccines existed against coronaviruses until 2020 in the midst of the COVID-19 pandemic, during which

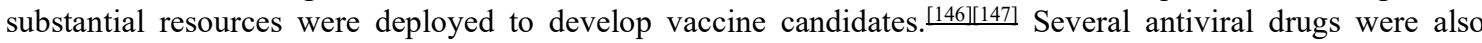


identified during that period which are theraputic against coronavirus. ${ }^{[148]}$ Previously, a number of antiviral targets were identified such as viral proteases, polymerases, and entry proteins. Drugs are in development which target these proteins and the different steps of viral replication. A number of vaccines using different methods are also under development for different human coronaviruses ${ }^{[50]}$

Vaccines are available for IBV, TGEV, and Canine CoV, although their effectiveness is limited. In the case of outbreaks of highly contagious animal coronaviruses, such as PEDV, measures such as destruction of entire herds of pigs may be used to prevent transmission to other herds.

2.1.9 Anemia

$\underline{\text { Anemia }}$ is defined as a low number of red blood cells. In a routine blood test, anemia is reported as a low hemoglobin or hematocrit. Hemoglobin is the main protein in your red blood cells. It carries oxygen, and delivers it throughout your body. If you have anemia, your hemoglobin level will be low too. If it is low enough, your tissues or organs may not get enough oxygen. Symptoms of anemia -- like fatigue or shortness of breath -- happen because your organs aren't getting what they need to work the way they should.

Anemia is the most common blood condition in the U.S. It affects almost $6 \%$ of the population. Women, young children, and people with long-term diseases are more likely to have anemia. Important things to remember are:

- Certain forms of anemia are passed down through your genes, and infants may have it from birth.

- Women are at risk of iron-deficiency anemia because of blood loss from their periods and higher blood supply demands during pregnancy.

- Older adults have a greater risk of anemia because they are more likely to have kidney disease or other chronic medical conditions.

There are many types of anemia. All have different causes and treatments. Some forms -- like the mild anemia that happens during pregnancy -- aren't a major concern. But some types of anemia maymay reflect a serious underlying medical condition

2.2.1 Anemia Symptoms

The signs of anemia can be so mild that you might not even notice them. At a certain point, as your blood cells decrease, symptoms often develop. Depending on the cause of the anemia, symptoms may include:

- Dizziness, lightheadness, or feeling like you are about to pass out

- $\quad$ Fast or unusual heartbeat

- $\quad$ Headache

- Pain, including in your bones, chest, belly, and joints

- Problems with growth, for children and teens

- Shortness of breath

- $\quad$ Skin that's pale or yellow

- Cold hands and feet

- Tiredness or weakness

2.2.2 Anemia Types and Causes

There are more than 400 types of anemia, and they're divided into three groups:

- Anemia caused by blood loss

- Anemia caused by decreased or faulty red blood cell production

- Anemia caused by destruction of red blood cells

2.2.3 Lupus Erythmatosus

This is inflammatory disease where the immune system attack the body tissues of it,s own. there are four types, namely:

- $\quad$ Systemic lupus erythmatosus

- Immunologic lupus erythmatosus

- Lupus dermatitis

- Congenital lupus erythmatosus

2.2.4 Histiocytosis

In medicine, histiocytosis is an excessive number of histiocytes ${ }^{[1]}$ (tissue macrophages), and the term is also often used to refer to a group of rare diseases which share this sign as a characteristic. Occasionally and confusingly, the term "histiocytosis" is sometimes used to refer to individual diseases.

According to the Histiocytosis Association of America, 1 in 200,000 children in the United States are born with histiocytosis each year. ${ }^{[2]}$ HAA also states that most of the people diagnosed with histiocytosis are children under the age of 10, although the disease can afflict adults. The disease usually occurs from birth to age 15. ${ }^{[3]}$

Histiocytosis (and malignant histiocytosis) are both important in veterinary as well as human pathology.

Types

Types of LCH have also been known as "eosinophilic granuloma", "Hand-Schuller-Christian disease", "LettererSiwe disease", and "histiocytosis. 
Alternatively, histiocytoses may be divided into the following groups:[4]:714-724

- X-type histiocytoses

- $\quad$ Non-X histiocytoses

Lymphohistiocytosis is "a widespread infiltrate of non-malignant lymphocytes and macrophages, involving principally the liver, spleen and central nervous system and associated with a severe lymphoid atrophy."[5] Diagnosis

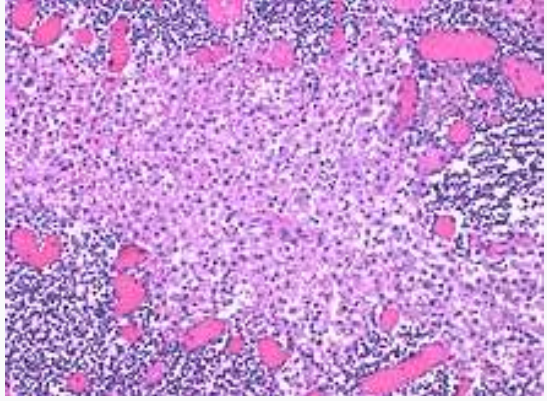

Sinus histiocytosis, a common feature in lymph node biopsies, is characterized by dilated sinuses containing variable numbers of histiocytes. ${ }^{[6]}$

2.2.3 Classification

There are competing systems for classifying histiocytoses. According to the 1999 classification proposed by the World Health Organization, they can be divided into three categories. ${ }^{[7][8]}$ However, the classifications in ICD10 and $\mathrm{MeSH}$ are slightly different, as shown below:

\begin{tabular}{|l|l|l|l|}
\hline Name & WHO & $\underline{\text { ICD10 }}$ & $\underline{\text { MeSH }}$ \\
\hline$\underline{\text { Langerhans cell histiocytosis (LCH) }}$ & I & $\underline{\text { D76.0 }}$ & Langerhans-cell histiocytosis \\
\hline Juvenile xanthogranuloma (JXG) & II & $\underline{\text { D76.3 }}$ & non-Langerhans-cell histiocytosis \\
\hline$\underline{\text { Hemophagocytic lymphohistiocytosis (HLH) }}$ & II & $\underline{\text { D76.1 }}$ & non-Langerhans-cell histiocytosis \\
\hline$\underline{\text { Niemann-Pick disease }}$ & II & $\underline{\text { E75.2 }}$ & non-Langerhans-cell histiocytosis \\
\hline$\underline{\text { Sea-blue histiocytosis }}$ & II & - & non-Langerhans-cell histiocytosis \\
\hline$\underline{\text { Acute monocytic leukemia }}$ & III & $\underline{\text { 993.0 }}$ & malignant histiocytic disorders \\
\hline$\underline{\text { Malignant histiocytosis }}$ & III & $\underline{\text { C96.1 }}$ & malignant histiocytic disorders \\
\hline$\underline{\text { Erdheim-Chester disease }}$ & II & $\underline{\text { C96.1 }}$ & malignant histiocytic disorders \\
\hline
\end{tabular}

Treatment

- Chemotherapy

- Cladribine (also known as 2CDA or Leustatin)

- Etoposide

- Vinblastine (Velban) 


\subsubsection{Hemophagocytic lymphohistiocytosis}

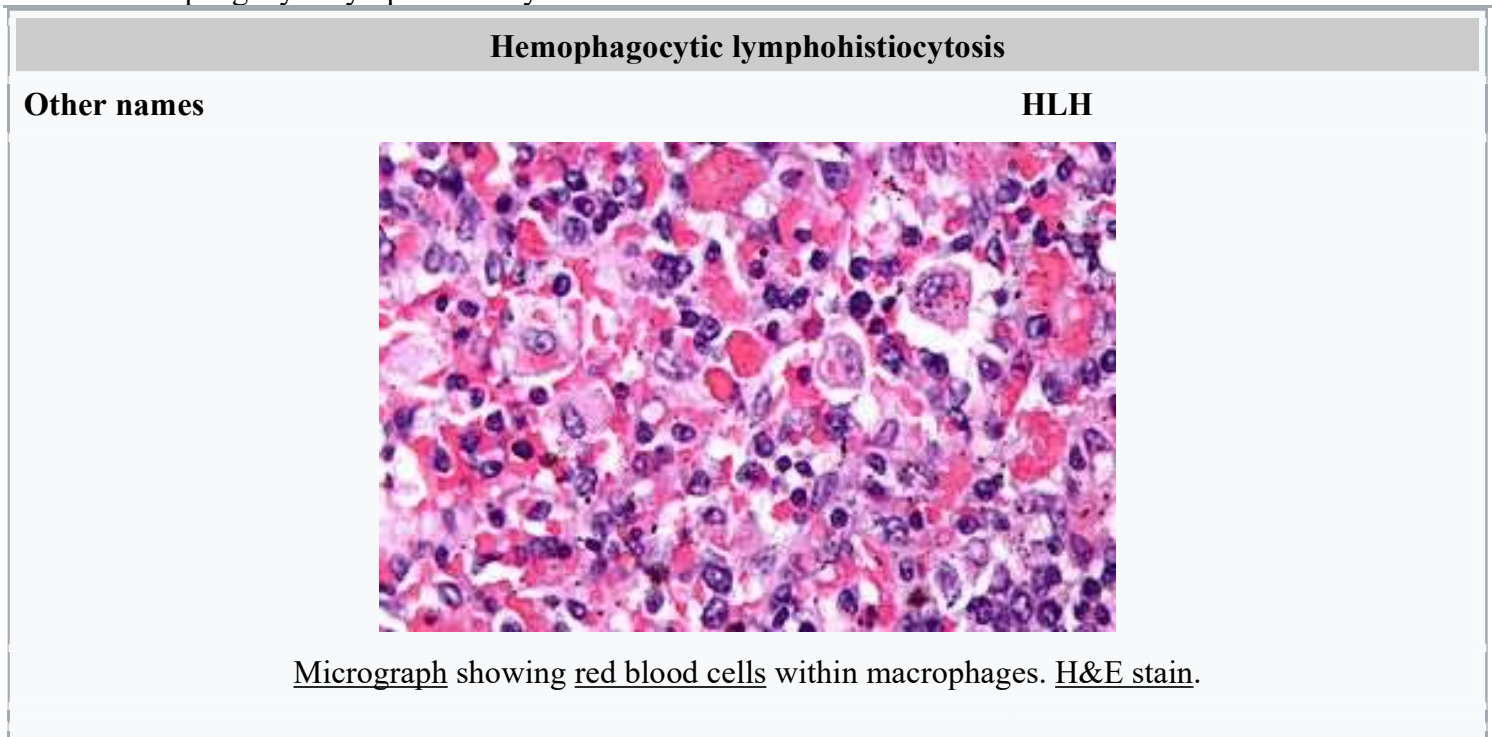

Hemophagocytic lymphohistiocytosis (HLH), also known as haemophagocytic lymphohistiocytosis (British spelling), and hemophagocytic or haemophagocytic syndrome, ${ }^{[1]}$ is an uncommon hematologic disorder seen more often in children than in adults. It is a life-threatening disease of severe hyperinflammation caused by uncontrolled proliferation of activated lymphocytes and macrophages, characterised by proliferation of morphologically benign lymphocytes and macrophages that secrete high amounts of inflammatory cytokines. It is classified as one of the cytokine storm syndromes. There are inherited and non-inherited (acquired) causes of hemophagocytic lymphohistiocytosis (HLH). $\Gamma$

Signs and symptoms

The onset of HLH occurs under the age of one year in approximately 70 percent of cases. Familial HLH should be suspected if siblings are diagnosed with HLH or if symptoms recur when therapy has been stopped. Each full sibling of a child with familial HLH has a twenty-five-percent chance of developing the disease, a fifty-percent chance of carrying the defective gene (which is very rarely associated with any risk of disease), and a twenty-fivepercent chance of not being affected and not carrying the gene defect. [citation needed]

Patients with HLH, especially when untreated, may need intensive therapy. Therefore, HLH should be included in the differential diagnosis of intensive care unit patients with cytopenia and hyperferritinemia. ${ }^{[2]}$ Patients in the earlier stages of HLH are frequently hospitalized at internal medicine wards. ${ }^{[3]}$

HLH clinically manifests with fever, enlargement of the liver and spleen, enlarged lymph nodes, yellow discoloration of the skin and eyes, and a rash. ${ }^{[4]}$ Laboratory findings may include elevated triglyceride levels, low fibrinogen levels, transaminitis, and elevated ferritin levels (among others). ${ }^{[4]}$

Causes

Primary HLH is caused by loss of function, (i.e. inactivating) mutations in genes that code for proteins cytotoxic $\underline{\mathrm{T} \text { cells }}$ and NK cells use to kill targeted cells, such as those infected with pathogens like the Epstein-Barr virus

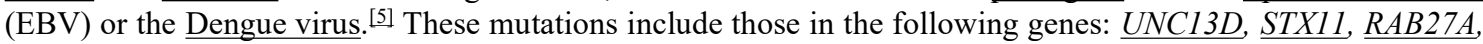
$\underline{S T X B P 2}, \underline{L Y S T}, \underline{P R F 1} 1, \underline{S H} 2 D 1 A, \underline{B I R C 4}, \underline{I T K}, \underline{C D 27}$, and MAGT1.

Secondary HLH (sHLH) is associated with, and thought to be promoted, by malignant and non-malignant diseases that likewise weaken the ability of the immune system ability to attack EBV-infected cells. Malignant disorders associated with secondary HLH include T-cell lymphoma, B-cell lymphoma, acute lymphocytic leukemia, acute myeloid leukemia, and myelodysplastic syndrome. Non-malignant disorders associated with secondary HLH include: autoimmune disorders such as juvenile idiopathic arthritis, juvenile Kawasaki disease, systemic lupus erythematosus, the juvenile onset and adult onset forms of Still's disease, and rheumatoid arthritis; $;$; immunodeficiency disorders such as severe combined immunodeficiency, DiGeorge syndrome, Wiskott-Aldrich syndrome, ataxia-telangiectasia, and dyskeratosis congenita); $;$ [7] and infections caused by EBV, cytomegalovirus, HIV/AIDS, bacteria, protozoa, fungi and possibly SARS-CoV-2. ${ }^{[8]}$ Secondary HLH may also result from iatrogenic causes such as bone marrow or other organ transplantations; chemotherapy; or therapy with immunosuppressing agents; $[9]$

About $33 \%$ of all HLH cases, $75 \%$ of Asian HLH cases, and nearly $100 \%$ of HLH cases caused by mutations in 
SH2D1A (see X-linked lymphoproliferative disease type 1) are associated with, and thought triggered or promoted by, EBV infection. These cases of HLH are classified as belonging to the class of Epstein-Barr virus-associated lymphoproliferative diseases and termed EBV+ HLH.

Pathophysiology

The underlying causes, either inherited or acquired, lead to an unchecked immune response when exposed to triggers. Impaired NK-cell cytotoxicity is the hallmark of HLH. All genetic defects for familial HLH are related to granule-dependent cytotoxicity. This inability to remove infected and antigen-presenting cells and terminate the immune response leads to uncontrolled proliferation and activation of the immune system with release of excessive cytokines. These cells then infiltrate organs, releasing more cytokines, which gives the clinical picture. The fever is caused by IL-1, IL-6 and TNF-alpha; the cytopenia is due to the suppressive effect on hematopoiesis by TNFalpha and TNF-gamma. TNF-alpha and TNF-gamma may also lead to inhibition of lipoprotein lipase or stimulate triglyceride synthesis. Activated macrophages secrete ferritin and plasminogen activator leading to hyperfibrinolysis. ${ }^{[11]}$

Genetics

Five genetic subtypes (FHL1, FHL2, FHL3, FHL4, and FHL5) are described, with an estimated overall prevalence of one in 50,000 and equal gender distribution. Molecular genetic testing for four of the causative genes, PRF1 (FHL2), UNC13D (FHL3), STX11 (FHL4), and STXBP2 (FHL5), is available on a clinical basis. Symptoms of FHL are usually evident within the first few months of life and may even develop in utero.

The five subtypes of FHL ${ }^{[12]}$ are each associated with a specific gene:

- FHL1: $\underline{\text { HPLH1 }}$

- $\quad$ FHL2: $\underline{P R F 1}$ (Perforin)

- FHL3: $\underline{U N C 13 D}$ (Munc13-4)

- FHL4: $\underline{\text { STX11 }}$ (Syntaxin 11)

- $\quad$ FHL5: $\underline{\text { STXBP2 }}$ (Syntaxin binding protein 2)/UNC18-2

Nearly half of the cases of type 2 familial hemophagocytic lymphohistiocytosis are due to bi-allelic PRF1 mutations. $\frac{[13]}{[}$

Diagnosis

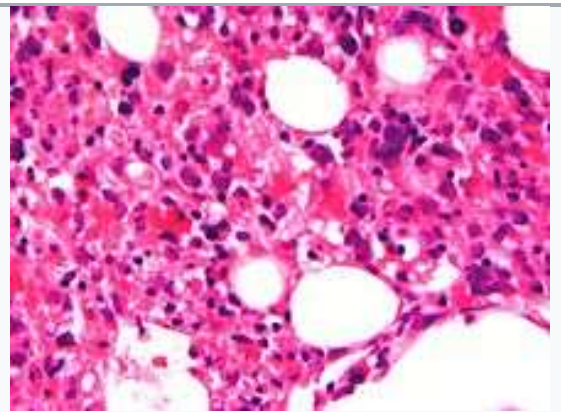

Light microscopic image of bone marrow showing stromal macrophages containing numerous red blood cells in their cytoplasm

The blood count typically shows decreased numbers of blood cells -including a decreased number of circulating red blood cells, white blood cells, and platelets. The bone marrow may show hemophagocytosis. The liver function tests are usually elevated. A low level of the protein albumin in the blood is common. [citation needed]

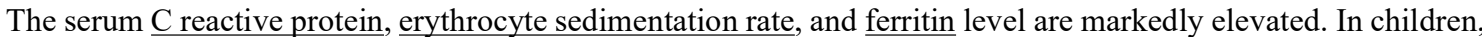
a ferritin above 10000 is very sensitive and specific for the diagnosis of $\mathrm{HLH}, \stackrel{[14]}{ }$ however, the diagnostic utility for ferritin is less for adult HLH patients. $\frac{[15]}{[}$

The serum fibrinogen level is usually low and the D-dimer level is elevated.

The sphingomyelinase is elevated. [16]

Bone marrow biopsy shows histiocytosis. ${ }^{[17]}$

2.2.5 Classification

Primary HLH, also known as familial haemophagocytic lymphohistiocytosis (FHL) or familial erythrophagocytic lymphohistiocytosis, is a heterogeneous autosomal recessive disorder found to be more prevalent with parental consanguinity. [itation needed]

Secondary haemophagocytic lymphohistiocytosis (acquired haemophagocytic lymphohistiocytosis) occurs after strong immunologic activation, such as that which can occur with systemic infection, immunodeficiency, or underlying malignancy. [citation needed $]$

Both forms are characterized by the overwhelming activation of normal $\mathrm{T}$ lymphocytes and macrophages, 
invariably leading to clinical and haematologic alterations and death in the absence of treatment. [citation needed]

A subtype of primary HLH where the inflammation is limited to the central nervous system has been described. ${ }^{[18]}$

2.2.6 Diagnostic criteria

The current (2008) diagnostic criteria for HLH are ${ }^{[19]}$

1. A molecular diagnosis consistent with HLH. These include the identification of pathologic mutations of PRF1, UNC13D, or STX11.

OR

2. Fulfillment of five out of the eight criteria below:

- $\quad$ Fever (defined as a temperature $>100.3^{\circ} \mathrm{F},>38^{\circ} \mathrm{C}$ )

- Enlargement of the spleen

- Decreased blood cell counts affecting at least two of three lineages in the peripheral blood:

○ Haemoglobin $<9 \mathrm{~g} / 100 \mathrm{ml}$ (in infants $<4$ weeks: haemoglobin $<10$ $\mathrm{g} / 100 \mathrm{ml})$ (吕emia)

- Platelets $<100 \times 10^{9} / \mathrm{L}$ (thrombocytopenia)

- Neutrophils $<1 \times 10^{9} / \mathrm{L}$ (neutropenia)

- High blood levels of triglycerides (fasting, greater than or equal to 265 $\mathrm{mg} / 100 \mathrm{ml})$ and/or decreased amounts of fibrinogen in the blood $(\leq 150$ $\mathrm{mg} / 100 \mathrm{ml}$ )

- $\quad \underline{\text { Ferritin }} \geq 500 \mathrm{ng} / \mathrm{ml}$

- Haemophagocytosis in the bone marrow, spleen or lymph nodes

- Low or absent natural killer cell activity

- Soluble $\underline{\text { CD25 }}$ (soluble IL-2 receptor) $>2400 \mathrm{U} / \mathrm{ml}$ (or per local reference laboratory)

In addition, in the case of familial HLH, no evidence of malignancy should be apparent.

Not all five out of eight criteria are required for diagnosis of HLH in adults, and a high index of suspicion is required for diagnosis as delays results in increased mortality. The diagnostic criteria were developed in pediatric populations and have not been validated for adult HLH patients. ${ }^{[20]}$ Attempts to improve diagnosis of HLH have included use of the HScore, which can be used to estimate an individual's risk of HLH. ${ }^{[21]}$ In adults, soluble IL-2 receptor has been found to be a very sensitive marker for $\mathrm{HLH}$, demonstrating $100 \%$ sensitivity for ruling out HLH below a cutoff of $2400 \mathrm{U} / \mathrm{mL}$ and optimal cutoff for ruling in at $2515 \mathrm{U} / \mathrm{mL}$ (sensitivity, 100\%; specificity, $72.5 \%$ ), with $93 \%$ specificity at $>10000 \mathrm{U} / \mathrm{mL}$. [22]

\section{Differential diagnosis}

The differential diagnosis of HLH includes secondary HLH and macrophage-activation syndrome or other primary immunodeficiencies that present with hemophagocytic lymphohistiocytosis, such as X-linked lymphoproliferative disease.. [citation needed]

Other conditions that may be confused with this condition include autoimmune lymphoproliferative syndrome. ${ }^{[23]}$ As a syndrome of intense inflammation it needs to be differentiated from sepsis, what may be extremely challenging. .24$]$

The diagnosis of acquired, or secondary, HLH is usually made in association with infection by viruses, bacteria, fungi, or parasites or in association with lymphoma, autoimmune disease, or metabolic disease. Acquired HLH may have decreased, normal, or increased NK cell activity. ${ }_{.}^{\text {[citation needed] }}$

2.2.7 Griscelli syndrome

A major differential diagnosis of HLH is Griscelli syndrome (type 2). This is a rare autosomal recessive disorder characterized by partial albinism, hepatosplenomegaly, pancytopenia, hepatitis, immunologic abnormalities, and lymphohistiocytosis. Most cases have been diagnosed between 4 months and 7 years of age, with a mean age of about 17 months. [ [itation needed]

Three types of Griscelli syndrome are recognised: type 1 has neurologic symptoms and mutations in $\underline{\mathrm{MYO}} \mathrm{A}$. Prognosis depends on the severity of neurologic manifestations. Type 2 has mutations in RAB27A and haemophagocytic syndrome, with abnormal T-cell and macrophage activation. This type has a grave prognosis if untreated. Type 3 has mutations in melanophilin and is characterized by partial albinism. This type does not pose a threat to those so affected. [citation needed]

Treatment

In secondary cases, treatment of the cause, where possible, is indicated. Additionally, treatment for HLH itself is usually required.

While optimal treatment of HLH is still being debated, current treatment regimes usually involve high dose $\underline{\text { corticosteroids, }}$ etoposide and cyclosporin. ${ }^{[\text {citation needed }]}$ Intravenous immunoglobulin is also used. Methotrexate and 
vincristine have also been used. Other medications include cytokine targeted therapy.

On 20 November 2018, the FDA approved the anti-IFN-gamma monoclonal antibody emapalumab (proprietary name Gamifant) for the treatment of pediatric and adult primary HLH. ${ }^{[25]}$

Prognosis

The prognosis is guarded with an overall mortality of 50\%. Poor prognostic factors included HLH associated with malignancy, with half the patients dying by 1.4 months compared to 22.8 months for non-tumour associated HLH patients. $\underline{[26]}$

Secondary HLH in some individuals may be self-limited because patients are able to fully recover after having received only supportive medical treatment (i.e., IV immunoglobulin only). However, long-term remission without the use of cytotoxic and immune-suppressive therapies is unlikely in the majority of adults with HLH and in those with involvement of the central nervous system (brain and/or spinal cord). ${ }^{[12]}$

2.2.8 The major histocompatibility complex (MHC)

MHC is a large locus on vertebrate DNA containing a set of closely linked polymorphic genes that code for cell surface proteins essential for the adaptive immune system. This locus got its name because it was discovered in the study of tissue compatibility upon transplantation. ${ }^{[1]}$ Later studies revealed that tissue rejection due to incompatibility is an experimental artifact masking the real function of MHC molecules - binding an antigen derived from self-proteins or from pathogen and the antigen presentation on the cell surface for recognition by the appropriate T-cells. ${ }^{[2]}$ MHC molecules mediate interactions of leukocytes, also called white blood cells (WBCs), which are immune cells, with other leukocytes or with body cells. The MHC determines compatibility of donors for organ transplant, as well as one's susceptibility to an autoimmune disease via cross-reacting immunization.

In a cell, protein molecules of the host's own phenotype or of other biologic entities are continually synthesized and degraded. Each MHC molecule on the cell surface displays a small peptide, molecular fraction of a protein, called an epitope..$^{[3]}$ The presented self-antigens prevent an organism's immune system targeting its own cells. Presentation of pathogen-derived proteins results in the elimination of the infected cell by the immune system.

Diversity of antigen presentation, mediated by MHC antigens, is attained in at least three ways: (1) an organism's MHC repertoire is polygenic (via multiple, interacting genes); (2) MHC expression is codominant (from both sets of inherited alleles); (3) MHC gene variants are highly polymorphic (diversely varying from organism to organism within a species). ${ }^{[4]}$ Sexual selection has been observed in male mice making mate choices of females with different MHCs and thus demonstrating sexual selection. ${ }^{[5]}$ Also, at least for MHC I presentation, there has been evidence of antigenic peptide splicing which can combine peptides from different proteins, vastly increasing antigen diversity. $\frac{[6]}{}$

Discovery

The first descriptions of the MHC were made by British immunologist Peter Gorer in 1936. ${ }^{[7]}$ MHC genes were first identified in inbred mice strains. Clarence Little transplanted tumors across differing strains and found rejection of transplanted tumors according to strains of host versus donor. ${ }^{[8]}$ George Snell selectively bred two mouse strains, attained a new strain nearly identical to one of the progenitor strains, but differing crucially in

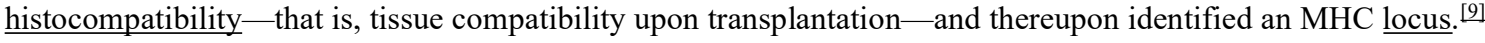
Later Jean Dausset demonstrated the existence of MHC genes in humans and described the first human leucocyte antigen, the protein which we call now HLA-A2. Some years later Baruj Benacerraf showed that polymorphic MHC genes not only determine an individual's unique constitution of antigens but also regulate the interaction among the various cells of the immunological system. These three scientists have been awarded the 1980 Nobel Prize in Physiology or Medicine ${ }^{[10]}$ for their discoveries concerning "genetically determined structures on the cell surface that regulate immunological reactions".

The first fully sequenced and annotated MHC was published for humans in 1999 by a consortium of sequencing centers from the UK, USA and Japan in Nature. ${ }^{[11]}$ It was a "virtual MHC" since it was a mosaic from different individuals. A much shorter MHC locus from chickens was published in the same issue of Nature. $\frac{[12]}{}$ Many other species have been sequenced and the evolution of the MHC was studied, e.g. in the gray short-tailed opossum (Monodelphis domestica), a marsupial, MHC spans $3.95 \mathrm{Mb}$, yielding 114 genes, 87 shared with humans. ${ }^{[13]}$ Marsupial MHC genotypic variation lies between eutherian mammals and birds, taken as the minimal MHC encoding, but is closer in organization to that of nonmammals. The IPD-MHC Database ${ }^{[14]}$ was created which provides a centralised repository for sequences of the Major Histocompatibility Complex (MHC) from a number of different species. The database contains 77 species for the release from 2019-12-19.

2.2.9 Genes

The MHC locus is present in all jawed vertebrates, it is assumed to have arisen about 450 million years ago. ${ }^{[15]}$ Despite the difference in the number of genes included in the MHC of different species, the overall organization of the locus is rather similar. Usual MHC contains about a hundred genes and pseudogenes, not all of them are involved in immunity. In humans, the MHC region occurs on chromosome 6 , between the flanking genetic markers $M O G$ and COL11A2 (from 6p22.1 to $6 \mathrm{p} 21.3$ about $29 \mathrm{Mb}$ to $33 \mathrm{Mb}$ on the hg 38 assembly), and contains 224 genes

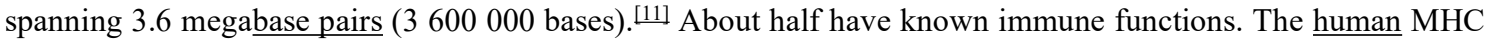


is also called the HLA (human leukocyte antigen) complex (often just the HLA). Similarly, there is SLA (Swine leukocyte antigens), BoLA (Bovine leukocyte antigens), DLA for dogs, etc. However, historically, the MHC in mice is called the Histocompatibility system 2 or just the H-2, in rats - RT1, and in chicken - B-locus.

The MHC gene family is divided into three subgroups: MHC class I, MHC class II, and MHC class III. Among all those genes present in $\mathrm{MHC}$, there are two types of genes coding for the proteins $\mathrm{MHC}$ class I molecules and MHC class II molecules that directly involved in the antigen presentation. These genes are highly polymorphic, 19031 alleles of class I HLA, and 7183 of class II HLA are deposited for human in the IMGT database. ${ }^{[16]}$

\begin{tabular}{|c|c|c|}
\hline Class & Encoding & Expression \\
\hline$\underline{I}$ & $\begin{array}{l}\text { (1) peptide-binding proteins, which select short sequences of } \\
\text { amino acids for antigen presentation, as well as (2) molecules } \\
\text { aiding antigen-processing (such as TAP and tapasin). }\end{array}$ & $\begin{array}{l}\text { One chain, called } \alpha \text {, whose ligands are } \\
\text { the CD } 8 \text { receptor-borne notably by } \\
\text { cytotoxic } T \text { cells-and inhibitory } \\
\text { receptors borne by NK cells }\end{array}$ \\
\hline$\underline{\text { II }}$ & 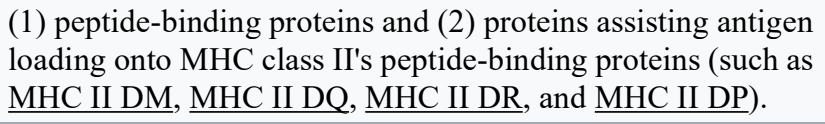 & $\begin{array}{l}\text { Two chains, called } \alpha \& \beta \text {, whose } \\
\text { ligands are the CD4 receptors borne by } \\
\text { helper T cells. }\end{array}$ \\
\hline$\underline{\text { III }}$ & $\begin{array}{l}\text { Other immune proteins, outside antigen processing and } \\
\text { presentation, such as components of the complement cascade } \\
\text { (e.g., } \underline{\mathrm{C} 2}, \underline{\mathrm{C} 4} \text {, factor B), the cytokines of immune signaling } \\
\text { (e.g., } \underline{\mathrm{TNF}-\alpha} \text { ), and heat shock proteins buffering cells from } \\
\text { stresses }\end{array}$ & Various \\
\hline
\end{tabular}

\subsubsection{Proteins}

\section{MHC class I}

MHC class I molecules are expressed in all nucleated cells and also in platelets - in essence all cells but red blood cells. It presents epitopes to killer T cells, also called cytotoxic T lymphocytes (CTLs). A CTL expresses CD8 receptors, in addition to T-cell receptors (TCR)s. When a CTL's CD8 receptor docks to a MHC class I molecule, if the CTL's TCR fits the epitope within the MHC class I molecule, the CTL triggers the cell to undergo programmed cell death by apoptosis. Thus, MHC class I helps mediate cellular immunity, a primary means to address intracellular pathogens, such as viruses and some bacteria, including bacterial $\underline{\mathrm{L} \text { forms }}$, bacterial genus

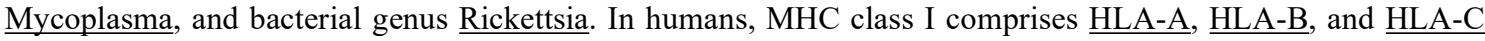
molecules.

The first crystal structure of Class I MHC molecule, human HLA-A2, was published in 1989. 117$]$ The structure revealed that MHC-I molecules are heterodimers, they have polymorphic heavy $\alpha$-subunit whose gene occurs inside the MHC locus and small invariant $\underline{\beta}_{2}$ microglobulin subunit whose gene is located usually outside of it. Polymorphic heavy chain of MHC-I molecule contains N-terminal extra-cellular region composed by three domains, $\alpha 1, \alpha 2$, and $\alpha 3$, transmembrane helix to hold MHC-I molecule on the cell surface and short cytoplasmic tail. Two domains, $\alpha 1$ and $\alpha 2$ form deep peptide-binding groove between two long $\alpha$-helices and the floor of the groove formed by eight $\beta$-strands. Immunoglobulin-like domain $\alpha 3$ involved in the interaction with $\underline{C D 8}$ coreceptor. $\underline{\beta}_{2}$ microglobulin provides stability of the complex and participates in the recognition of peptide-MHC class I complex by $\underline{\mathrm{CD} 8}$ co-receptor. ${ }^{[18]}$ The peptide is non-covalently bound to MHC-I, it is held by the several pockets on the floor of the peptide-binding groove. Amino acid side-chains that are most polymorphic in human alleles fill up the central and widest portion of the binding groove, while conserved side-chains are clustered at the narrower ends of the groove.

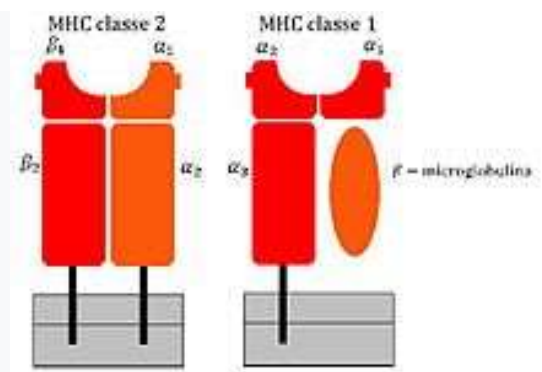

Schematic view of MHC class I and MHC class II molecules

Classical MHC molecules present epitopes to the TCRs of CD8+ T lymphocytes. Nonclassical molecules (MHC class IB) exhibit limited polymorphism, expression patterns, and presented antigens; this group is subdivided into a group encoded within MHC loci (e.g., HLA-E, -F, -G), as well as those not (e.g., stress ligands such as ULBPs, Rae1, and H60); the antigen/ligand for many of these molecules remain unknown, but they can interact with each 
of CD8+ T cells, NKT cells, and NK cells. The evolutionary oldest nonclassical MHC class I lineage in human was deduced to be the lineage that includes the CD1 and PROCR (alias EPCR) molecules, and this lineage may have been established before the origin of tetrapod species ${ }^{[19]}$. However, the only nonclassical MHC class I lineage for which evidence exists that it was established before the evolutionary separation of Actinopterygii (ray-finned fish) and Sarcopterygii (lobe-finned fish plus tetrapods) is lineage $\mathrm{Z}$ of which members are found, together in each species with classical MHC class I, in lungfish and throughout ray-finned fishes [20]; why the Z lineage was well conserved in ray-finned fish but lost in tetrapods is not understood.

2.3.2 MHC class II

MHC class II can be conditionally expressed by all cell types, but normally occurs only on "professional" antigenpresenting cells (APCs): macrophages, B cells, and especially dendritic cells (DCs). An APC takes up an antigenic protein, performs antigen processing, and returns a molecular fraction of it - a fraction termed the epitope-and displays it on the APC's surface coupled within an MHC class II molecule (antigen presentation). On the cell's surface, the epitope can be recognized by immunologic structures like T-cell receptors (TCRs). The molecular region which binds to the epitope is the paratope.

On surfaces of helper T cells are CD4 receptors, as well as TCRs. When a naive helper T cell's CD4 molecule docks to an APC's MHC class II molecule, its TCR can meet and bind the epitope coupled within the MHC class II. This event primes the naive T cell. According to the local milieu, that is, the balance of cytokines secreted by APCs in the microenvironment, the naive helper $\mathrm{T}$ cell $\left(\mathrm{Th}_{0}\right)$ polarizes into either a memory Th cell or an effector Th cell of phenotype either type $1\left(\mathrm{Th}_{1}\right)$, type $2\left(\mathrm{Th}_{2}\right)$, type $17\left(\mathrm{Th}_{17}\right)$, or regulatory/suppressor $\left(\mathrm{T}_{\text {reg }}\right)$, as so far identified, the Th cell's terminal differentiation.

MHC class II thus mediates immunization to-or, if APCs polarize $\mathrm{Th}_{0}$ cells principally to $\mathrm{T}_{\text {reg }}$ cells, $\underline{\text { immune }}$ tolerance of - an antigen. The polarization during primary exposure to an antigen is key in determining a number of chronic diseases, such as inflammatory bowel diseases and asthma, by skewing the immune response that memory Th cells coordinate when their memory recall is triggered upon secondary exposure to similar antigens. $\mathrm{B}$ cells express $\mathrm{MHC}$ class II to present antigens to $\mathrm{Th}_{0}$, but when their $\mathrm{B}$ cell receptors bind matching epitopes, interactions which are not mediated by MHC, these activated B cells secrete soluble immunoglobulins: antibody molecules mediating humoral immunity.

Class II MHC molecules are also heterodimers, genes for both $\alpha$ and $\beta$ subunits are polymorphic and located within MHC class II subregion. Peptide-binding groove of MHC-II molecules is forms by N-terminal domains of both subunits of the heterodimer, $\alpha 1$ and $\beta 1$, unlike MHC-I molecules, where two domains of the same chain are involved. In addition, both subunits of MHC-II contain transmembrane helix and immunoglobulin domains $\alpha 2$ or $\beta 2$ that can be recognized by $\underline{\mathrm{CD} 4}$ co-receptors. ${ }^{[21]}$ In this way MHC molecules chaperone which type of lymphocytes may bind to the given antigen with high affinity, since different lymphocytes express different $\mathrm{T}$ Cell Receptor (TCR) co-receptors.

MHC class II molecules in humans have five to six isotypes. Classical molecules present peptides to CD4+ lymphocytes. Nonclassical molecules, accessories, with intracellular functions, are not exposed on cell membranes, but in internal membranes, assisting with the loading of antigenic peptides onto classic MHC class II molecules. The important nonclassical MHC class II molecule DM is only found from the evolutionary level of

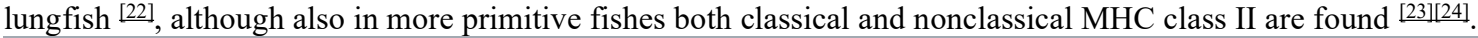

\begin{tabular}{|l|l|l|l|}
\hline Sr.No & \multicolumn{1}{|c|}{ Feature ${ }^{[25]}$} & \multicolumn{1}{|c|}{ Class I MHC } & \multicolumn{1}{c|}{ Class II MHC } \\
\hline 1 & $\begin{array}{l}\text { Constituting polypeptide } \\
\text { chains }\end{array}$ & $\begin{array}{l}\alpha \text { chain (45Ka in humans) } \\
\beta_{2} \text { chain (12 KDa in humans) }\end{array}$ & $\begin{array}{l}\alpha \text { chain (30-34 KDa in humans) } \\
\beta \text { chain (26-29 KDa in humans) }\end{array}$ \\
\hline 2 & Antigen binding domain & $\alpha 1$ and $\alpha 2$ domains & $\alpha_{1}$ and $\beta_{1}$ domains \\
\hline 3 & Binds protein antigens of & $8-10$ amino acids residues & $13-18$ amino acids residues \\
\hline 5 & $\begin{array}{l}\text { Peptide bending cleft } \\
\text { involved in binding }\end{array}$ & $\begin{array}{l}\text { Floor formed by } \beta \text { sheets and } \\
\text { sides by a } \\
\text { helices, blocked at both the ends }\end{array}$ & $\begin{array}{l}\text { Floor formed by } \beta \text { sheets and sides } \\
\text { by a } \\
\text { helices, opened at both the ends }\end{array}$ \\
\hline 6 & $\begin{array}{l}\text { Presents antigenic peptide } \\
\text { to }\end{array}$ & $\begin{array}{l}\text { Anchor residues located at amino } \\
\text { and } \\
\text { carbon terminal ends }\end{array}$ & $\begin{array}{l}\text { Anchor residues located almost } \\
\text { uniformly } \\
\text { along the peptide }\end{array}$ \\
\hline 3.3
\end{tabular}

2.3.3 MHC class III

Class III molecules have physiologic roles unlike classes I and II, but are encoded between them in the short arm of human chromosome 6. Class III molecules include several secreted proteins with immune functions: 
components of the complement system (such as $\mathrm{C} 2, \mathrm{C} 4$, and B factor), cytokines (such as TNF- $\alpha$, LTA, and LTB), and heat shock proteins.

\section{Function}

MHC is the tissue-antigen that allows the immune system (more specifically $\mathrm{T}$ cells) to bind to, recognize, and tolerate itself (autorecognition). MHC is also the chaperone for intracellular peptides that are complexed with MHCs and presented to T cell receptors (TCRs) as potential foreign antigens. MHC interacts with TCR and its coreceptors to optimize binding conditions for the TCR-antigen interaction, in terms of antigen binding affinity and specificity, and signal transduction effectiveness.

Essentially, the MHC-peptide complex is a complex of auto-antigen/allo-antigen. Upon binding, T cells should in principle tolerate the auto-antigen, but activate when exposed to the allo-antigen. Disease states occur when this principle is disrupted.

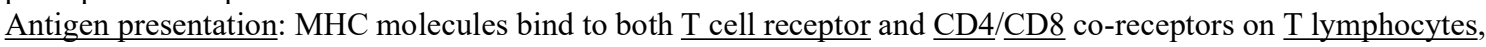
and the antigen epitope held in the peptide-binding groove of the MHC molecule interacts with the variable IgLike domain of the TCR to trigger T-cell activation 26$]$

Autoimmune reaction: Having some MHC molecules increases the risk of autoimmune diseases more than having others. HLA-B27 is an example. It is unclear how exactly having the HLA-B27 tissue type increases the risk of ankylosing spondylitis and other associated inflammatory diseases, but mechanisms involving aberrant antigen presentation or $\mathrm{T}$ cell activation have been hypothesized.

Tissue allorecognition: MHC molecules in complex with peptide epitopes are essentially ligands for TCRs. T cells become activated by binding to the peptide-binding grooves of any MHC molecule that they were not trained to recognize during positive selection in the thymus.

\subsubsection{Antigen processing and presentation}

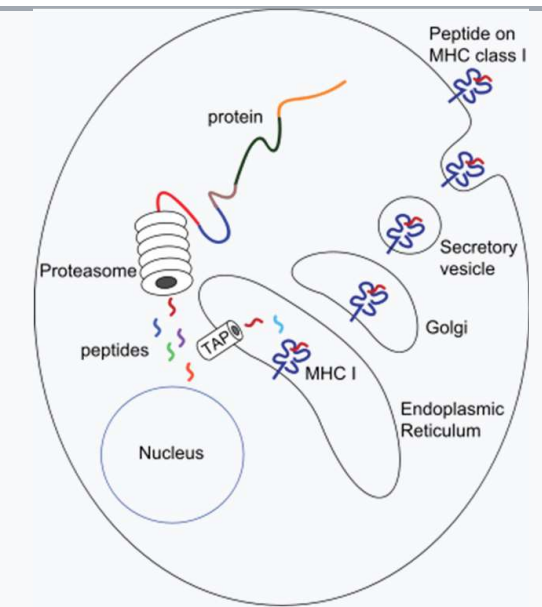

MHC class I pathway: Proteins in the cytosol are degraded by the proteasome, liberating peptides internalized by TAP channel in the endoplasmic reticulum, there associating with MHC-I molecules freshly synthesized. MHCI/peptide complexes enter Golgi apparatus, are glycosylated, enter secretory vesicles, fuse with the cell membrane, and externalize on the cell membrane interacting with T lymphocytes.

Peptides are processed and presented by two classical pathways:

- In MHC class II, phagocytes such as macrophages and immature dendritic cells take up entities by phagocytosis into phagosomes - though B cells exhibit the more general endocytosis into endosomes-which fuse with lysosomes whose acidic enzymes cleave the uptaken protein into many different peptides. Via physicochemical dynamics in molecular interaction with the particular MHC class II variants borne by the host, encoded in the host's genome, a particular peptide exhibits immunodominance and loads onto MHC class II molecules. These are trafficked to and externalized on the cell surface. ${ }^{[27]}$

- In MHC class I, any nucleated cell normally presents cytosolic peptides, mostly self peptides derived from protein turnover and defective ribosomal products. During viral infection, intracellular microorganism infection, or cancerous transformation, such proteins degraded in the proteosome are as well loaded onto MHC class I molecules and displayed on the cell surface. T lymphocytes can detect a peptide displayed at $0.1 \%-1 \%$ of the MHC molecules. 


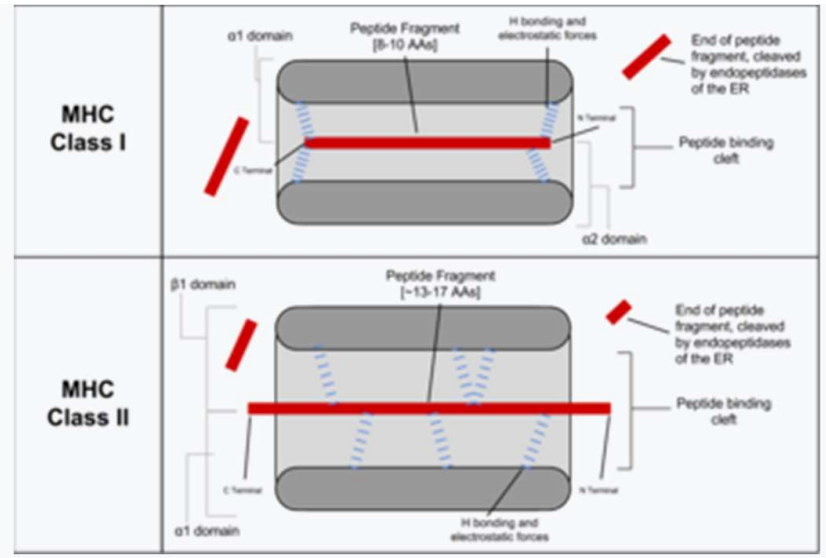

Peptide binding for Class I and Class II MHC molecules, showing the binding of peptides between the alphahelix walls, upon a beta-sheet base. The difference in binding positions is shown. Class I primarily makes contact with backbone residues at the Carboxy and amino terminal regions, while Class II primarily makes contacts along the length of the residue backbone. The precise location of binding residues is determined by the MHC allele. 28$]$

Table 2. Characteristics of the antigen processing pathways

\begin{tabular}{|c|c|c|}
\hline Characteristic & MHC-I pathway & MHC-II pathway \\
\hline $\begin{array}{l}\text { Composition of the stable } \\
\text { peptide-MHC complex }\end{array}$ & $\begin{array}{c}\text { Polymorphic chain } \alpha \text { and } \beta_{2} \\
\text { microglobulin, peptide bound to } \alpha \\
\text { chain }\end{array}$ & $\begin{array}{l}\text { Polymorphic chains } \alpha \text { and } \beta \text {, } \\
\text { peptide binds to both }\end{array}$ \\
\hline 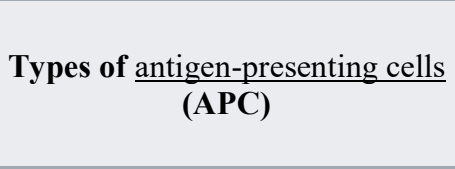 & All nucleated cells & $\begin{array}{l}\text { Dendritic cells, mononuclear } \\
\text { phagocytes, B lymphocytes, some } \\
\text { endothelial cells, epithelium of } \\
\underline{\text { thymus }}\end{array}$ \\
\hline T lymphocytes able to respond & Cytotoxic T lymphocytes (CD8+) & Helper T lymphocytes (CD4+) \\
\hline Origin of antigenic proteins & $\begin{array}{l}\text { cytosolic proteins (mostly } \\
\text { synthetized by the cell; may also } \\
\text { enter from the extracellular medium } \\
\text { via phagosomes) }\end{array}$ & $\begin{array}{l}\text { Proteins present in endosomes or } \\
\text { lysosomes (mostly internalized } \\
\text { from extracellular medium) }\end{array}$ \\
\hline $\begin{array}{l}\text { Enzymes responsible for } \\
\text { peptide generation }\end{array}$ & Cytosolic proteasome & $\begin{array}{c}\text { Proteases from endosomes and } \\
\text { lysosomes (for instance, } \\
\text { cathepsin) }\end{array}$ \\
\hline $\begin{array}{l}\text { Location of loading the peptide } \\
\text { on the MHC molecule }\end{array}$ & $\underline{\text { Endoplasmic reticulum }}$ & $\begin{array}{l}\text { Specialized vesicular } \\
\text { compartment }\end{array}$ \\
\hline $\begin{array}{c}\text { Molecules implicated in } \\
\text { transporting the peptides and } \\
\text { loading them on the MHC } \\
\text { molecules }\end{array}$ & $\begin{array}{c}\underline{\text { TAP }} \text { (transporter associated with } \\
\text { antigen processing) }\end{array}$ & DM, invariant chain \\
\hline
\end{tabular}

\subsubsection{T lymphocyte recognition restrictions}

\section{MHC restriction}

In their development in the thymus, T lymphocytes are selected to recognize MHC molecules of the host, but not recognize other self antigens. Following selection, each T lymphocyte shows dual specificity: The TCR recognizes self MHC, but only non-self antigens.

MHC restriction occurs during lymphocyte development in the thymus through a process known as positive selection. $T$ cells that do not receive a positive survival signal - mediated mainly by thymic epithelial cells presenting self peptides bound to MHC molecules - to their TCR undergo apoptosis. Positive selection ensures that mature T cells can functionally recognize MHC molecules in the periphery (i.e. elsewhere in the body).

The TCRs of T lymphocytes recognise only sequential epitopes, also called linear epitopes, of only peptides and only if coupled within an MHC molecule. (Antibody molecules secreted by activated B cells, though, recognize diverse epitopes - peptide, lipid, carbohydrate, and nucleic acid - and recognize conformational epitopes, which have three-dimensional structure.) 
2.3.6 Role of Leucotrienes in airway inflammation

IL-4 Eosinophil growth, increase and decrease T helper cells type 2 and 1 respectively and increase $\operatorname{IgE}$.

IL-5 Eosinophil maturation, decrease cellular apoptosis, increase IgE and thelper cells 2

IL-10 Decrease survival of eosiniphils and TH2 and TH1 and activation of monocytes.

IL-13 Activate Eosinophils, decrease apoptosis and increase IgE.

IL15 Growth and differenciation of T- cells

1L-16 Eosinophil migration and growth factor and chemotaxis of T-cells

IL-17 T-cell proliferation, activation of fibroblast and epithelial and endothelium cells

IL-18 Interferon- $\gamma$ release from TH1 cells, activation of Natural killer cells and monocytes and decrease IgE

INF- $\gamma$ Decrease in TH2 cells and Eosinophil influx after allegen,activation of endothelium and epithelium and also macrophages and monocytes, decrease IgE

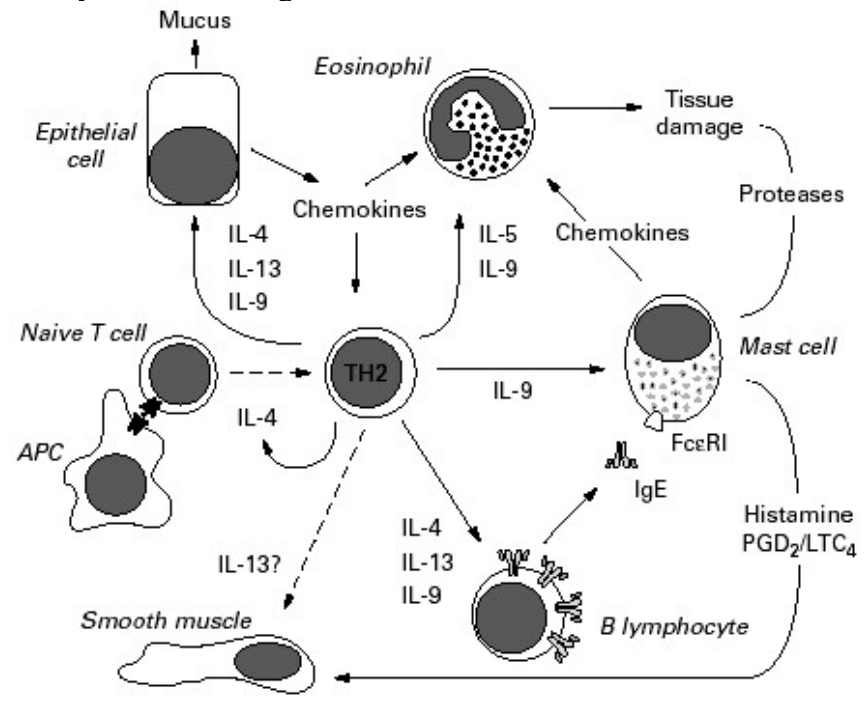

Pleiotropic activities of T helper type 2 (Th2) cytokines in allergic asthma. Upon recognition of the antigen and activation by antigen presenting cells (APC), naive T-cells differentiate into Th2 cells, a process that is promoted by interleukin 4 (IL-4). Activated Th2 cells stimulate B cells to produce IgE antibodies in response to IL-4, and to a lower extend to IL-13 or IL-9. IgE binds the high affinity IgE receptor at the surface of mast cells, the proliferation and differentiation of which is promoted by IL-9, in synergy with other factors such as fibroblast derived mast cell growth factor. At contact with antigen, mast cells release the contents of their granules, including histamine, which will induce a bronchospasm, together with newly synthesized prostaglandins and leukotrienes (PGD2 and LTC4). Mast cells also release chemotactic factors that contribute to the recruitment of inflammatory cells, particularly eosinophils, whose proliferation and differentiation from bone marrow progenitors is promoted by IL-5 and IL-9. Finally, epithelial cells up regulate their production of mucus and chemokines in responses to Th2 cytokines such as Il-4, IL-13, and IL-9. The presence of the IL-13 receptor at the surface of smooth muscle cell suggests that this factor can also directly affect smooth muscle contractility, but this remains to be demonstrated. 


\subsubsection{Citric acid cycle}

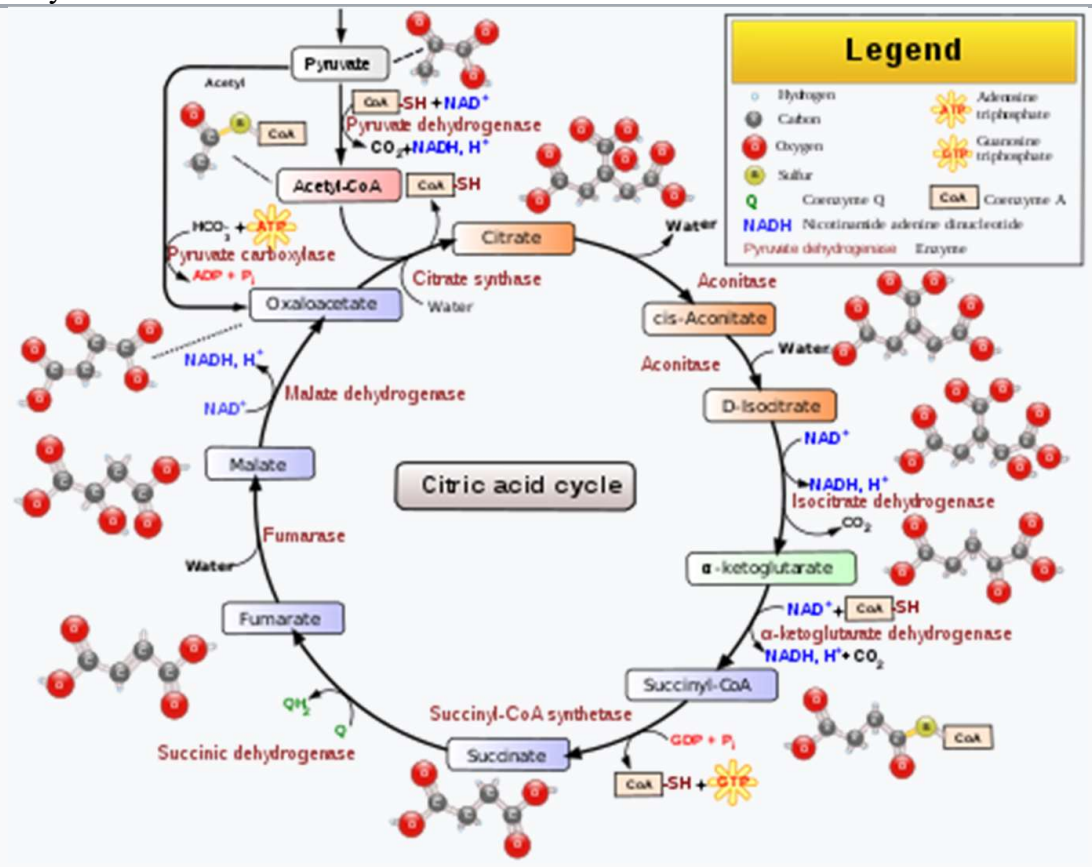

Overview of the citric acid cycle

The citric acid cycle (CAC) - also known as the TCA cycle (tricarboxylic acid cycle) or the Krebs cycle ${ }^{[1][2]}-$ is a series of chemical reactions used by all aerobic organisms to release stored energy through the oxidation of acetyl-CoA derived from carbohydrates, fats, and proteins. In addition, the cycle provides precursors of certain amino acids, as well as the reducing agent $\mathrm{NADH}$, that are used in numerous other reactions. Its central importance to many biochemical pathways suggests that it was one of the earliest components of metabolism and may have originated abiogenically. ${ }^{[3][4]}$ Even though it is branded as a 'cycle', it is not necessary for metabolites to follow only one specific route; at least three segments of the citric acid cycle have been recognized. $[5]$

The name of this metabolic pathway is derived from the citric acid (a tricarboxylic acid, often called citrate, as the ionized form predominates at biological $\mathrm{pH}^{[6]}$ ) that is consumed and then regenerated by this sequence of reactions to complete the cycle. The cycle consumes acetate (in the form of acetyl-CoA) and water, reduces $\underline{\mathrm{NAD}^{+}}$to $\mathrm{NADH}_{\text {, }}$ releasing carbon dioxide. The NADH generated by the citric acid cycle is fed into the oxidative phosphorylation (electron transport) pathway. The net result of these two closely linked pathways is the oxidation of nutrients to produce usable chemical energy in the form of ATP.

In eukaryotic cells, the citric acid cycle occurs in the matrix of the mitochondrion. In prokaryotic cells, such as bacteria, which lack mitochondria, the citric acid cycle reaction sequence is performed in the cytosol with the proton gradient for ATP production being across the cell's surface (plasma membrane) rather than the inner membrane of the mitochondrion. The overall yield of energy-containing compounds from the TCA cycle is three $\mathrm{NADH}$, one $\underline{\mathrm{FADH}}_{2}$, and one $\underline{\mathrm{GTP}} .{ }^{[7]}$

ए

\subsubsection{Discovery}

Several of the components and reactions of the citric acid cycle were established in the 1930s by the research of Albert Szent-Györgyi, who received the Nobel Prize in Physiology or Medicine in 1937 specifically for his discoveries pertaining to fumaric acid, a key component of the cycle. ${ }^{[8]} \mathrm{He}$ made this discovery by studying pigeon breast muscle. Because this tissue maintains its oxidative capacity well after breaking down in the "Latapie" mill and releasing in aqueous solutions, breast muscle of the pigeon was very well qualified for the study of oxidative reactions. ${ }^{[9]}$ The citric acid cycle itself was finally identified in 1937 by Hans Adolf Krebs and William Arthur Johnson while at the University of Sheffield, ${ }^{[10]}$ for which the former received the Nobel Prize for Physiology or Medicine in 1953, and for whom the cycle is sometimes named (Krebs cycle). $\underline{[11]}$ 


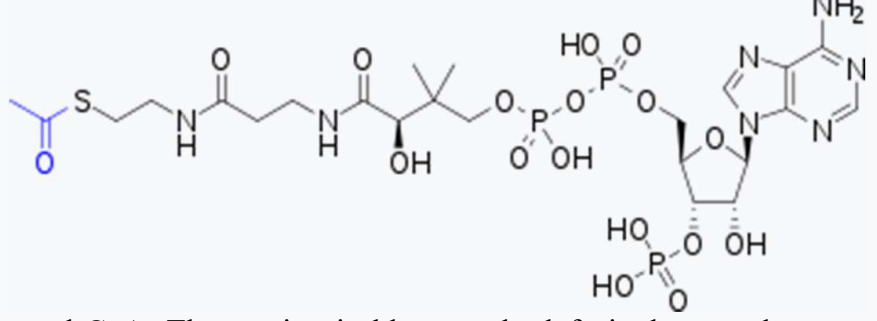

Structural diagram of acetyl-CoA: The portion in blue, on the left, is the acetyl group; the portion in black is coenzyme A.

The citric acid cycle is a key metabolic pathway that connects carbohydrate, fat, and protein metabolism. The reactions of the cycle are carried out by eight enzymes that completely oxidize acetate (a two carbon molecule), in the form of acetyl-CoA, into two molecules each of carbon dioxide and water. Through catabolism of sugars, fats, and proteins, the two-carbon organic product acetyl-CoA (a form of acetate) is produced which enters the citric acid cycle. The reactions of the cycle also convert three equivalents of nicotinamide adenine dinucleotide $\left(\mathrm{NAD}^{+}\right)$into three equivalents of reduced $\mathrm{NAD}^{+}(\mathrm{NADH})$, one equivalent of flavin adenine dinucleotide $(\mathrm{FAD})$ into one equivalent of $\mathrm{FADH}_{2}$, and one equivalent each of guanosine diphosphate (GDP) and inorganic phosphate $\left(\mathrm{P}_{\mathrm{i}}\right)$ into one equivalent of guanosine triphosphate (GTP). The NADH and $\mathrm{FADH}_{2}$ generated by the citric acid cycle are, in turn, used by the oxidative phosphorylation pathway to generate energy-rich ATP.

One of the primary sources of acetyl-CoA is from the breakdown of sugars by glycolysis which yield pyruvate that in turn is decarboxylated by the pyruvate dehydrogenase complex generating acetyl-CoA according to the following reaction scheme:

$$
\begin{aligned}
& \mathrm{CH}_{3} \mathrm{C}(=\mathrm{O}) \mathrm{C}\left(=\mathrm{O}^{-} \mathrm{O}^{-} \text {pyruvate }+\underline{\mathrm{HSCoA}}+\underline{\mathrm{NAD}^{+}}\right. \\
& \mathrm{CH}_{3} \mathrm{C}(=\mathrm{O}) \mathrm{SCoAacetyl}-\mathrm{CoA}+\mathrm{NADH}+\mathrm{CO}_{2}
\end{aligned}
$$

The product of this reaction, acetyl-CoA, is the starting point for the citric acid cycle. Acetyl-CoA may also be obtained from the oxidation of fatty acids. Below is a schematic outline of the cycle:

- The citric acid cycle begins with the transfer of a two-carbon acetyl group from acetyl-CoA to the four-carbon acceptor compound (oxaloacetate) to form a six-carbon compound (citrate).

- The citrate then goes through a series of chemical transformations, losing two carboxyl groups as $\mathrm{CO}_{2}$. The carbons lost as $\mathrm{CO}_{2}$ originate from what was oxaloacetate, not directly from acetyl-CoA. The carbons donated by acetyl-CoA become part of the oxaloacetate carbon backbone after the first turn of the citric acid cycle. Loss of the acetyl-CoA-donated carbons as $\mathrm{CO}_{2}$ requires several turns of the citric acid cycle. However, because of the role of the citric acid cycle in anabolism, they might not be lost, since many citric acid cycle intermediates are also used as precursors for the biosynthesis of other molecules. ${ }^{[12]}$

- Most of the electrons made available by the oxidative steps of the cycle are transferred to $\mathrm{NAD}^{+}$, forming NADH. For each acetyl group that enters the citric acid cycle, three molecules of NADH are produced. The citric acid cycle includes a series of oxidation reduction reaction in mitochondria . [clarification needed $][13]$

- In addition, electrons from the succinate oxidation step are transferred first to the FAD cofactor of succinate dehydrogenase, reducing it to $\mathrm{FADH}_{2}$, and eventually to ubiquinone (Q) in the mitochondrial membrane, reducing it to ubiquinol $\left(\mathrm{QH}_{2}\right)$ which is a substrate of the electron transfer chain at the level of Complex III.

- For every NADH and $\mathrm{FADH}_{2}$ that are produced in the citric acid cycle, 2.5 and 1.5 ATP molecules are generated in oxidative phosphorylation, respectively.

- At the end of each cycle, the four-carbon oxaloacetate has been regenerated, and the cycle continues. ${ }^{[14]}$

The theoretical maximum yield of ATP through oxidation of one molecule of glucose in glycolysis, citric acid cycle, and oxidative phosphorylation is 38 (assuming 3 molar equivalents of ATP per equivalent NADH and 2 ATP per $\mathrm{UQH}_{2}$ ). In eukaryotes, two equivalents of NADH and four equivalents of ATP are generated in glycolysis, which takes place in the cytoplasm. Transport of two of these equivalents of NADH into the mitochondria consumes two equivalents of ATP, thus reducing the net production of ATP to 36. Furthermore, inefficiencies in oxidative phosphorylation due to leakage of protons across the mitochondrial membrane and slippage of the ATP synthase/proton pump commonly reduces the ATP yield from NADH and $\mathrm{UQH}_{2}$ to less than the theoretical maximum yield. ${ }^{[18]}$ The observed yields are, therefore, closer to $\sim 2.5$ ATP per NADH and $\sim 1.5$ ATP per UQH , $_{2}$ further reducing the total net production of ATP to approximately $30 .{ }^{[19]}$ An assessment of provides an estimate of 29.85 ATP per glucose molecule. 20$]$

2.4.1 Roles of Iron, copper and Zinc in Nutrition.

2.4.2 Iron in Diet

Iron is pervasive, but particularly rich sources of dietary iron include red meat, oysters, lentils, beans, poultry, fish,

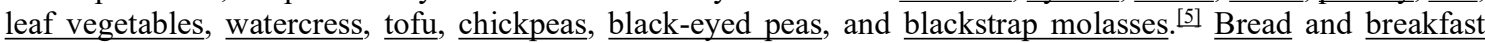


cereals are sometimes specifically fortified with iron. ${ }^{[5]}$

Iron provided by dietary supplements is often found as iron(II) fumarate, although iron(II) sulfate is cheaper and is absorbed equally well. ${ }^{[135]}$ Elemental iron, or reduced iron, despite being absorbed at only one-third to two-thirds the efficiency (relative to iron sulfate), ${ }^{[153]}$ is often added to foods such as breakfast cereals or enriched wheat flour. Iron is most available to the body when chelated to amino acids ${ }^{[154]}$ and is also available for use as a common iron

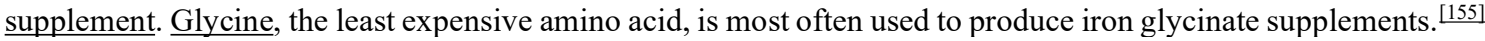
Dietary recommendations

The U.S. Institute of Medicine (IOM) updated Estimated Average Requirements (EARs) and Recommended Dietary Allowances (RDAs) for iron in 2001. ${ }^{[5]}$ The current EAR for iron for women ages 14-18 is 7.9 mg/day, 8.1 for ages 19-50 and 5.0 thereafter (post menopause). For men the EAR is $6.0 \mathrm{mg} /$ day for ages 19 and up. The RDA is $15.0 \mathrm{mg} /$ day for women ages $15-18,18.0$ for $19-50$ and 8.0 thereafter. For men, $8.0 \mathrm{mg} /$ day for ages 19 and up. RDAs are higher than EARs so as to identify amounts that will cover people with higher than average requirements. RDA for pregnancy is $27 \mathrm{mg}$ /day and, for lactation, $9 \mathrm{mg} /$ day. ${ }^{[5]}$ For children ages $1-3$ years 7 $\mathrm{mg} /$ day, 10 for ages 4-8 and 8 for ages 9-13. As for safety, the IOM also sets Tolerable upper intake levels (ULs) for vitamins and minerals when evidence is sufficient. In the case of iron the UL is set at $45 \mathrm{mg} /$ day. Collectively the EARs, RDAs and ULs are referred to as Dietary Reference Intakes. ${ }^{[156]}$

The European Food Safety Authority (EFSA) refers to the collective set of information as Dietary Reference Values, with Population Reference Intake (PRI) instead of RDA, and Average Requirement instead of EAR. AI and UL defined the same as in United States. For women the PRI is $13 \mathrm{mg} /$ day ages $15-17$ years, $16 \mathrm{mg} /$ day for women ages 18 and up who are premenopausal and $11 \mathrm{mg}$ /day postmenopausal. For pregnancy and lactation, 16 $\mathrm{mg} /$ day. For men the PRI is $11 \mathrm{mg}$ /day ages 15 and older. For children ages 1 to 14 the PRI increases from 7 to 11 $\mathrm{mg}$ /day. The PRIs are higher than the U.S. RDAs, with the exception of pregnancy. ${ }^{[157]}$ The EFSA reviewed the same safety question did not establish a UL. $\stackrel{[158]}{[}$

Infants may require iron supplements if they are bottle-fed cow's milk. ${ }^{[159]}$ Frequent blood donors are at risk of low iron levels and are often advised to supplement their iron intake. $\frac{[160]}{}$

For U.S. food and dietary supplement labeling purposes the amount in a serving is expressed as a percent of Daily Value (\%DV). For iron labeling purposes 100\% of the Daily Value was $18 \mathrm{mg}$, and as of May 27, 2016 remained unchanged at $18 \mathrm{mg} \cdot \frac{[161][162]}{}$ Compliance with the updated labeling regulations was required by 1 January 2020 , for manufacturers with $\$ 10$ million or more in annual food sales, and by 1 January 2021 , for manufacturers with less than $\$ 10$ million in annual food sales. $\frac{[163][164][165]}{}$ During the first six months following the 1 January 2020 compliance date, the FDA plans to work cooperatively with manufacturers to meet the new Nutrition Facts label requirements and will not focus on enforcement actions regarding these requirements during that time. ${ }^{[163]} \mathrm{A}$ table of the old and new adult Daily Values is provided at Reference Daily Intake.

Deficiency

Iron deficiency

Iron deficiency is the most common nutritional deficiency in the world. [5][166][167][168] When loss of iron is not adequately compensated by adequate dietary iron intake, a state of latent iron deficiency occurs, which over time leads to iron-deficiency anemia if left untreated, which is characterised by an insufficient number of red blood cells and an insufficient amount of hemoglobin. ${ }^{[169]}$ Children, pre-menopausal women (women of child-bearing age), and people with poor diet are most susceptible to the disease. Most cases of iron-deficiency anemia are mild, but if not treated can cause problems like fast or irregular heartbeat, complications during pregnancy, and delayed growth in infants and children. $\frac{[170]}{}$

Excess

Iron overload

Iron uptake is tightly regulated by the human body, which has no regulated physiological means of excreting iron. Only small amounts of iron are lost daily due to mucosal and skin epithelial cell sloughing, so control of iron levels is primarily accomplished by regulating uptake. ${ }^{[171]}$ Regulation of iron uptake is impaired in some people as a result of a genetic defect that maps to the HLA-H gene region on chromosome 6 and leads to abnormally low levels of hepcidin, a key regulator of the entry of iron into the circulatory system in mammals. ${ }^{[172]}$ In these people, excessive iron intake can result in iron overload disorders, known medically as hemochromatosis. ${ }^{[5]}$ Many people have an undiagnosed genetic susceptibility to iron overload, and are not aware of a family history of the problem. Overdoses of ingested iron can cause excessive levels of free iron in the blood. High blood levels of free ferrous iron react with peroxides to produce highly reactive free radicals that can damage DNA, proteins, lipids, and other cellular components. Iron toxicity occurs when the cell contains free iron, which generally occurs when iron levels exceed the availability of transferrin to bind the iron. Damage to the cells of the gastrointestinal tract can also prevent them from regulating iron absorption, leading to further increases in blood levels. Iron typically damages cells in the heart, liver and elsewhere, causing adverse effects that include coma, metabolic acidosis, shock, liver failure, coagulopathy, adult respiratory distress syndrome, long-term organ damage, and even death. $\frac{[174]}{1}$ Humans experience iron toxicity when the iron exceeds 20 milligrams for every kilogram of body mass; 60 milligrams per 
kilogram is considered a lethal dose. ${ }^{[175]}$ Overconsumption of iron, often the result of children eating large quantities of ferrous sulfate tablets intended for adult consumption, is one of the most common toxicological causes of death in children under six. ${ }^{[175]}$ The Dietary Reference Intake (DRI) sets the Tolerable Upper Intake Level (UL) for adults at $45 \mathrm{mg} /$ day. For children under fourteen years old the UL is $40 \mathrm{mg} /$ day. ${ }^{[176]}$

The medical management of iron toxicity is complicated, and can include use of a specific chelating agent called

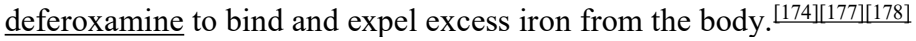

\section{COPPER}

Copper is an essential trace element in plants and animals, but not all microorganisms. The human body contains copper at a level of about 1.4 to $2.1 \mathrm{mg}$ per $\mathrm{kg}$ of body mass. $\stackrel{[149]}{ }$

\section{Absorption}

Copper is absorbed in the gut, then transported to the liver bound to albumin. ${ }^{[150]}$ After processing in the liver, copper is distributed to other tissues in a second phase, which involves the protein ceruloplasmin, carrying the majority of copper in blood. Ceruloplasmin also carries the copper that is excreted in milk, and is particularly wellabsorbed as a copper source. $\stackrel{[151]}{ }$ Copper in the body normally undergoes enterohepatic circulation (about $5 \mathrm{mg}$ a day, vs. about $1 \mathrm{mg}$ per day absorbed in the diet and excreted from the body), and the body is able to excrete some excess copper, if needed, via bile, which carries some copper out of the liver that is not then reabsorbed by the intestine. $\stackrel{[152][153]}{\text { (Decom }}$

\section{Dietary recommendations}

The U.S. Institute of Medicine (IOM) updated the estimated average requirements (EARs) and recommended dietary allowances (RDAs) for copper in 2001. If there is not sufficient information to establish EARs and RDAs, an estimate designated Adequate Intake (AI) is used instead. The AIs for copper are: $200 \mu \mathrm{g}$ of copper for 0-6month-old males and females, and $220 \mu \mathrm{g}$ of copper for 7-12-month-old males and females. For both sexes, the RDAs for copper are: $340 \mu \mathrm{g}$ of copper for 1-3 years old, $440 \mu \mathrm{g}$ of copper for $4-8$ years old, $700 \mu \mathrm{g}$ of copper for 9-13 years old, $890 \mu \mathrm{g}$ of copper for 14-18 years old and $900 \mu \mathrm{g}$ of copper for ages 19 years and older. For pregnancy, 1,000 $\mu \mathrm{g}$. For lactation, $1,300 \mu \mathrm{g} .{ }^{[154]}$ As for safety, the IOM also sets Tolerable upper intake levels (ULs) for vitamins and minerals when evidence is sufficient. In the case of copper the UL is set at $10 \mathrm{mg} / \mathrm{day}$. Collectively the EARs, RDAs, AIs and ULs are referred to as Dietary Reference Intakes. ${ }^{\text {.155] }}$

The European Food Safety Authority (EFSA) refers to the collective set of information as Dietary Reference Values, with Population Reference Intake (PRI) instead of RDA, and Average Requirement instead of EAR. AI and UL defined the same as in United States. For women and men ages 18 and older the AIs are set at 1.3 and 1.6 $\mathrm{mg}$ /day, respectively. AIs for pregnancy and lactation is $1.5 \mathrm{mg} /$ day. For children ages $1-17$ years the AIs increase with age from 0.7 to $1.3 \mathrm{mg} /$ day. These AIs are higher than the U.S. RDAs. ${ }^{[156]}$ The European Food Safety Authority reviewed the same safety question and set its UL at $5 \mathrm{mg} /$ day, which is half the U.S. value. ${ }^{[157]}$

For U.S. food and dietary supplement labeling purposes the amount in a serving is expressed as a percent of Daily Value (\%DV). For copper labeling purposes 100\% of the Daily Value was $2.0 \mathrm{mg}$, but as of May 27, 2016 it was revised to $0.9 \mathrm{mg}$ to bring it into agreement with the RDA. 158$][159]$ Compliance with the updated labeling regulations was required by 1 January 2020, for manufacturers with $\$ 10$ million or more in annual food sales, and

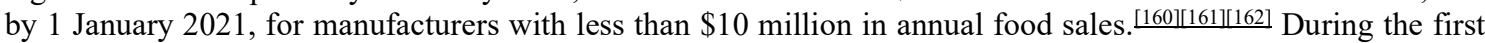
six months following the 1 January 2020 compliance date, the FDA plans to work cooperatively with manufacturers to meet the new Nutrition Facts label requirements and will not focus on enforcement actions regarding these requirements during that time. ${ }^{[160]} \mathrm{A}$ table of the old and new adult Daily Values is provided at Reference Daily Intake.

\section{Deficiency}

Because of its role in facilitating iron uptake, copper deficiency can produce anemia-like symptoms, neutropenia, bone abnormalities, hypopigmentation, impaired growth, increased incidence of infections, osteoporosis, hyperthyroidism, and abnormalities in glucose and cholesterol metabolism. Conversely, Wilson's disease causes an accumulation of copper in body tissues.

Severe deficiency can be found by testing for low plasma or serum copper levels, low ceruloplasmin, and low red blood cell superoxide dismutase levels; these are not sensitive to marginal copper status. The "cytochrome c oxidase activity of leucocytes and platelets" has been stated as another factor in deficiency, but the results have not been confirmed by replication. $\stackrel{[163]}{[}$

\section{Toxicity}

\section{Copper toxicity}

Gram quantities of various copper salts have been taken in suicide attempts and produced acute copper toxicity in humans, possibly due to redox cycling and the generation of reactive oxygen species that damage DNA. [164][165] Corresponding amounts of copper salts $(30 \mathrm{mg} / \mathrm{kg})$ are toxic in animals. ${ }^{[166]}$ A minimum dietary value for healthy growth in rabbits has been reported to be at least $3 \mathrm{ppm}$ in the diet. ${ }^{[167]}$ However, higher concentrations of copper $(100 \mathrm{ppm}, 200 \mathrm{ppm}$, or $500 \mathrm{ppm})$ in the diet of rabbits may favorably influence feed conversion efficiency, growth rates, and carcass dressing percentages. $\stackrel{[168]}{[}$ 
Chronic copper toxicity does not normally occur in humans because of transport systems that regulate absorption and excretion. Autosomal recessive mutations in copper transport proteins can disable these systems, leading to Wilson's disease with copper accumulation and cirrhosis of the liver in persons who have inherited two defective genes. ${ }^{[149]}$

Elevated copper levels have also been linked to worsening symptoms of Alzheimer's disease. ${ }^{[169][170]}$

\section{Human exposure}

In the US, the Occupational Safety and Health Administration (OSHA) has designated a permissible exposure limit (PEL) for copper dust and fumes in the workplace as a time-weighted average (TWA) of $1 \mathrm{mg} / \mathrm{m}^{3}$. National Institute for Occupational Safety and Health (NIOSH) has set a Recommended exposure limit (REL) of $1 \mathrm{mg} / \mathrm{m}^{3}$, time-weighted average. The IDLH (immediately dangerous to life and health) value is $100 \mathrm{mg} / \mathrm{m}^{3}$. 172$]$

Copper is a constituent of tobacco smoke..$^{[173][174]}$ The tobacco plant readily absorbs and accumulates heavy $\underline{\text { metals, }}$, such as copper from the surrounding soil into its leaves. These are readily absorbed into the user's body following smoke inhalation. $[175]$

ZINC

\section{Nutrition}

\section{Dietary recommendation}

The U.S. Institute of Medicine (IOM) updated Estimated Average Requirements (EARs) and Recommended Dietary Allowances (RDAs) for zinc in 2001. The current EARs for zinc for women and men ages 14 and up is 6.8 and $9.4 \mathrm{mg} /$ day, respectively. The RDAs are 8 and $11 \mathrm{mg}$ /day. RDAs are higher than EARs so as to identify amounts that will cover people with higher than average requirements. RDA for pregnancy is $11 \mathrm{mg} / \mathrm{day}$. RDA for lactation is $12 \mathrm{mg} /$ day. For infants up to $12 \mathrm{months}$ the RDA is $3 \mathrm{mg} / \mathrm{day}$. For children ages $1-13$ years the RDA increases with age from 3 to $8 \mathrm{mg} /$ day. As for safety, the IOM sets Tolerable upper intake levels (ULs) for vitamins and minerals when evidence is sufficient. In the case of zinc the adult UL is $40 \mathrm{mg} / \mathrm{day}$ (lower for children). Collectively the EARs, RDAs, AIs and ULs are referred to as Dietary Reference Intakes (DRIs). ${ }^{[186]}$

The European Food Safety Authority (EFSA) refers to the collective set of information as Dietary Reference Values, with Population Reference Intake (PRI) instead of RDA, and Average Requirement instead of EAR. AI and UL are defined the same as in the United States. For people ages 18 and older the PRI calculations are complex, as the EFSA has set higher and higher values as the phytate content of the diet increases. For women, PRIs increase from 7.5 to $12.7 \mathrm{mg}$ /day as phytate intake increases from 300 to $1200 \mathrm{mg} /$ day; for men the range is 9.4 to 16.3

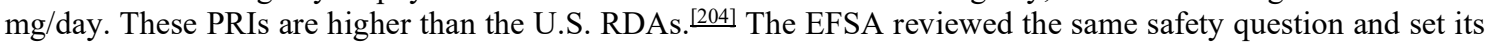
UL at $25 \mathrm{mg} /$ day, which is much lower than the U.S. value. ${ }^{[205]}$

For U.S. food and dietary supplement labeling purposes the amount in a serving is expressed as a percent of Daily Value (\%DV). For zinc labeling purposes $100 \%$ of the Daily Value was $15 \mathrm{mg}$, but on May 27, 2016 it was revised to $11 \mathrm{mg}$. [206][207] Compliance with the updated labeling regulations was required by 1 January 2020, for manufacturers with $\$ 10$ million or more in annual food sales, and by 1 January 2021 , for manufacturers with less than $\$ 10$ million in annual food sales. 208$][209][210]$ During the first six months following the 1 January 2020 compliance date, the FDA plans to work cooperatively with manufacturers to meet the new Nutrition Facts label requirements and will not focus on enforcement actions regarding these requirements during that time. $\frac{[208]}{\mathrm{A} \text { table }}$ of the old and new adult Daily Values is provided at Reference Daily Intake.

Dietary intake

Foods and spices containing zinc

Animal products such as meat, fish, shellfish, fowl, eggs, and dairy contain zinc. The concentration of zinc in plants varies with the level in the soil. With adequate zinc in the soil, the food plants that contain the most zinc are

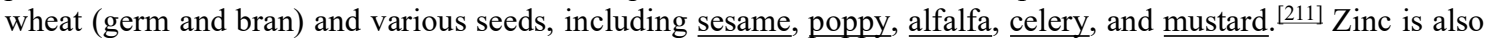
found in beans, $\underline{\text { nuts}}, \underline{\text { almonds, }}, \underline{\text { whole grains, }}$ pumpkin seeds, sunflower seeds, and blackcurrant. ${ }^{[212]}$ Plant phytates are particularly found in pulses and cereals and interfere with zinc absorption.

Other sources include fortified food and dietary supplements in various forms. A 1998 review concluded that zinc oxide, one of the most common supplements in the United States, and zinc carbonate are nearly insoluble and poorly absorbed in the body. ${ }^{[213]}$ This review cited studies that found lower plasma zinc concentrations in the subjects who consumed zinc oxide and zinc carbonate than in those who took zinc acetate and sulfate salts. ${ }^{[213]}$ For fortification, however, a 2003 review recommended cereals (containing zinc oxide) as a cheap, stable source that is as easily absorbed as the more expensive forms. ${ }^{[214]}$ A 2005 study found that various compounds of zinc, including oxide and sulfate, did not show statistically significant differences in absorption when added as fortificants to maize tortillas. $\stackrel{[215]}{[}$

Deficiency

Zinc deficiency

Nearly two billion people in the developing world are deficient in zinc. Groups at risk include children in developing countries and elderly with chronic illnesses. ${ }^{[10]}$ In children, it causes an increase in infection and diarrhea and contributes to the death of about 800,000 children worldwide per year. [9] The World Health 
Organization advocates zinc supplementation for severe malnutrition and diarrhea. ${ }^{[216]}$ Zinc supplements help prevent disease and reduce mortality, especially among children with low birth weight or stunted growth. ${ }^{[216]}$ However, zinc supplements should not be administered alone, because many in the developing world have several deficiencies, and zinc interacts with other micronutrients. ${ }^{[217]}$ While zinc deficiency is usually due to insufficient dietary intake, it can be associated with malabsorption, acrodermatitis enteropathica, chronic liver disease, chronic renal disease, sickle cell disease, diabetes, malignancy, and other chronic illnesses. $\frac{[10]}{}$

In the United States, a federal survey of food consumption determined that for women and men over the age of 19, average consumption was 9.7 and $14.2 \mathrm{mg}$ /day, respectively. For women, 17\% consumed less than the EAR, for men $11 \%$. The percentages below EAR increased with age. ${ }^{[218]}$ The most recent published update of the survey (NHANES 2013-2014) reported lower averages - 9.3 and $13.2 \mathrm{mg} /$ day - again with intake decreasing with age. [219] Symptoms of mild zinc deficiency are diverse. ${ }^{[186]}$ Clinical outcomes include depressed growth, diarrhea, impotence and delayed sexual maturation, alopecia, eye and skin lesions, impaired appetite, altered cognition, impaired immune functions, defects in carbohydrate utilization, and reproductive teratogenesis. ${ }^{[186]}$ Zinc deficiency depresses immunity,,$[220]$ but excessive zinc does also. $\stackrel{[176]}{ }$

Despite some concerns, $\stackrel{[221]}{2}$ western vegetarians and vegans do not suffer any more from overt zinc deficiency than meat-eaters. ${ }^{[222]}$ Major plant sources of zinc include cooked dried beans, sea vegetables, fortified cereals, soy

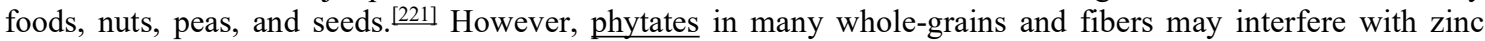
absorption and marginal zinc intake has poorly understood effects. The zinc chelator phytate, found in seeds and cereal bran, can contribute to zinc malabsorption. ${ }^{[10]}$ Some evidence suggests that more than the US RDA (8 $\mathrm{mg}$ /day for adult women; $11 \mathrm{mg}$ /day for adult men) may be needed in those whose diet is high in phytates, such

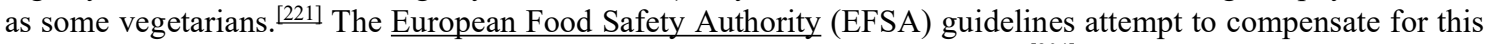
by recommending higher zinc intake when dietary phytate intake is greater. [204] These considerations must be balanced against the paucity of adequate zinc biomarkers, and the most widely used indicator, plasma zinc, has poor sensitivity and specificity. ${ }^{[223]}$

\section{Zinc toxicity}

Although zinc is an essential requirement for good health, excess zinc can be harmful. Excessive absorption of zinc suppresses copper and iron absorption. ${ }^{[199]}$ The free zinc ion in solution is highly toxic to plants, invertebrates, and even vertebrate fish. ${ }^{[226]}$ The Free Ion Activity Model is well-established in the literature, and shows that just micromolar amounts of the free ion kills some organisms. A recent example showed 6 micromolar killing $93 \%$ of all Daphnia in water. $\underline{\text {.227] }}$

The free zinc ion is a powerful Lewis acid up to the point of being corrosive. Stomach acid contains hydrochloric acid, in which metallic zinc dissolves readily to give corrosive zinc chloride. Swallowing a post-1982 American one cent piece $(97.5 \%$ zinc) can cause damage to the stomach lining through the high solubility of the zinc ion in the acidic stomach. .228$]$

Evidence shows that people taking 100-300 mg of zinc daily may suffer induced copper deficiency. A 2007 trial observed that elderly men taking $80 \mathrm{mg}$ daily were hospitalized for urinary complications more often than those taking a placebo. ${ }^{[229]}$ Levels of $100-300 \mathrm{mg}$ may interfere with the utilization of copper and iron or adversely affect cholesterol. $\frac{[199]}{}$ Zinc in excess of $500 \mathrm{ppm}$ in soil interferes with the plant absorption of other essential metals, such as iron and manganese. $\frac{[100]}{}$ A condition called the zinc shakes or "zinc chills" can be induced by inhalation of zinc fumes while brazing or welding galvanized materials. ${ }^{[131]}$ Zinc is a common ingredient of denture cream which may contain between 17 and $38 \mathrm{mg}$ of zinc per gram. Disability and even deaths from excessive use of these products have been claimed. $\underline{[230]}$

The U.S. Food and Drug Administration (FDA) states that zinc damages nerve receptors in the nose, causing anosmia. Reports of anosmia were also observed in the 1930s when zinc preparations were used in a failed attempt to prevent polio infections. $\stackrel{[231]}{ }$ On June 16, 2009, the FDA ordered removal of zinc-based intranasal cold products from store shelves. The FDA said the loss of smell can be life-threatening because people with impaired smell cannot detect leaking gas or smoke, and cannot tell if food has spoiled before they eat it. ${ }^{[232]}$

Recent research suggests that the topical antimicrobial zinc pyrithione is a potent heat shock response inducer that may impair genomic integrity with induction of PARP-dependent energy crisis in cultured human keratinocytes and melanocytes. ${ }^{[233]}$

In 1982, the US Mint began minting pennies coated in copper but containing primarily zinc. Zinc pennies pose a risk of zinc toxicosis, which can be fatal. One reported case of chronic ingestion of 425 pennies (over $1 \mathrm{~kg}$ of zinc) resulted in death due to gastrointestinal bacterial and fungal sepsis. Another patient who ingested 12 grams of zinc showed only lethargy and ataxia (gross lack of coordination of muscle movements). 234$]$ Several other cases have been reported of humans suffering zinc intoxication by the ingestion of zinc coins. $\frac{[235][236]}{2}$

Pennies and other small coins are sometimes ingested by dogs, requiring veterinary removal of the foreign objects. The zinc content of some coins can cause zinc toxicity, commonly fatal in dogs through severe hemolytic anemia and liver or kidney damage; vomiting and diarrhea are possible symptoms. ${ }^{[237]}$ Zinc is highly toxic in parrots and poisoning can often be fatal. $\stackrel{[238]}{ }$ The consumption of fruit juices stored in galvanized cans has resulted 
in mass parrot poisonings with zinc. $\frac{[57]}{[1}$

\subsection{MATERIALS AND METHOD}

3.1.Experimental design

Data on covid 19 disease was collected on the internet Worldometer.info/coronavirus/country and data was obtained from February to December 152020 and Five continents were of interest namely North America, South America ,Europe, Asia and Africa and main countries of interest where United states of America, France,United Kingdom, China,Brazil and Nigeria. The countries were chosen as case study because of their gross domestic product(GDP) and World trade with other Countries and also according to how developed or underdeveloped they were.The population per country, incident rates and death associated with each were reviewed.The United state of America had an incident rate of 1,7143942 and France,UK,China,Brazil and Nigeria had $2391447,1888116,8681821,6974258$ and 174132 respectively between February and 15 December 2020.Mortality rates were alarming for these countries, which is the major concern the U.S.A had 311073 and France,UK,China and Nigeria had 59072,64905, 182854,4634 and 1200 respectively.

Data was analysed statistically using Analysis of variants, tables were used to determine percentage monthly incidence, prevalence, morbidity, fatality, mortality rates and population at risk.

\subsection{RESULT AND DISCUSSION}

4.1 Result

Table I Prevalence rates of Covid 19 in selected countries from February to December 152020.

\begin{tabular}{|l|l|l|l|l|l|l|}
\hline & USA & FRANCE & UK & CHINA & BRAZIL & NIGERIA \\
\hline FEBRUARY & 68 & 100 & 23 & 79824 & 2 & 0 \\
\hline MARCH & 197844 & 52128 & 22792 & 81554 & 5717 & 135 \\
\hline APRIL & 1108447 & 129581 & 155151 & 82862 & 85380 & 627 \\
\hline MAY & 1863739 & 151753 & 248925 & 83001 & 10162 & 10162 \\
\hline JUNE & 2747901 & 164801 & 283253 & 83531 & 25694 & 25694 \\
\hline JULY & 4766320 & 187919 & 303101 & 84292 & 45151 & 45151 \\
\hline AUGUST & 6291051 & 281025 & 335873 & 85048 & 54008 & 54008 \\
\hline SEPTEMBER & 7513080 & 563535 & 465125 & 85048 & 58848 & 58848 \\
\hline OCTOBER & 9461184 & 1367625 & 1011660 & 85973 & 62855 & 62855 \\
\hline NOVEMBER & 13965693 & 2222488 & 1629656 & 85973 & 67557 & 67557 \\
\hline DECEMBER & 17143942 & 2391447 & 1888116 & 86758 & 74132 & 74132 \\
\hline & & & & & & \\
\hline
\end{tabular}

Source: http;/www.Worldometer.info/coronavirus.

Table II Percentage population at risk.

\begin{tabular}{|l|l|l|l|l|}
\hline & Total population & Prevalence rate & Mortality rate & Population at Risk \\
\hline USA & 331891557 & 17143942 & 31103 & $95 \%$ \\
\hline FRANCE & 65339853 & 2391447 & 59072 & $97 \%$ \\
\hline UK & 68049406 & 1888116 & 64905 & $98 \%$ \\
\hline CHINA & 1439323776 & 8681821 & 4634 & $96 \%$ \\
\hline BRAZIL & 213312046 & 6974258 & 182854 & $98 \%$ \\
\hline NIGERIA & 180000000 & 74132 & 1200 & $96 \%$ \\
\hline & & & & \\
\hline
\end{tabular}

Table III showing fatality, morbidity and mortality rates in percentages

\begin{tabular}{|l|l|l|l|}
\hline & Morbidity rate \% & Mortality rate \% & Fatality rate \% \\
\hline USA & 5.17 & 0.01 & 0.18 \\
\hline FRANCE & 3.66 & 0.9 & 2.47 \\
\hline UK & 2.77 & 0.1 & 3.43 \\
\hline CHINA & 0.006 & 0.0001 & 0.05 \\
\hline BRAZIL & 3.26 & 0.09 & 2.62 \\
\hline NIGERIA & 0.04 & 0.0006 & 1.21 \\
\hline
\end{tabular}


Table IV showing incident rates per month from February to December 152020

\begin{tabular}{|l|l|l|l|l|l|l|}
\hline & USA & France & UK & China & Brazil & Nigeria \\
\hline February & 197776 & 52028 & 22769 & 1730 & 5715 & 134 \\
\hline March & 910603 & 77453 & 132359 & 1308 & 79663 & 492 \\
\hline April & 755292 & 22172 & 90774 & 139 & 429469 & 1305 \\
\hline May & 884162 & 13048 & 34328 & 530 & 893636 & 8230 \\
\hline June & 2018419 & 23118 & 19928 & 761 & 1257813 & 15532 \\
\hline July & 1524731 & 93106 & 32692 & 756 & 1244603 & 17457 \\
\hline August & 1222029 & 282510 & 129252 & 0 & 902685 & 10857 \\
\hline September & 1948104 & 804090 & 546535 & 925 & 722019 & 4840 \\
\hline October & 4504509 & 854863 & 617996 & 0 & 800673 & 4005 \\
\hline November & 3178249 & 168959 & 258460 & 785 & 637980 & 4704 \\
\hline
\end{tabular}

\subsection{Discussion}

Table I shows the beginning of infection in the month of February with China having the highest prevalence due to the fact that the first case of covid 19 was found there but in the month of March the Prevalence of USA became more than that of China.Incidence of this disease has been on the rise till date and it is accompanied by high Mortality.

Table II shows that in the countries in this study, the population at risk of contacting the disease is $95 \%$ to $98 \%$, this is not a good sign and so warrants urgent measures to curb the menace of this disease because the rate of infection is high.

Table III shows that fatality and mortality of the disease may seem low in most countries but the disease is highly infectious and contagious, it is very risky not to quickly devise measures of tackling this disease. Mortality has been on the increase in USA, France, UK and Brazil with values of $0.01 \%, 0.9 \%, 0.1 \%$ and $0.09 \%$ respectively and the fatality rates were on the increase most especially in UK, France, USA and Brazil with values of $3.43 \%, 2.47 \%, 0.18 \%$ and $2.62 \%$ respectively.

Table IV showing the incident rates per month and in the month of February, USA, France, UK

and Brazil had relatively low rates but in the month of July and October the incident rates for the five countries increased significantly. It was an intriguing to find that in the months of August and October China had no incidents. The incident rate in Brazil in the month of June was very high . The data was not truly representative.

Among Clinical signs observed included Anemia,Dyspnea,hypoxia and cellular and tissue degradation which are the major problems. Anemia was megaloblstic, hemolyitic and hemorrhagic and whole blood was lost through petechial hemorrhages as a result of Lupus dermatitis and immunologic lupus erythmatosus due to the host immune responses to the viral attack. Secondarily, signs of anemia such as dyspnea, edema and dehydration were noticed.

Dehydration and Low packed cell volume indicated the inability of tissues to utilize oxygen and hypoxia produces decrease energy resulting in cell membrane depolarization and tissue necrosis, which in effect results in cellular and tissue degradation. Anemia observed was firstly Normocytic normochromic and later in late stages of the infection becoming Macrocytic hypochromic anemia,due to the failure of the bone marrow to produce sufficient viable red blood cells into peripheral circulation and emaciation seen was as a result of dehydration and anorexia.

Pathologic findings in some of the vital organs such as the Lung, Liver ,spleen and heart include necrosis and degeneration, edema,petechial hemorrhages, hypertrophy .This is so because of the decrease blood volume and cells and a decrease in peripheral circulation due to pooling of blood into the heart resulting in edema of the extremities especially the legs a phenomenon which is associated with Systemic lupus erythmatosus. Degeneration of the organs result in loss of function for example the liver no longer metabolise glucose nor store it and as we know glucose is essential for energy production the splenic pulps do not produce red blood cells anymore, and with depression of the bone marrow oxygen tissue supply is decreased,Lungs are pneumonic and there maybe Bronchopneumonia ,interstitial or embolic pneumonia depending on duration of disease, Patients in most cases suffer cardiogenic, anaphylactic and hypovolemic shock, dyspnea (gasping for oxygen) and/ or hypoxia result in tissue necrosis and degeneration,loss of function of organs and apoptosis(cell death).

\subsection{CONCLUSION}

Anemia, hypoxia and tissue death and dehydration are the major threat in this disease

Dehydration as a result of fluid and electrolyte loss which makes packed cell volume appear normal but in actual sense there is hemoconcentration leading to a false representation of blood picture.

Whole Blood, electrolyte fluid therapy and administration of oxygen might not help much because they do not tackle the underlying cause which is the disease. 
Prophylactically, to prevent covid 19 daily intake of blood tonic and ascorbic acid at required at recommended daily doses are measures which should be tried experimentally pre-infection to encourage tissue growth and re-epithelisation and also to help hasten maturity of the blood cells and improve their immune mechanism ,more so ascorbic acid can help a lot in the area of energy generation and build by maintaining and improving transmembrane permeability and action potential to prevent tissue and cellular degradation by histiocytes.

My sincere gratitude goes to Professors Sani Adamu, M.N Salka and S.Bisalla, and not forgetting M.Y Fatihu, U.S Abdullahi , L.S Makarfi and Dr A.A Abdulkadir all in the department of veterinary pathology and veterinary medicine and surgery,Ahmadu Bello University Zaria.Nigeria.

My children Mariam ,Mulikat and Mustapha Jnr.

\section{REFERENCES}

1. ^ "Virus Taxonomy: 2018b Release". International Committee on Taxonomy of Viruses (ICTV). March 2019. Archived from the original on 2018-03-04. Retrieved 2020-01-24.

2. ^ Giaimo C (2020-04-01). "The Spiky Blob Seen Around the World". The New York Times. Archived from the original on 2020-04-02. Retrieved 2020-04-06.

3. ^ Jump up to: $:^{\mathbf{b}}$ "2017.012-015S" (xlsx). International Committee on Taxonomy of Viruses (ICTV). October 2018. Archived from the original on 2019-05-14. Retrieved 2020-01-24.

4. ^ Jump up to: ${ }^{\mathbf{b}} \mathbf{c}$ "ICTV Taxonomy history: Orthocoronavirinae". International Committee on Taxonomy of Viruses (ICTV). Retrieved 2020-01-24.

5. ^ Jump up to: ${ }^{\mathbf{a}} \mathbf{c}$ Fan Y, Zhao K, Shi ZL, Zhou P (March 2019). "Bat Coronaviruses in China". Viruses. 11 (3): 210. doi:10.3390/v11030210. PMC 6466186. PMID 30832341.

6. ^ Cherry, James; Demmler-Harrison, Gail J.; Kaplan, Sheldon L.; Steinbach, William J.; Hotez, Peter J. (2017). Feigin and Cherry's Textbook of Pediatric Infectious Diseases. ElsevierHealth Sciences. p. PT6615. ISBN 978-0-323-39281-5.

7. ^ Jump up to: $:^{\mathbf{b}}$ Woo PC, Huang Y, Lau SK, Yuen KY (August 2010). "Coronavirus genomics and bioinformatics analysis". Viruses. 2 (8): 1804-20. doi:10.3390/v2081803. PMC 3185738. PMID 21994708. Coronaviruses possess the largest genomes [26.4 kb (ThCoV HKU12) to $31.7 \mathrm{~kb}$ (SW1)] among all known RNA viruses (Figure 1) [2,13,16].

8. ^ Jump up to: ${ }^{\mathbf{a}} \mathbf{b} \mathbf{c} \mathbf{d}$ Almeida JD, Berry DM, Cunningham CH, Hamre D, Hofstad MS, Mallucci L, McIntosh K, Tyrrell DA (November 1968). "Virology: Coronaviruses". Nature. 220 (5168): 650. Bibcode:1968Natur.220..650.. doi:10.1038/220650b0. [T] here is also a characteristic "fringe" of projections 200 A long, which are rounded or petal shaped ... This appearance, recalling the solar corona, is shared by mouse hepatitis virus and several viruses recently recovered from man, namely strain B814, 229E and several others.

9. ^ "Definition of Coronavirus by Merriam-Webster". Merriam-Webster. Archived from the original on 202003-23. Retrieved 2020-03-24.

10. ^ "Definition of Corona by Merriam-Webster". Merriam-Webster. Archived from the original on 2020-0324. Retrieved 2020-03-24.

11. ^ Jump up to: ${ }^{\mathbf{b}}$ Tyrrell DA, Fielder M (2002). Cold Wars: The Fight Against the Common Cold. Oxford University Press. p. 96. ISBN 978-0-19-263285-2. We looked more closely at the appearance of the new viruses and noticed that they had a kind of halo surrounding them. Recourse to a dictionary produced the Latin equivalent, corona, and so the name coronavirus was born.

12. ^ Sturman LS, Holmes KV (1983-01-01). Lauffer MA, Maramorosch K (eds.). "The molecular biology of coronaviruses". Advances in Virus Research. 28: 35-112. doi:10.1016/s0065-3527(08)60721-6. ISBN 9780120398287. PMC 7131312. PMID 6362367. [T]hese viruses displayed a characteristic fringe of large, distinctive, petal-shaped peplomers or spikes which resembled a crown, like the corona spinarum in religious art; hence the name coronaviruses.

13. ^ Jump up to: ${ }^{\mathbf{a}} \mathbf{b}$ Lalchhandama K (2020). "The chronicles of coronaviruses: the bronchitis, the hepatitis and the common cold". Science Vision. 20 (1): 43-53. doi:10.33493/scivis.20.01.04.

14. ^ Carstens, E. B. (2010). "Ratification vote on taxonomic proposals to the International Committee on Taxonomy of Viruses (2009)". Archives of Virology. 155 (1): 133-146. doi:10.1007/s00705-009-0547-x. PMC 7086975. PMID 19960211.

15. ^ "International Committee on Taxonomy of Viruses (ICTV)". talk.ictvonline.org. Retrieved 2020-09-14.

16. ^ Estola T (1970). "Coronaviruses, a New Group of Animal RNA Viruses". Avian Diseases. 14 (2): 330-336. doi:10.2307/1588476. ISSN 0005-2086. JSTOR 1588476. PMID 4316767.

17. ^ Fabricant J (1998). "The Early History of Infectious Bronchitis". Avian Diseases. 42 (4): 648-650. doi:10.2307/1592697. ISSN 0005-2086. JSTOR 1592697. PMID 9876830.

18. ^ Bushnell LD, Brandly CA (1933). "Laryngotracheitis in chicks". Poultry Science. 12 (1): 55-60. 
doi: $10.3382 / \mathrm{ps} .0120055$.

19. ^ Jump up to: ${ }^{\mathbf{a}}$ Decaro N (2011). "Gammacoronavirus". In Tidona C, Darai G (eds.). Gammacoronavirusł: Coronaviridae. The Springer Index of Viruses. Springer. pp. 403-413. doi:10.1007/978-0-387-95919-1_58. ISBN 978-0-387-95919-1. PMC 7176155.

20. ^ Jump up to: ${ }^{\mathbf{a}} \mathbf{b} \mathbf{c}$ McIntosh K (1974). "Coronaviruses: A Comparative Review". In Arber W, Haas R, Henle W, Hofschneider PH, Jerne NK, Koldovský P, Koprowski H, Maaløe O, Rott R (eds.). Current Topics in Microbiology and Immunology / Ergebnisse der Mikrobiologie und Immunitätsforschung. Current Topics in Microbiology and Immunology / Ergebnisse der Mikrobiologie und Immunitätsforschung. Berlin, Heidelberg: Springer. p. 87. doi:10.1007/978-3-642-65775-7_3. ISBN 978-3-642-65775-7.

21. ^ "Il était une fois les coronavirus". Réalités Biomédicales(in French). 2020-03-27. Retrieved 2020-04-18.

22. ^ Kahn JS, McIntosh K (November 2005). "History and recent advances in coronavirus discovery". The Pediatric Infectious Disease Journal. $24 \quad(11 \quad$ Suppl): S223-7, discussion S226. doi:10.1097/01.inf.0000188166.17324.60. PMID 16378050.

23. ^ Mahase E (April 2020). "The BMJ in 1965". BMJ. 369: m1547. doi:10.1136/bmj.m1547. PMID 32299810.

24. ^ Monto AS (1984). "Coronaviruses". In Evans AS (ed.). Viral Infections of Humans. Viral Infections of Humans: Epidemiology and Control. Springer US. pp. 151-165. doi:10.1007/978-1-4684-4727-9_7. ISBN 978-1-4684-4727-9.

25. ^ Jump up to: $:^{\mathbf{b}}$ Kendall EJ, Bynoe ML, Tyrrell DA (July 1962). "Virus isolations from common colds occurring in a residential school". British Medical Journal. 2 (5297): 82-6. doi:10.1136/bmj.2.5297.82. PMC 1925312. PMID 14455113.

26. ^ Richmond C (2005-06-18). "David Tyrrell". BMJ : British Medical Journal. 330 (7505): 1451. doi:10.1136/bmj.330.7505.1451. PMC 558394.

27. ^ "Obituary Notices: Malcom Byone". British Medical Journal. 2 (5660): 827-829. 1969-06-28. doi:10.1136/bmj.2.5660.827. S2CID 220187042.

28. ^ Tyrrell DA, Bynoe ML (June 1965). "Cultivation of a Novel Type of Common-Cold Virus in Organ Cultures". British Medical Journal. 1 (5448): 1467-70. doi:10.1136/bmj.1.5448.1467. PMC 2166670. PMID 14288084.

29. ^ Tyrrell DA, Fielder M (2002). Cold Wars: The Fight Against the Common Cold. Oxford University Press. pp. 93-95. ISBN 978-0-19-263285-2.

30. ^ Hagan WA, Bruner DW, Gillespie JH, Timoney JF, Scott FW, Barlough JE (1988). Hagan and Bruner's Microbiology and Infectious Diseases of Domestic Animals: With Reference to Etiology, Epizootiology, Pathogenesis, Immunity, Diagnosis, and Antimicrobial Susceptibility. Cornell University Press. p. 440. ISBN 978-0-8014-1896-9.

31. ^ Knapp, Alex. "The Secret History Of The First Coronavirus". Forbes. Retrieved 2020-05-06.

32. ^ Hamre D, Procknow JJ (January 1966). "A new virus isolated from the human respiratory tract". Proceedings of the Society for Experimental Biology and Medicine. 121 (1): 190-3. doi:10.3181/00379727121-30734. PMID 4285768. S2CID 1314901.

33. ^ "The woman who discovered the first coronavirus".

34. ^ Almeida J (2008-06-26). "June Almeida (née Hart)". BMJ. 336 (7659): 1511.1-1511. doi:10.1136/bmj.a434. ISSN 0959-8138. PMC 2440895.

35. ^ Almeida JD, Tyrrell DA (April 1967). "The morphology of three previously uncharacterized human respiratory viruses that grow in organ culture". The Journal of General Virology. 1 (2): 175-8. doi:10.1099/0022-1317-1-2-175. PMID 4293939.

36. ^ McIntosh K, Becker WB, Chanock RM (December 1967). "Growth in suckling-mouse brain of "IBV-like" viruses from patients with upper respiratory tract disease". Proceedings of the National Academy of Sciences of the United States of America. 58 (6): 2268-73. Bibcode:1967PNAS...58.2268M. doi:10.1073/pnas.58.6.2268. PMC 223830. PMID 4298953.

37. ^ McIntosh K, Dees JH, Becker WB, Kapikian AZ, Chanock RM (April 1967). "Recovery in tracheal organ cultures of novel viruses from patients with respiratory disease". Proceedings of the National Academy of Sciences of the United States of America. 57 (4): 933-40. Bibcode:1967PNAS...57..933M. doi:10.1073/pnas.57.4.933. PMC 224637. PMID 5231356.

38. ^ Times, Harold M. Schmeck Jr Special To the New York (1967-05-05). "Six Newly Discovered Viruses May Explain Cold; Strains Are Similar to Germ That Causes a Bronchial Infection in Chickens Believed to Be New Group". The New York Times. ISSN 0362-4331. Retrieved 2020-04-25.

39. ^ Myint SH (1995). "Human Coronavirus Infections". In Siddell SG (ed.). The Coronaviridae. The Viruses. Springer US. pp. 389-401. doi:10.1007/978-1-4899-1531-3_18. ISBN 978-1-4899-1531-3.

40. ^ Geller C, Varbanov M, Duval RE (November 2012). "Human coronaviruses: insights into environmental resistance and its influence on the development of new antiseptic strategies". Viruses. 4 (11): 3044-68. doi:10.3390/v4113044. PMC 3509683. PMID 23202515. 
41. ^ Corman VM, Jores J, Meyer B, Younan M, Liljander A, Said MY, et al. (August 2014). "Antibodies against MERS coronavirus in dromedary camels, Kenya, 1992-2013". Emerging Infectious Diseases. 20 (8): 1319 22. doi:10.1007/978-1-4899-7448-8_10. ISBN 978-1-4899-7447-1. PMC 7122465. PMID 25075637. The other OC strains and B814 that could not be adapted to mouse brain resisted adaptation to cell culture as well; these distinct viruses have since been lost and may actually have been rediscovered recently.

42. ^ Zhu N, Zhang D, Wang W, Li X, Yang B, Song J, et al. (February 2020). "A Novel Coronavirus from Patients with Pneumonia in China, 2019". The New England Journal of Medicine. 382 (8): 727-733. doi:10.1056/NEJMoa2001017. PMC 7092803. PMID 31978945.

43. ^ Jump up to: ${ }^{\mathbf{b}} \mathbf{c} \mathbf{d}$ e de Groot RJ, Baker SC, Baric R, Enjuanes L, Gorbalenya AE, Holmes KV, Perlman S, Poon L, Rottier PJ, Talbot PJ, Woo PC, Ziebuhr J (2011). "FamilyCoronaviridae". In King AM, Lefkowitz E, Adams MJ, Carstens EB, International Committee on Taxonomy of Viruses, International Union of Microbiological Societies. Virology Division (eds.). Ninth Report of the International Committee on Taxonomy of Viruses. Oxford: Elsevier. pp. 806-28. doi:10.1016/B978-0-12-384684-6.00068-9. ISBN 9780-12-384684-6. S2CID 212719285.

44. ^ Goldsmith CS, Tatti KM, Ksiazek TG, Rollin PE, Comer JA, Lee WW, et al. (February 2004). "Ultrastructural characterization of SARS coronavirus". Emerging Infectious Diseases. 10 (2): 320-26. doi:10.3201/eid1002.030913. PMC 3322934. PMID 15030705. Virions acquired an envelope by budding into the cisternae and formed mostly spherical, sometimes pleomorphic, particles that averaged $78 \mathrm{~nm}$ in diameter (Figure 1A).

45. ^ Jump up to: ${ }^{\mathbf{b}} \mathbf{b}$ c Masters, Paul S. (2006). "The molecular biology of coronaviruses". Advances in Virus Research. 66: 193-292. doi:10.1016/S0065-3527(06)66005-3. ISBN 9780120398690. PMC 7112330. PMID 16877062.

46. ^ Jump up to: a b c d e Lalchhandama, K. (2020). "The chronicles of coronaviruses: the electron microscope, the doughnut, and the spike". Science Vision. 20 (2): 78-92. doi:10.33493/scivis.20.02.03.

47. ^ Neuman BW, Kiss G, Kunding AH, Bhella D, Baksh MF, Connelly S, et al. (April 2011). "A structural analysis of $\mathrm{M}$ protein in coronavirus assembly and morphology". Journal of Structural Biology. 174 (1): $11-$ 22. doi:10.1016/j.jsb.2010.11.021. PMC 4486061. PMID 21130884. See Figure 10.

48. ^ Lai MM, Cavanagh D (1997). "The molecular biology of coronaviruses". Advances in Virus Research. 48: 1-100. doi:10.1016/S0065-3527(08)60286-9. ISBN 9780120398485. PMC 7130985. PMID 9233431.

49. ^ Cavanagh D, Mawditt K, Sharma M, Drury SE, Ainsworth HL, Britton P, Gough RE (August 2001). Schmidt A, Weber O, Wolff MH (eds.). "Detection of a coronavirus from turkey poults in Europe genetically related to infectious bronchitis virus of chickens". Avian Pathology. Birkhäuser Advances in Infectious Diseases BAID. Birkhäuser. 30 (4): 355-68. doi:10.1007/3-7643-7339-3_1. ISBN 978-3-7643-7339-9. PMC 7123520. PMID 19184921.

50. ^ Jump up to: ${ }^{\mathbf{a}} \mathbf{b} \mathbf{c} \mathbf{d}$ e $\mathbf{f} \mathbf{g} \mathbf{h} \mathbf{i} \mathbf{j} \mathbf{k} \mathbf{~} \mathbf{~ m ~} \mathbf{n}$ o p Fehr AR, Perlman S (2015). "Coronaviruses: an overview of their replication and pathogenesis". In Maier HJ, Bickerton E, Britton P (eds.). Coronaviruses. Methods in Molecular Biology. 1282. Springer. pp. 1-23. doi:10.1007/978-1-4939-2438-7_1. ISBN 978-1-4939-2438-7. PMC 4369385. PMID 25720466. See section: Virion Structure.

51. ^ Naskalska, Antonina; Dabrowska, Agnieszka; Szczepanski, Artur; Milewska, Aleksandra; Jasik, Krzysztof Piotr; Pyrc, Krzysztof (2019). "Membrane Protein of Human Coronavirus NL63 Is Responsible for Interaction with the Adhesion Receptor". Journal of Virology. 93 (19). doi:10.1128/JVI.00355-19. PMC 6744225. PMID 31315999.

52. ^ Neuman BW, Adair BD, Yoshioka C, Quispe JD, Orca G, Kuhn P, et al. (August 2006). "Supramolecular architecture of severe acute respiratory syndrome coronavirus revealed by electron cryomicroscopy". Journal of Virology. 80 (16): 7918-28. doi:10.1128/JVI.00645-06. PMC 1563832. PMID 16873249. Particle diameters ranged from 50 to $150 \mathrm{~nm}$, excluding the spikes, with mean particle diameters of 82 to $94 \mathrm{~nm}$; Also See Figure 1 for double shell.

53. ^ Schoeman, Dewald; Fielding, Burtram C. (2019). "Coronavirus envelope protein: current knowledge". Virology Journal. 16 (1): 69. doi:10.1186/s12985-019-1182-0. PMC 6537279. PMID 31133031.

54. ^ Neuman, Benjamin W.; Kiss, Gabriella; Kunding, Andreas H.; Bhella, David; Baksh, M. Fazil; Connelly, Stephen; Droese, Ben; Klaus, Joseph P.; Makino, Shinji; Sawicki, Stanley G.; Siddell, Stuart G. (April 2011). "A structural analysis of M protein in coronavirus assembly and morphology". Journal of Structural Biology. 174 (1): 11-22. doi:10.1016/j.jsb.2010.11.021. ISSN 1047-8477. PMC 4486061. PMID 21130884.

55. ^ Alsaadi, Entedar A. J.; Jones, Ian M. (2019). "Membrane binding proteins of coronaviruses". Future Virology. 14 (4): 275-286. doi:10.2217/fvl-2018-0144. PMC 7079996. PMID 32201500.

56. ^ Zeng, Qinghong; Langereis, Martijn A.; van Vliet, Arno L. W.; Huizinga, Eric G.; de Groot, Raoul J. (2008). "Structure of coronavirus hemagglutinin-esterase offers insight into corona and influenza virus evolution". Proceedings of the National Academy of Sciences of the United States of America. 105(26): 9065-9069. doi:10.1073/pnas.0800502105. PMC 2449365. PMID 18550812. 
57. ^ Chang CK, Hou MH, Chang CF, Hsiao CD, Huang TH (March 2014). "The SARS coronavirus nucleocapsid protein-forms and functions". Antiviral Research. 103: 39-50. doi:10.1016/j.antiviral.2013.12.009. PMC 7113676. PMID 24418573. See Figure 4c.

58. ^ Snijder EJ, Bredenbeek PJ, Dobbe JC, Thiel V, Ziebuhr J, Poon LL, et al. (August 2003). "Unique and conserved features of genome and proteome of SARS-coronavirus, an early split-off from the coronavirus group 2 lineage". Journal of Molecular Biology. 331 (5): 991-1004. doi:10.1016/S0022-2836(03)00865-9. PMC 7159028. PMID 12927536. See Figure 1.

59. ^ Simmons G, Zmora P, Gierer S, Heurich A, Pöhlmann S (December 2013). "Proteolytic activation of the SARS-coronavirus spike protein: cutting enzymes at the cutting edge of antiviral research". Antiviral Research. 100 (3): 605-14. doi:10.1016/j.antiviral.2013.09.028. PMC 3889862. PMID 24121034. See Figure 2.

60. ^ Masters PS (2006-01-01). "The molecular biology of coronaviruses". Advances in Virus Research. Academic Press. 66: 193-292. doi:10.1016/S0065-3527(06)66005-3. ISBN 9780120398690. PMC 7112330. PMID 16877062. See Figure 8.

61. ^ Sexton NR, Smith EC, Blanc H, Vignuzzi M, Peersen OB, Denison MR (August 2016). "Homology-Based Identification of a Mutation in the Coronavirus RNA-Dependent RNA Polymerase That Confers Resistance to Multiple Mutagens". Journal of Virology. 90 (16): 7415-28. doi:10.1128/JVI.00080-16. PMC 4984655. PMID 27279608. Finally, these results, combined with those from previous work $(33,44)$, suggest that CoVs encode at least three proteins involved in fidelity (nsp12-RdRp, nsp14-ExoN, and nsp10), supporting the assembly of a multiprotein replicase-fidelity complex, as described previously (38).

62. ^ Jump up to: ${ }^{\text {b }}$ Payne, Susan (2017-01-01), Payne, Susan (ed.), "Chapter 17 - Family Coronaviridae", Viruses, Academic Press, pp. 149-158, ISBN 978-0-12-803109-4, retrieved 2020-05-15

63. ^ Jump up to: ${ }^{\mathbf{a}} \mathbf{b}$ Su S, Wong G, Shi W, Liu J, Lai ACK, Zhou J, Liu W, Bi Y, Gao GF. Epidemiology, Genetic Recombination, and Pathogenesis of Coronaviruses. Trends Microbiol. 2016 Jun;24(6):490-502. doi: 10.1016/j.tim.2016.03.003. Epub 2016 Mar 21. Review. PMID 27012512

64. ^ Fehr AR, Perlman S (2015). "Coronaviruses: an overview of their replication and pathogenesis". In Maier HJ, Bickerton E, Britton P (eds.). Coronaviruses. Methods in Molecular Biology. 1282. Springer. pp. 1-23. doi:10.1007/978-1-4939-2438-7 1. ISBN 978-1-4939-2438-7. PMC 4369385. PMID 25720466. See section: Coronavirus Life Cycle-Assembly and Release

65. ^ Masters PS (2006-01-01). "The molecular biology of coronaviruses". Advances in Virus Research. Academic Press. 66: 193-292. doi:10.1016/S0065-3527(06)66005-3. ISBN 978-0120398690. PMC 7112330. PMID 16877062. Nevertheless, the interaction between S protein and receptor remains the principal, if not sole, determinant of coronavirus host species range and tissue tropism.

66. ^ Cui J, Li F, Shi ZL (March 2019). "Origin and evolution of pathogenic coronaviruses". Nature Reviews. Microbiology. 17 (3): 181-92. doi:10.1038/s41579-018-0118-9. PMC 7097006. PMID 30531947. Different SARS-CoV strains isolated from several hosts vary in their binding affinities for human ACE2 and consequently in their infectivity of human cells 76, 78 (Fig. 6b)

67. ^ Jump up to: ${ }^{\mathbf{b}} \mathbf{c}^{\mathbf{c}}$ Decaro N (2011). Tidona C, Darai G (eds.). Alphacoronavirus. The Springer Index of Viruses. Springer. pp. 371-383. doi:10.1007/978-0-387-95919-1_56. ISBN 978-0-387-95919-1. PMC 7176201 .

68. ^ Jump up to: ${ }^{\mathbf{a}} \mathbf{b}$ Decaro N (2011). Tidona C, Darai G (eds.). Betacoronavirus. The Springer Index of Viruses. Springer. pp. 385-401. doi:10.1007/978-0-387-95919-1_57. ISBN 978-0-387-95919-1. PMC 7176184.

69. ^ Jump up to: ${ }^{\mathbf{b}} \mathbf{L i}$ F, Li W, Farzan M, Harrison SC (September 2005). "Structure of SARS coronavirus spike receptor-binding domain complexed with receptor". Science. 309 (5742): 1864-68. Bibcode:2005Sci...309.1864L. doi:10.1126/science.1116480. PMID 16166518. S2CID 12438123.

70. ^ International Committee on Taxonomy of Viruses (2010-08-24). "ICTV Master Species List 2009—v10" (xls).

71. ^ Wertheim JO, Chu DK, Peiris JS, Kosakovsky Pond SL, Poon LL (June 2013). "A case for the ancient origin of coronaviruses". Journal of Virology. 87 (12): 7039-45. doi:10.1128/JVI.03273-12. PMC 3676139. PMID 23596293. Alphacoronaviruses and betacoronaviruses are found exclusively in mammals, whereas gammacoronaviruses and deltacoronaviruses primarily infect birds.

72. ^ Nextstrain, phylogenetic tree of Beta-CoV

73. ^ Wertheim JO, Chu DK, Peiris JS, Kosakovsky Pond SL, Poon LL (June 2013). "A case for the ancient origin of coronaviruses". Journal of Virology. 87 (12): 7039-45. doi:10.1128/JVI.03273-12. PMC 3676139. PMID 23596293.

74. ^ Woo PC, Lau SK, Lam CS, Lau CC, Tsang AK, Lau JH, et al. (April 2012). "Discovery of seven novel mammalian and avian coronaviruses in the genus deltacoronavirus supports bat coronaviruses as the gene source of alphacoronavirus and betacoronavirus and avian coronaviruses as the gene source of gammacoronavirus and deltacoronavirus". Journal of Virology. 86 (7): 3995-4008. doi:10.1128/JVI.06540- 
11. PMC 3302495. PMID 22278237.

75. ^ Jump up to: ${ }^{\mathbf{a}} \mathbf{c}$ Forni D, Cagliani R, Clerici M, Sironi M (January 2017). "Molecular Evolution of Human Coronavirus Genomes". Trends in Microbiology. 25 (1): 35-48. doi:10.1016/j.tim.2016.09.001. PMC 7111218. PMID 27743750. Specifically, all HCoVs are thought to have a bat origin, with the exception of lineage A beta-CoVs, which may have reservoirs in rodents [2].

76. ^ Huynh J, Li S, Yount B, Smith A, Sturges L, Olsen JC, et al. (December 2012). "Evidence supporting a zoonotic origin of human coronavirus strain NL63". Journal of Virology. 86(23): 12816-25. doi:10.1128/JVI.00906-12. PMC 3497669. PMID 22993147. If these predictions are correct, this observation suggests that HCoV-NL63 may have originated from bats between 1190 and 1449 CE.

77. ^ Pfefferle S, Oppong S, Drexler JF, Gloza-Rausch F, Ipsen A, Seebens A, et al. (September 2009). "Distant relatives of severe acute respiratory syndrome coronavirus and close relatives of human coronavirus $229 \mathrm{E}$ in bats, Ghana". Emerging Infectious Diseases. 15 (9): 1377-84. doi:10.3201/eid1509.090224. PMC 2819850. PMID 19788804. The most recent common ancestor of hCoV-229E and GhanaBt-CoVGrp1 existed in $\approx 1686$ 1800 AD.

78. ^ Crossley BM, Mock RE, Callison SA, Hietala SK (December 2012). "Identification and characterization of a novel alpaca respiratory coronavirus most closely related to the human coronavirus 229E". Viruses. 4 (12): 3689-700. doi:10.3390/v4123689. PMC 3528286. PMID 23235471.

79. ^ Forni D, Cagliani R, Clerici M, Sironi M (January 2017). "Molecular Evolution of Human Coronavirus Genomes". Trends in Microbiology. 25 (1): 35-48. doi:10.1016/j.tim.2016.09.001. PMC 7111218. PMID 27743750.

80. ^ Lau SK, Li KS, Tsang AK, Lam CS, Ahmed S, Chen H, et al. (August 2013). "Genetic characterization of Betacoronavirus lineage $\mathrm{C}$ viruses in bats reveals marked sequence divergence in the spike protein of pipistrellus bat coronavirus HKU5 in Japanese pipistrelle: implications for the origin of the novel Middle East respiratory syndrome coronavirus". Journal of Virology. 87 (15): 8638-50. doi:10.1128/JVI.01055-13. PMC 3719811. PMID 23720729.

81. ^ Vijaykrishna D, Smith GJ, Zhang JX, Peiris JS, Chen H, Guan Y (April 2007). "Evolutionary insights into the ecology of coronaviruses". Journal of Virology. 81 (8): 4012-20. doi:10.1128/jvi.02605-06. PMC 1866124. PMID 17267506.

82. ^ Gouilh MA, Puechmaille SJ, Gonzalez JP, Teeling E, Kittayapong P, Manuguerra JC (October 2011). "SARS-Coronavirus ancestor's foot-prints in South-East Asian bat colonies and the refuge theory". Infection, Genetics and Evolution. 11 (7): 1690-702. doi:10.1016/j.meegid.2011.06.021. PMC 7106191. PMID 21763784.

83. ^ Cui J, Han N, Streicker D, Li G, Tang X, Shi Z, et al. (October 2007). "Evolutionary relationships between bat coronaviruses and their hosts". Emerging Infectious Diseases. 13 (10): 1526-32. doi:10.3201/eid1310.070448. PMC 2851503. PMID 18258002.

84. ^ Lau SK, Woo PC, Li KS, Tsang AK, Fan RY, Luk HK, et al. (March 2015). "Discovery of a novel coronavirus, China Rattus coronavirus HKU24, from Norway rats supports the murine origin of Betacoronavirus 1 and has implications for the ancestor of Betacoronavirus lineage A". Journal of Virology. 89 (6): 3076-92. doi:10.1128/JVI.02420-14. PMC 4337523. PMID 25552712.

85. ^ Jump up to: ${ }^{\mathbf{a}} \mathbf{b}$ Bidokhti MR, Tråvén M, Krishna NK, Munir M, Belák S, Alenius S, Cortey M (September 2013). "Evolutionary dynamics of bovine coronaviruses: natural selection pattern of the spike gene implies adaptive evolution of the strains". The Journal of General Virology. 94 (Pt 9): 2036-2049. doi:10.1099/vir.0.054940-0. PMID 23804565. See Table 1

86. ^ Vijgen L, Keyaerts E, Moës E, Thoelen I, Wollants E, Lemey P, et al. (February 2005). "Complete genomic sequence of human coronavirus OC43: molecular clock analysis suggests a relatively recent zoonotic coronavirus transmission event". Journal of Virology. 79 (3): 1595-604. doi:10.1128/jvi.79.3.15951604.2005. PMC 544107. PMID 15650185.

87. ^ Vijgen L, Keyaerts E, Moës E, Thoelen I, Wollants E, Lemey P, et al. (February 2005). "Complete genomic sequence of human coronavirus OC43: molecular clock analysis suggests a relatively recent zoonotic coronavirus transmission event". Journal of Virology. 79 (3): 1595-604. doi:10.1128/JVI.79.3.15951604.2005. PMC 544107. PMID 15650185. However, it is tempting to speculate about an alternative hypothesis, that the 1889-1890 pandemic may have been the result of interspecies transmission of bovine coronaviruses to humans, resulting in the subsequent emergence of HCoV-OC43.

88. ^ Corman VM, Muth D, Niemeyer D, Drosten C (2018). "Hosts and Sources of Endemic Human Coronaviruses". Advances in Virus Research. 100: 163-188. doi:10.1016/bs.aivir.2018.01.001. ISBN 9780128152010. PMC 7112090. PMID 29551135.

89. ^ Lau SK, Lee P, Tsang AK, Yip CC, Tse H, Lee RA, et al. (November 2011). "Molecular epidemiology of human coronavirus OC43 reveals evolution of different genotypes over time and recent emergence of a novel genotype due to natural recombination". Journal of Virology. 85 (21): 11325-37. doi:10.1128/JVI.05512-11. 
PMC 3194943. PMID 21849456.

90. ^ Schaumburg CS, Held KS, Lane TE (May 2008). "Mouse hepatitis virus infection of the CNS: a model for defense, disease, and repair". Frontiers in Bioscience. 13 (13): 4393-406. doi:10.2741/3012. PMC 5025298. PMID 18508518.

91. ^ Liu P, Shi L, Zhang W, He J, Liu C, Zhao C, et al. (November 2017). "Prevalence and genetic diversity analysis of human coronaviruses among cross-border children". Virology Journal. 14 (1): 230. doi:10.1186/s12985-017-0896-0. PMC 5700739. PMID 29166910.

92. ^ Jump up to: ${ }^{\mathbf{a}}$ Forgie S, Marrie TJ (February 2009). "Healthcare-associated atypical pneumonia". Seminars in Respiratory and Critical Care Medicine. 30 (1): 67-85. doi:10.1055/s-0028-1119811. PMID 19199189.

93. ^ Corman VM, Muth D, Niemeyer D, Drosten C (2018). "Hosts and Sources of Endemic Human Coronaviruses". Advances in Virus Research. 100: 163-188. doi:10.1016/bs.aivir.2018.01.001. ISBN 978-012-815201-0. PMID 29551135.

94. ^ Pelczar (2010). Microbiology: Application Based Approach. p. 656. ISBN 978-0-07-015147-5. Archivedfrom the original on 2016-05-16.

95. ^ Cecil RL, Goldman L, Schafer AI (2012). Goldman's Cecil Medicine, Expert Consult Premium Edition (24 ed.). Elsevier Health Sciences. pp. 2103-. ISBN 978-1-4377-1604-7. Archived from the original on 2016-0504.

96. ^ Charlton CL, Babady E, Ginocchio CC, Hatchette TF, Jerris RC, Li Y, et al. (January 2019). "Practical Guidance for Clinical Microbiology Laboratories: Viruses Causing Acute Respiratory Tract Infections". Clinical Microbiology Reviews. 32 (1). doi:10.1128/CMR.00042-18. PMC 6302358. PMID 30541871. See Figure 1.

97. ^ Monto AS, DeJonge P, Callear AP, Bazzi LA, Capriola S, Malosh RE, et al. (April 2020). "Coronavirus occurrence and transmission over 8 years in the HIVE cohort of households in Michigan". The Journal of Infectious Diseases. 222: 9-16. doi:10.1093/infdis/jiaa161. PMC 7184402. PMID 32246136.

98. ^ Abdul-Rasool S, Fielding BC (May 2010). "Understanding Human Coronavirus HCoV-NL63". The Open Virology Journal. 4: 76-84. doi:10.2174/1874357901004010076. PMC 2918871. PMID 20700397.

99. ^ Wang C, Horby PW, Hayden FG, Gao GF (February 2020). "A novel coronavirus outbreak of global health concern". Lancet. 395 (10223): 470-473. doi:10.1016/S0140-6736(20)30185-9. PMID 31986257.

100.^ Lau EH, Hsiung CA, Cowling BJ, Chen CH, Ho LM, Tsang T, et al. (March 2010). "A comparative epidemiologic analysis of SARS in Hong Kong, Beijing and Taiwan". BMC Infectious Diseases. 10: 50. doi:10.1186/1471-2334-10-50. PMC 2846944. PMID 20205928.

101.^ Jump up to: ${ }^{\mathbf{a}} \mathbf{b}$ "Old age, sepsis tied to poor COVID-19 outcomes, death". CIDRAP, University of Minnesota. Retrieved 2020-03-29.

102.^ Karlberg J, Chong DS, Lai WY (February 2004). "Do men have a higher case fatality rate of severe acute respiratory syndrome than women do?". American Journal of Epidemiology. 159 (3): $229-31$. doi:10.1093/aje/kwh056. PMID 14742282.

103.^ Jump up to: ${ }^{\mathbf{b}}$ "Summary of probable SARS cases with onset of illness from 1 November 2002 to 31 July 2003". World Health Organization. April 2004.

104.^ Jump up to: ${ }^{\mathbf{a}} \mathbf{b} \mathbf{c} \mathbf{~}$ e "COVID-19 Dashboard by the Center for Systems Science and Engineering (CSSE) at Johns Hopkins University (JHU)". ArcGIS. Johns Hopkins University. Retrieved 2020-12-07.

105.^ Jump up to: ${ }^{\mathbf{a}} \mathbf{b} \mathbf{c} \mathbf{d}$ e "Report of the WHO-China Joint Mission on Coronavirus Disease 2019 (COVID-19)" (PDF). World Health Organization. February 2020.

106.^ Oh MD, Park WB, Park SW, Choe PG, Bang JH, Song KH, et al. (March 2018). "Middle East respiratory syndrome: what we learned from the 2015 outbreak in the Republic of Korea". The Korean Journal of Internal Medicine. 33 (2): 233-246. doi:10.3904/kjim.2018.031. PMC 5840604. PMID 29506344.

107.^ Namendys-Silva SA (March 2020). "Respiratory support for patients with COVID-19 infection". The Lancet. Respiratory Medicine. doi:10.1016/S2213-2600(20)30110-7. PMID 32145829.

108.^ Pasley, James. "How SARS terrified the world in 2003, infecting more than 8,000 people and killing 774". Business Insider. Retrieved 2020-11-08.

109.^ Doucleef M (2012-09-26). "Scientists Go Deep On Genes Of SARS-Like Virus". Associated Press. Archived from the original on 2012-09-27. Retrieved 2012-09-27.

110.^ Falco M (2012-09-24). "New SARS-like virus poses medical mystery". CNN Health. Archived from the original on 2013-11-01. Retrieved 2013-03-16.

111. ^ "New SARS-like virus found in Middle East". Al-Jazeera. 2012-09-24. Archived from the original on $2013-$ 03-09. Retrieved 2013-03-16.

112.^ Kelland K (2012-09-28). "New virus not spreading easily between people: WHO". Reuters. Archived from the original on 2012-11-24. Retrieved 2013-03-16.

113.^ Nouveau coronavirus-Point de situation : Un nouveau cas d'infection confirmé Archived 8 June 2013 at the Wayback Machine (Novel coronavirus-Status report: A new case of confirmed infection) 12 May 2013, 
social-sante.gouv.fr

114. ${ }^{\wedge}$ "MERS Transmission". Centers for Disease Control and Prevention (CDC). 2019-08-02. Archived from the original on 2019-12-07. Retrieved 2019-12-10.

115.^ "Novel coronavirus infection". World Health Association. 2013-05-22. Archived from the original on $2013-$ 06-07. Retrieved 2013-05-23.

116. ${ }^{\wedge}$ "MERS in the U.S." Center for Disease Control. 2019-08-02. Archived from the original on 2019-12-15. Retrieved 2019-12-10.

117.^ Sang-Hun C (2015-06-08). "MERS Virus's Path: One Man, Many South Korean Hospitals". The New York Times. Archived from the original on 2017-07-15. Retrieved 2017-03-01.

118. ${ }^{\wedge}$ "Middle East respiratory syndrome coronavirus (MERS-CoV)". WHO. Archived from the original on $2019-$ 10-18. Retrieved 2019-12-10.

119.^ The Editorial Board (2020-01-29). "Is the World Ready for the Coronavirus?-Distrust in science and institutions could be a major problem if the outbreak worsens". The New York Times. Retrieved 2020-01-30.

120.^ "WHO Statement Regarding Cluster of Pneumonia Cases in Wuhan, China". www.who.int. 2020-01-09. Archived from the original on 2020-01-14. Retrieved 2020-01-10.

121. ${ }^{\wedge}$ "Laboratory testing of human suspected cases of novel coronavirus ( $\mathrm{nCoV}$ ) infection. Interim guidance, 10 January 2020" (PDF). Archived (PDF) from the original on 2020-01-20. Retrieved 2020-01-14.

122.^ "Novel Coronavirus 2019, Wuhan, China". www.cdc.gov (CDC). 2020-01-23. Archived from the original on 2020-01-20. Retrieved 2020-01-23.

123.^ "2019 Novel Coronavirus infection (Wuhan, China): Outbreak update". Canada.ca. 2020-01-21.

124.^ Hui DS, I Azhar E, Madani TA, Ntoumi F, Kock R, Dar O, et al. (February 2020). "The continuing 2019 nCoV epidemic threat of novel coronaviruses to global health-The latest 2019 novel coronavirus outbreak in Wuhan, China". International Journal of Infectious Diseases. 91: 264-66. doi:10.1016/j.ijid.2020.01.009. PMC 7128332. PMID 31953166.

125.^ Cohen J (2020-01-26). "Wuhan seafood market may not be source of novel virus spreading globally". ScienceMagAmerican Association for the Advancement of Science. (AAAS). Archived from the original on 2020-01-27. Retrieved 2020-01-29.

126.^ Eschner K (2020-01-28). "We're still not sure where the COVID-19 really came from". Popular Science. Archivedfrom the original on 2020-01-30. Retrieved 2020-01-30.

127. ^ Jump up to:a b c d e f g h $\mathbf{~ i ~ j ~ k ~ " C h a p t e r ~} 24$ - Coronaviridae". Fenner's Veterinary Virology (Fifth ed.). Academic Press. 2017. pp. 435-461. doi:10.1016/B978-0-12-800946-8.00024-6. ISBN 978-0-12-800946-8. S2CID 219575461.

128.^ Murphy FA, Gibbs EP, Horzinek MC, Studdart MJ (1999). Veterinary Virology. Boston: Academic Press. pp. 495-508. ISBN 978-0-12-511340-3.

129.^ Jump up to: ${ }^{\mathbf{b}}$ Tirotta E, Carbajal KS, Schaumburg CS, Whitman L, Lane TE (July 2010). "Cell replacement therapies to promote remyelination in a viral model of demyelination". Journal of Neuroimmunology. 224 (12): 101-07. doi:10.1016/j.jneuroim.2010.05.013. PMC 2919340. PMID 20627412.

130.^ Jump up to: ${ }^{\mathbf{b}}$ "Merck Veterinary Manual". Merck Veterinary Manual. Retrieved 2020-06-08.

131.^ Jump up to: ${ }^{\mathbf{b}} \mathbf{b}$ Bande F, Arshad SS, Bejo MH, Moeini H, Omar AR (2015). "Progress and challenges toward the development of vaccines against avian infectious bronchitis". Journal of Immunology Research. 2015: 424860. doi:10.1155/2015/424860. PMC 4411447. PMID 25954763.

132.^ Cavanagh, D (2007). "Coronavirus avian infectious bronchitis virus". Veterinary Research. 38 (2): $281-97$. doi:10.1051/vetres:2006055. PMID 17296157.ఠ

133.^ "Taxonomy browser (Avian coronavirus)". www.ncbi.nlm.nih.gov. Retrieved 2020-06-03.

134.^ Zhou P, Fan H, Lan T, Yang XL, Shi WF, Zhang W, et al. (April 2018). "Fatal swine acute diarrhoea syndrome caused by an HKU2-related coronavirus of bat origin". Nature. 556(7700): $255-58$. Bibcode:2018Natur.556..255Z. doi:10.1038/s41586-018-0010-9. PMC 7094983. PMID 29618817.

135.^ Wei X, She G, Wu T, Xue C, Cao Y (February 2020). "PEDV enters cells through clathrin-, caveolae-, and lipid raft-mediated endocytosis and traffics via the endo-/lysosome pathway". Veterinary Research. 51 (1): 10. doi:10.1186/s13567-020-0739-7. PMC 7011528. PMID 32041637.

136.^ Jump up to: ${ }^{\mathbf{a}} \mathbf{c}$ "Taxonomy browser (Alphacoronavirus 1)". www.ncbi.nlm.nih.gov. Retrieved 2020-06-08.

137.^ Cruz JL, Sola I, Becares M, Alberca B, Plana J, Enjuanes L, Zuñiga S (June 2011). "Coronavirus gene 7 counteracts host defenses and modulates virus virulence". PLOS Pathogens. 7 (6): e1002090. doi:10.1371/journal.ppat.1002090. PMC 3111541. PMID 21695242.

138.^ Cruz JL, Becares M, Sola I, Oliveros JC, Enjuanes L, Zúñiga S (September 2013). "Alphacoronavirus protein 7 modulates host innate immune response". Journal of Virology. 87 (17): 9754-67. doi:10.1128/JVI.01032-13. PMC 3754097. PMID 23824792.

139.^ Jump up to: ${ }^{\mathbf{a}} \mathbf{b}$ "Taxonomy browser (Betacoronavirus 1)". www.ncbi.nlm.nih.gov. Retrieved 2020-06-08. 140.^ "Taxonomy browser (Alphacoronavirus)". www.ncbi.nlm.nih.gov. Retrieved 2020-06-08. 
141.^ Murray J (2014-04-16). "What's New With Ferret FIP-like Disease?" (xls). Archived from the original on 2014-04-24. Retrieved 2014-04-24.

142. ^ "Infectious Diseases of Ferrets - Exotic and Laboratory Animals". Merck Veterinary Manual. Retrieved 2020-06-08.

143.^ Jump up to: ${ }^{\mathbf{b}}$ "Taxonomy browser (Embecovirus)". www.ncbi.nlm.nih.gov. Retrieved 2020-06-08.

144.^ Weiss SR, Navas-Martin S (December 2005). "Coronavirus pathogenesis and the emerging pathogen severe acute respiratory syndrome coronavirus". Microbiology and Molecular Biology Reviews. 69 (4): $635-64$. doi:10.1128/MMBR.69.4.635-664.2005. PMC 1306801. PMID 16339739.

145. ^ "Enteric Coronavirus". Diseases of Research Animals. Archived from the original on 2019-07-01. Retrieved 2020-01-24.

146. ${ }^{\wedge}$ "EMA receives application for conditional marketing authorisation of Moderna COVID-19 vaccine". European Medicines Agency (EMA) (Press release). 2020-12-01. Retrieved 2020-12-01.

147.^ "EMA receives application for conditional marketing authorisation of COVID-19 mRNA vaccine BNT162b2". European Medicines Agency (EMA) (Press release). 2020-12-01. Retrieved 2020-12-01.

148.^^ Dong L, Hu S, Gao J (2020). "Discovering drugs to treat coronavirus disease 2019 (COVID-19)". Drug Discoveries \& Therapeutics. 14 (1): 58-60. doi:10.5582/ddt.2020.01012. PMID 32147628.

149.^ Hull P (August 1970). "Notes on Dr Snell's observations concerning the H-2 locus polymorphism". Heredity. 25 (3): 461-5. doi:10.1038/hdy.1970.47. PMID 5275401.

150.^ Janeway Jr CA, Travers P, Walport M, et al. (2001). "The Major Histocompatibility Complex and Its Functions". Immunobiology: The Immune System in Health and Disease(5th ed.). New York: Garland Science.

151.^ Kimball JW (11 February 2011). "Histocompatibility Molecules". Kimball's Biology Pages. Archived from the original on 4 February 2016.

152.^ Janeway Jr CA, Travers P, Walport M, et al. (2001). "The major histocompatibility complex and its functions". Immunobiology: The Immune System in Health and Disease(5th ed.). New York: Garland Science.

153.^ Yamazaki K, Boyse EA, Miké V, Thaler HT, Mathieson BJ, Abbott J, et al. (November 1976). "Control of mating preferences in mice by genes in the major histocompatibility complex". The Journal of Experimental Medicine. 144 (5): 1324-35. doi:10.1084/jem.144.5.1324. PMC 2190468. PMID 1032893.

154.^ Vigneron N, Stroobant V, Chapiro J, Ooms A, Degiovanni G, Morel S, et al. (April 2004). "An antigenic peptide produced by peptide splicing in the proteasome". Science. 304 (5670): 587-90. Bibcode:2004Sci...304..587V. doi:10.1126/science.1095522. PMID 15001714.

155.^ Klein J (1986). "Seeds of time: fifty years ago Peter A. Gorer discovered the H-2 complex". Immunogenetics. 24 (6): 331-8. doi:10.1007/bf00377947. PMID 3539775.

156.^ Little CC 1941, "The genetics of tumor transplantation", pp 279-309, in Biology of the Laboratory Mouse, ed by Snell GD, New York: Dover.

157.^ Snell GD, Higgins GF (May 1951). "Alleles at the histocompatibility-2 locus in the mouse as determined by tumor transplantation". Genetics. 36 (3): 306-10. PMC 1209522. PMID 14840651.

158.^ "The Nobel Prize in Physiology or Medicine 1980". 10 October 1980. The Nobel Assembly of Karolinska Institutet has decided today to award the Nobel Prize in Physiology or Medicine for 1980 jointly to Baruj Benacerraf, Jean Dausset and George Snell

159.^ Jump up to:a $\mathrm{b}$ "Complete sequence and gene map of a human major histocompatibility complex. The MHC sequencing consortium". Nature. 401 (6756): 921-3. October 1999. Bibcode:1999Natur.401..921T. doi:10.1038/44853. PMID 10553908.

160.^ Kaufman J, Milne S, Göbel TW, Walker BA, Jacob JP, Auffray C, et al. (October 1999). "The chicken B locus is a minimal essential major histocompatibility complex". Nature. 401 (6756): 923-5. Bibcode:1999Natur.401..923K. doi:10.1038/44856. PMID 10553909.

161.^ Belov K, Deakin JE, Papenfuss AT, Baker ML, Melman SD, Siddle HV, et al. (March 2006). "Reconstructing an ancestral mammalian immune supercomplex from a marsupial major histocompatibility complex". PLoS Biology. 4 (3): e46. doi:10.1371/journal.pbio.0040046. PMC 1351924. PMID 16435885.

162.^ "IPD-MHC Database". EMBL-EBI.

163.^ Kulski JK, Shiina T, Anzai T, Kohara S, Inoko H (December 2002). "Comparative genomic analysis of the MHC: the evolution of class I duplication blocks, diversity and complexity from shark to man". Immunological Reviews. 190: 95-122. doi:10.1034/j.1600-065x.2002.19008.x. PMID 12493009.

164. ${ }^{\wedge}$ "The International ImMunoGeneTics Information System".

165.^ Saper MA, Bjorkman PJ, Wiley DC (May 1991). "Refined structure of the human histocompatibility antigen HLA-A2 at 2.6 A resolution". Journal of Molecular Biology. 219 (2): 277-319. doi:10.1016/00222836(91)90567-p. PMID 2038058.

166.^ Gao GF, Tormo J, Gerth UC, Wyer JR, McMichael AJ, Stuart DI, et al. (June 1997). "Crystal structure of the complex between human CD8alpha(alpha) and HLA-A2". Nature. 387(6633): 630-4. doi:10.1038/42523. 
PMID 9177355.

167.^ Dijkstra JM, Yamaguchi T, Grimholt U (July 2018). "Conservation of sequence motifs suggests that the nonclassical MHC class I lineages CD1/PROCR and UT were established before the emergence of tetrapod species". Immunogenetics. 70 (7): 459-476. doi:10.1007/s00251-017-1050-2. PMID 29270774.

168.^ Jump up to:a b Grimholt U, Tsukamoto K, Azuma T, Leong J, Koop BF, Dijkstra JM (March 2015). "A comprehensive analysis of teleost MHC class I sequences". BMC Evolutionary Biology. 15: 32. doi:10.1186/s12862-015-0309-1. PMC 4364491. PMID 25888517.

169.^ Wang XX, Li Y, Yin Y, Mo M, Wang Q, Gao W, et al. (September 2011). "Affinity maturation of human CD4 by yeast surface display and crystal structure of a CD4-HLA-DR1 complex". Proceedings of the National Academy of Sciences of the United States of America. 108 (38): 15960-5. Bibcode:2011PNAS..10815960W. doi:10.1073/pnas.1109438108. PMC 3179091. PMID 21900604.

170.^ Dijkstra JM, Yamaguchi T (March 2019). "Ancient features of the MHC class II presentation pathway, and a model for the possible origin of MHC molecules". Immunogenetics. 71 (3): 233-249. doi:10.1007/s00251018-1090-2. PMID 30377750.

171.^ Dijkstra JM, Grimholt U, Leong J, Koop BF, Hashimoto K (November 2013). "Comprehensive analysis of MHC class II genes in teleost fish genomes reveals dispensability of the peptide-loading DM system in a large part of vertebrates". BMC Evolutionary Biology. 13: 260. doi:10.1186/1471-2148-13-260. PMID 24279922.

172.^ Almeida T, Gaigher A, Muñoz-Mérida A, Neves F, Castro LF, Flajnik MF, et al. (October 2020). "Cartilaginous fish class II genes reveal unprecedented old allelic lineages and confirm the late evolutionary emergence of DM". Molecular Immunology. 128: 125-138. doi:10.1016/j.molimm.2020.10.003. PMID 33126081 .

173.^ Khan FH (2009). The elements of immunology. Delhi: Pearson Education. ISBN 9788131711583. OCLC 276274663.

174.^ Kindt TJ, Goldsby RA, Osborne BA, Kuby J (2007). Kuby immunology. Macmillan. ISBN 978-1-42920211-4. Retrieved 28 November 2010.

175.^ Aderem A, Underhill DM (1999). "Mechanisms of phagocytosis in macrophages". Annual Review of Immunology. 17: 593-623. doi:10.1146/annurev.immunol.17.1.593. PMID 10358769.

176.^ Murphy (2012). "Antigen recognition by T cells". Janeway's Immunobiology (8th ed.). Garland Science. pp. $138-153$

177.^ Boehm T, Zufall F (February 2006). "MHC peptides and the sensory evaluation of genotype". Trends in Neurosciences. 29(2): 100-7. doi:10.1016/j.tins.2005.11.006. PMID 16337283.

178.^ Haig D (November 1997). "Maternal-fetal interactions and MHC polymorphism". Journal of Reproductive Immunology. 35(2): 101-9. doi:10.1016/s0165-0378(97)00056-9. PMID 9421795.

179.^ Ober C, Weitkamp LR, Cox N, Dytch H, Kostyu D, Elias S (September 1997). "HLA and mate choice in humans". American Journal of Human Genetics. 61 (3): 497-504. doi:10.1086/515511. PMC 1715964. PMID 9326314.

180.^ Chaix R, Cao C, Donnelly P (September 2008). "Is mate choice in humans MHC-dependent?". PLoS Genetics. 4 (9): e1000184. doi:10.1371/journal.pgen.1000184. PMC 2519788. PMID 18787687.

181.^ Derti A, Cenik C, Kraft P, Roth FP (April 2010). "Absence of evidence for MHC-dependent mate selection within HapMap populations". PLoS Genetics. 6 (4): e1000925. doi:10.1371/journal.pgen.1000925. PMC 2861700. PMID 20442868.

182.^ Janeš D, Klun I, Vidan-Jeras B, Jeras M, Kreft S (2010). "Influence of MHC on odour perception of 43 chemicals and body odor". Central European Journal of Biology. 5 (3): 324-330. doi:10.2478/s11535-0100020-6.

183.^ Wedekind C, Seebeck T, Bettens F, Paepke AJ (June 1995). "MHC-dependent mate preferences in humans". Proceedings. Biological Sciences. 260 (1359): 245-9. Bibcode:1995RSPSB.260..245W. doi:10.1098/rspb.1995.0087. PMID 7630893.

184.^ Jacob S, McClintock MK, Zelano B, Ober C (February 2002). "Paternally inherited HLA alleles are associated with women's choice of male odor". Nature Genetics. 30 (2): 175-9. doi:10.1038/ng830. PMID 11799397.

185.^ Santos PS, Schinemann JA, Gabardo J, Bicalho MD (April 2005). "New evidence that the MHC influences odor perception in humans: a study with 58 Southern Brazilian students". Hormones and Behavior. 47 (4): 384-8. doi:10.1016/j.yhbeh.2004.11.005. PMID 15777804.

186.^ Bryner J (12 August 2008). "The pill makes women pick bad mates". Live Science. Future US Inc.

187.^ Sznarkowska A, Mikac S, Pilch M (May 2020). "MHC Class I Regulation: The Origin Perspective". Cancers. 12 (5): 1155. doi:10.3390/cancers12051155. PMID 32375397.

188. ${ }^{\wedge}$ "HLA Alleles Numbers". hla.alleles.org.

189.^ van Oosterhout C (February 2009). "A new theory of MHC evolution: beyond selection on the immune genes". Proceedings. Biological Sciences. 276 (1657): 657-65. doi:10.1098/rspb.2008.1299. PMC 2660941. 
PMID 18986972.

190.^ Manczinger M, Boross G, Kemény L, Müller V, Lenz TL, Papp B, Pál C (January 2019). "Pathogen diversity drives the evolution of generalist MHC-II alleles in human populations". PLoS Biology. 17 (1): e3000131. doi:10.1371/journal.pbio.3000131. PMC 6372212. PMID 30703088.

191.^ Zeisset I, Beebee TJ (2014). "Drift rather than selection dominates MHC class II allelic diversity patterns at the biogeographical range scale in natterjack toads Bufo calamita". PloS One. 9 (6): e100176. Bibcode:2014PLoSO...9j0176Z. doi:10.1371/journal.pone.0100176. PMC 4061088. PMID 24937211.

192.^ Cortázar-Chinarro M, Lattenkamp EZ, Meyer-Lucht Y, Luquet E, Laurila A, Höglund J (August 2017). "Drift, selection, or migration? Processes affecting genetic differentiation and variation along a latitudinal gradient in an amphibian". BMC Evolutionary Biology. 17 (1): 189. doi:10.1186/s12862-017-1022-z. PMC 5557520. PMID 28806900.

193.^ Apanius V, Penn D, Slev PR, Ruff LR, Potts WK (2017). "The Nature of Selection on the Major Histocompatibility Complex". Critical Reviews in Immunology. 37 (2-6): 75-120. doi:10.1615/CritRevImmunol.v37.i2-6.10. PMID 29773018.

194.^ Sommer S (October 2005). "The importance of immune gene variability (MHC) in evolutionary ecology and conservation". Frontiers in Zoology. 2 (16): 16. doi:10.1186/1742-9994-2-16. PMC 1282567. PMID 16242022 .

195.^ Manlik O, Krützen M, Kopps AM, Mann J, Bejder L, Allen SJ, et al. (June 2019). "Is MHC diversity a better marker for conservation than neutral genetic diversity? A case study of two contrasting dolphin populations". Ecology and Evolution. 9 (12): 6986-6998. doi:10.1002/ece3.5265. PMC 6662329. PMID 31380027.

196.^ Castro-Prieto A, Wachter B, Sommer S (April 2011). "Cheetah paradigm revisited: MHC diversity in the world's largest free-ranging population". Molecular Biology and Evolution. 28 (4): 1455-68. doi:10.1093/molbev/msq330. PMID 21183613.

197.^ Babik W, Durka W, Radwan J (December 2005). "Sequence diversity of the MHC DRB gene in the Eurasian beaver (Castor fiber)". Molecular Ecology. 14 (14): 4249-57. doi:10.1111/j.1365-294X.2005.02751.x. PMID 16313590.

198.^ Zhu L, Ruan XD, Ge YF, Wan QH, Fang SG (June 2007). "Low major histocompatibility complex class II DQA diversity in the Giant Panda (Ailuropoda melanoleuca)". BMC Genetics. 8: 29. doi:10.1186/1471-21568-29. PMC 1904234. PMID 17555583.

199.^ Siddle HV, Kreiss A, Eldridge MD, Noonan E, Clarke CJ, Pyecroft S, et al. (October 2007). "Transmission of a fatal clonal tumor by biting occurs due to depleted MHC diversity in a threatened carnivorous marsupial". Proceedings of the National Academy of Sciences of the United States of America. 104 (41): 16221-6. doi:10.1073/pnas.0704580104. PMC 1999395. PMID 17911263.

200.^ Jump up to:a b Shum BP, Guethlein L, Flodin LR, Adkison MA, Hedrick RP, Nehring RB, et al. (March 2001). "Modes of salmonid MHC class I and II evolution differ from the primate paradigm". Journal of Immunology. 166 (5): 3297-308. doi:10.4049/jimmunol.166.5.3297. PMID 11207285.

201.^ Aoyagi K, Dijkstra JM, Xia C, Denda I, Ototake M, Hashimoto K, Nakanishi T (January 2002). "Classical MHC class I genes composed of highly divergent sequence lineages share a single locus in rainbow trout (Oncorhynchus mykiss)". Journal of Immunology. 168 (1): 260-73. doi:10.4049/jimmunol.168.1.260. PMID 11751970.

202.^ Yamaguchi T, Dijkstra JM (April 2019). "Major Histocompatibility Complex (MHC) Genes and Disease Resistance in Fish". Cells. 8 (4): 378. doi:10.3390/cells8040378. PMID 31027287.

203.^ Abi Rached L, McDermott MF, Pontarotti P (February 1999). "The MHC big bang". Immunological Reviews. 167 (1): 33-44. doi:10.1111/j.1600-065X.1999.tb01380.x. PMID 10319249.

204.^ Suurväli J, Jouneau L, Thépot D, Grusea S, Pontarotti P, Du Pasquier L, et al. (September 2014). "The protoMHC of placozoans, a region specialized in cellular stress and ubiquitination/proteasome pathways". Journal of Immunology. 193 (6): 2891-901. doi:10.4049/jimmunol.1401177. PMID 25114105.

205.^ Abbas AB, Lichtman AH (2009). "Ch.10 Immune responses against tumors and transplant". Basic Immunology. Functions and disorders of the immune system (3rd ed.). Saunders (Elsevier). ISBN 978-14160-4688-2.

206.^ Sarder MR, Fischer U, Dijkstra JM, Kiryu I, Yoshiura Y, Azuma T, et al. (August 2003). "The MHC class I linkage group is a major determinant in the in vivo rejection of allogeneic erythrocytes in rainbow trout (Oncorhynchus mykiss)". Immunogenetics. 55 (5): 315-24. doi:10.1007/s00251-003-0587-4. PMID 12879308.

207.^ Quiniou SM, Wilson M, Bengtén E, Waldbieser GC, Clem LW, Miller NW (2005). "MHC RFLP analyses in channel catfish full-sibling families: identification of the role of MHC molecules in spontaneous allogeneic cytotoxic responses". Developmental and Comparative Immunology. 29 (5): 457-67. doi:10.1016/j.dci.2004.08.008. PMID 15707666.

208.^ Cardwell TN, Sheffer RJ, Hedrick PW (August 2001). "MHC variation and tissue transplantation in fish". 
The Journal of Heredity. 92 (4): 305-8. doi:10.1093/jhered/92.4.305. PMID 11535641.

209.^ Abbas AB, Lichtman AH (2009). "Ch.3 Antigen capture and presentation to lymphocytes". Basic Immunology. Functions and disorders of the immune system (3rd ed.). Saunders (Elsevier). ISBN 978-14160-4688-2.

210.

211.

212.^ Histiocytosis Archived 2016-10-09 at the Wayback Machine at eMedicine Dictionary

213.^ Disease information at the Histiocytosis Association of America

214. ^ "Histiocytosis - Signs and Symptoms". Archived from the original on 2007-09-28. Retrieved 2007-05-07.

215.^ James, William D.; Berger, Timothy G.; et al. (2006). Andrews' Diseases of the Skin: clinical Dermatology. Saunders Elsevier. ISBN 0-7216-2921-0.

216.^ Goldberg, J; Nezelof, C (1986), "Lymphohistiocytosis: a multi-factorial syndrome of macrophagic activation clinico-pathological study of 38 cases", Hematol Oncol, 4 (4): 275-289, PMID 3557322.

217.^ Egan, Caoimhe; Jaffe, Elaine S. (2018). "Non-neoplastic histiocytic and dendritic cell disorders in lymph nodes". Seminars in Diagnostic Pathology. 35 (1): 20-33. doi:10.1053/j.semdp.2017.11.002. ISSN 07402570. PMC 5803315.

218.^ Harris N, Jaffe E, Diebold J, Flandrin G, Muller-Hermelink H, Vardiman J, Lister T, Bloomfield C (1999). "The World Health Organization classification of neoplastic diseases of the hematopoietic and lymphoid tissues. Report of the Clinical Advisory Committee meeting, Airlie House, Virginia, November, 1997". Ann Oncol. 10 (12): 1419-32. doi:10.1023/A:1008375931236. PMID 10643532.

219.^ Histiocytosis at eMedicine

220.^ Tebbi, Cameron K. (16 September 2020). Kanwar, Vikramjit S (ed.). "What is the Histiocyte Society classification of histiocytosis syndromes?". Medscape. Retrieved 4 December 2020.

221.^ Chang, Karen L.; Snyder, David S. (2007). "17. Langerhans Cell Histiocytosis". In Stephen M. Ansell (ed.). Rare Hematological Malignancies. Springer Science \& Business Media. p. 383. ISBN 978-0-387-73743-0.^ Lowenstein JM (1969). Methods in Enzymology, Volume 13: Citric Acid Cycle. Boston: Academic Press. ISBN 978-0-12-181870-8.

222.^ Kay J, Weitzman PD (1987). Krebs' citric acid cycle: half a century and still turning. London: Biochemical Society. pp. 25. ISBN 978-0-904498-22-6.

223.^ Wagner, Andreas (2014). Arrival of the Fittest (first ed.). PenguinYork. p. 100. ISBN 9781591846468.

224.^ Lane, Nick (2009). Life Ascending: The Ten Great Inventions of Evolution. New York: W. W. Norton \& Co. ISBN 978-0-393-06596-1.

225.^ Chinopoulos C (August 2013). "Which way does the citric acid cycle turn during hypoxia? The critical role of $\alpha$-ketoglutarate dehydrogenase complex" (PDF). Journal of Neuroscience Research. 91 (8): 1030-43. doi:10.1002/jnr.23196. PMID 23378250.

226.^ Jump up to:a b c Voet D, Voet JG (2004). Biochemistry (3rd ed.). New York: John Wiley \& Sons, Inc. p. 615.

227.^ Lieberman, Michael (2013). Marks' basic medical biochemistry : a clinical approach. Marks, Allan D., Peet, Alisa. (Fourth ed.). Philadelphia: Wolters Kluwer Health/Lippincott Williams \& Wilkins. ISBN 9781608315727. OCLC 769803483.

228. ^ "The Nobel Prize in Physiology or Medicine 1937". The Nobel Foundation. Retrieved 2011-10-26.

229.^ Chandramana, Sudeep. (2014). Inclusive Growth And Youth Empowerment: Adevelopment Model For Aspirational India. Journal of Science, Technology and Management. 7. 52-62.

230.^ Krebs HA, Johnson WA (April 1937). "Metabolism of ketonic acids in animal tissues". The Biochemical Journal. 31 (4): 645-60. doi:10.1042/bj0310645. PMC 1266984. PMID 16746382.

231.^ "The Nobel Prize in Physiology or Medicine 1953". The Nobel Foundation. Retrieved 2011-10-26.

232.^ Wolfe RR, Jahoor F (February 1990). "Recovery of labeled CO2 during the infusion of C-1- vs C-2-labeled acetate: implications for tracer studies of substrate oxidation". The American Journal of Clinical Nutrition. 51 (2): 248-52. doi:10.1093/ajcn/51.2.248. PMID 2106256.

233.^ Berg JM, Tymoczko JL, Stryer L (2002). "The Citric Acid Cycle". Biochemistry (5th ed.). W H Freeman. ISBN 0-7167-3051-0.

234.^ Jump up to:a b Jones RC, Buchanan BB, Gruissem W (2000). Biochemistry \& molecular biology of plants (1st ed.). Rockville, Md: American Society of Plant Physiologists. ISBN 978-0-943088-39-6.

235.^ Jump up to:a b c d Stryer L, Berg J, Tymoczko JL (2002). Biochemistry. San Francisco: W. H. Freeman. ISBN 978-0-7167-4684-3.

236.^ Johnson JD, Mehus JG, Tews K, Milavetz BI, Lambeth DO (October 1998). "Genetic evidence for the expression of ATP- and GTP-specific succinyl-CoA synthetases in multicellular eucaryotes". The Journal of Biological Chemistry. 273 (42): 27580-6. doi:10.1074/jbc.273.42.27580. PMID 9765291.

237.^ Barnes SJ, Weitzman PD (June 1986). "Organization of citric acid cycle enzymes into a multienzyme 
cluster". FEBS Letters. 201 (2): 267-70. doi:10.1016/0014-5793(86)80621-4. PMID 3086126.

238.^ Jump up to:a b Porter RK, Brand MD (September 1995). "Mitochondrial proton conductance and H+/O ratio are independent of electron transport rate in isolated hepatocytes". The Biochemical Journal. 310 (2): $379-82$. doi:10.1042/bj3100379. PMC 1135905. PMID 7654171.

239.^ Stryer L, Berg JM, Tymoczko JL (2002). "Section 18.6: The Regulation of Cellular Respiration Is Governed Primarily by the Need for ATP". Biochemistry. San Francisco: W. H. Freeman. ISBN 978-0-7167-4684-3.

240.^ Rich PR (December 2003). "The molecular machinery of Keilin's respiratory chain". Biochemical Society Transactions. 31 (Pt 6): 1095-105. doi:10.1042/BST0311095. PMID 14641005. S2CID 32361233.

241.^ "Citric acid cycle variants at MetaCyc".

242.^ Sahara T, Takada Y, Takeuchi Y, Yamaoka N, Fukunaga N (March 2002). "Cloning, sequencing, and expression of a gene encoding the monomeric isocitrate dehydrogenase of the nitrogen-fixing bacterium, Azotobacter vinelandii". Bioscience, Biotechnology, and Biochemistry. 66 (3): 489-500. doi:10.1271/bbb.66.489. PMID 12005040. S2CID 12950388.

243.^ van der Rest ME, Frank C, Molenaar D (December 2000). "Functions of the membrane-associated and cytoplasmic malate dehydrogenases in the citric acid cycle of Escherichia coli". Journal of Bacteriology. 182 (24): 6892-9. doi:10.1128/jb.182.24.6892-6899.2000. PMC 94812. PMID 11092847.

244.^ Lambeth DO, Tews KN, Adkins S, Frohlich D, Milavetz BI (August 2004). "Expression of two succinylCoA synthetases with different nucleotide specificities in mammalian tissues". The Journal of Biological Chemistry. 279 (35): 36621-4. doi:10.1074/jbc.M406884200. PMID 15234968.

245.^ Mullins EA, Francois JA, Kappock TJ (July 2008). "A specialized citric acid cycle requiring succinylcoenzyme A (CoA):acetate CoA-transferase (AarC) confers acetic acid resistance on the acidophile Acetobacter aceti". Journal of Bacteriology. 190 (14): 4933-40. doi:10.1128/JB.00405-08. PMC 2447011. PMID 18502856.

246.^ Corthésy-Theulaz IE, Bergonzelli GE, Henry H, Bachmann D, Schorderet DF, Blum AL, Ornston LN (October 1997). "Cloning and characterization of Helicobacter pylori succinyl CoA:acetoacetate CoAtransferase, a novel prokaryotic member of the CoA-transferase family". The Journal of Biological Chemistry. 272 (41): 25659-67. doi:10.1074/jbc.272.41.25659. PMID 9325289.

247.^ Baughn AD, Garforth SJ, Vilchèze C, Jacobs WR (November 2009). "An anaerobic-type alpha-ketoglutarate ferredoxin oxidoreductase completes the oxidative tricarboxylic acid cycle of Mycobacterium tuberculosis". PLOS Pathogens. 5 (11): e1000662. doi:10.1371/journal.ppat.1000662. PMC 2773412. PMID 19936047.

248.^ Zhang S, Bryant DA (December 2011). "The tricarboxylic acid cycle in cyanobacteria". Science. 334 (6062): 1551-3. doi:10.1126/science.1210858. PMID 22174252.

249.^ Dang L, Su SM (June 2017). "Isocitrate Dehydrogenase Mutation and (R)-2-Hydroxyglutarate: From Basic Discovery to Therapeutics Development". Annual Review of Biochemistry. 86 (1): 305-331. doi:10.1146/annurev-biochem-061516-044732. PMID 28375741.

250.^ Yong C, Stewart GD, Frezza C (March 2020). "Oncometabolites in renal cancer". Nature Reviews. Nephrology. 16 (3): 156-172. doi:10.1038/s41581-019-0210-z. PMC 7030949. PMID 31636445.

251.^ Gelman SJ, Mahieu NG, Cho K, Llufrio EM, Wencewicz TA, Patti GJ (December 2015). "Evidence that 2hydroxyglutarate is not readily metabolized in colorectal carcinoma cells". Cancer \& Metabolism. 3 (1): 13. doi:10.1186/s40170-015-0139-z. PMC 4665876. PMID 26629338.

252.^ Rotili D, Mai A (June 2011). "Targeting Histone Demethylases: A New Avenue for the Fight against Cancer". Genes \& Cancer. 2 (6): 663-79. doi:10.1177/1947601911417976. PMC 3174264. PMID 21941621.

253.^ Ivannikov MV, Macleod GT (June 2013). "Mitochondrial free $\mathrm{Ca}^{2+}$ levels and their effects on energy metabolism in Drosophila motor nerve terminals". Biophysical Journal. 104(11): $2353-61$. Bibcode:2013BpJ...104.2353I. doi:10.1016/j.bpj.2013.03.064. PMC 3672877. PMID 23746507.

254.^ Denton RM, Randle PJ, Bridges BJ, Cooper RH, Kerbey AL, Pask HT, et al. (October 1975). "Regulation of mammalian pyruvate dehydrogenase". Molecular and Cellular Biochemistry. 9 (1): $27-53$. doi:10.1007/BF01731731. PMID 171557.

255.^ Koivunen P, Hirsilä M, Remes AM, Hassinen IE, Kivirikko KI, Myllyharju J (February 2007). "Inhibition of hypoxia-inducible factor (HIF) hydroxylases by citric acid cycle intermediates: possible links between cell metabolism and stabilization of HIF". The Journal of Biological Chemistry. 282 (7): 4524-32. doi:10.1074/jbc.M610415200. PMID 17182618.

256.^ Jump up to:a b c d e Voet, Donald; Judith G. Voet; Charlotte W. Pratt (2006). Fundamentals of Biochemistry, 2nd Edition. John Wiley and Sons, Inc. pp. 547, 556. ISBN 978-0-471-21495-3.

257.^ Jump up to:a b c d e f g h i j k $1 \mathrm{~m}$ n o Stryer, Lubert (1995). "Citric acid cycle". In: Biochemistry (Fourth ed.). New York: W. H. Freeman and Company. pp. 509-527, 569-579, 614-616, 638-641, 732-735, 739748, 770-773. ISBN 978-0-7167-2009-6.

258.^ Schmidt-Rohr K (2020). "Oxygen Is the High-Energy Molecule Powering Complex Multicellular Life: Fundamental Corrections to Traditional Bioenergetics". ACS Omega. 5: 2221-2233. 
doi:10.1021/acsomega.9b03352. PMC 7016920. PMID 32064383.

259.^ Garrett, Reginald H.; Grisham, Charles M. (2013). Biochemistry (5th ed.). Belmont, CA: Brooks/Cole, Cengage Learning. pp. 623-625, 771-773. ISBN 9781133106296. OCLC 777722371.

260.^ Halarnkar PP, Blomquist GJ (1989). "Comparative aspects of propionate metabolism". Comparative Biochemistry and Physiology. B, Comparative Biochemistry. 92 (2): 227-31. doi:10.1016/03050491(89)90270-8. PMID 2647392.

261.^ Ferré P, Foufelle F (2007). "SREBP-1c transcription factor and lipid homeostasis: clinical perspective". Hormone Research. 68 (2): 72-82. doi:10.1159/000100426. PMID 17344645. this process is outlined graphically in page 73

262.^ Hui S, Ghergurovich JM, Morscher RJ, Jang C, Teng X, Lu W, et al. (November 2017). "Glucose feeds the TCA cycle via circulating lactate". Nature. 551 (7678): 115-118. doi:10.1038/nature24057. PMC 5898814. PMID 29045397.

263.^ Gest H (1987). "Evolutionary roots of the citric acid cycle in prokaryotes". Biochemical Society Symposium. 54: 3-16. PMID 3332996.

264.^ Meléndez-Hevia E, Waddell TG, Cascante M (September 1996). "The puzzle of the Krebs citric acid cycle: assembling the pieces of chemically feasible reactions, and opportunism in the design of metabolic pathways during evolution". Journal of Molecular Evolution. 43 (3): 293-303. doi:10.1007/BF02338838. PMID 8703096.

265.^ Ebenhöh O, Heinrich R (January 2001). "Evolutionary optimization of metabolic pathways. Theoretical reconstruction of the stoichiometry of ATP and NADH producing systems". Bulletin of Mathematical Biology. 63 (1): 21-55. doi:10.1006/bulm.2000.0197. PMID 11146883. 